\title{
Amostragem por Linhas Transectas \\ e Pontos Transectos: \\ uma comparação dos estimadores da densidade populacional
}

\author{
Diana Milena Galvis Soto
}

\author{
Dissertação apresentada \\ ao \\ Instituto de Matemática e Estatística \\ da \\ Universidade de São Paulo \\ para \\ obtenção do grau \\ de \\ Mestre em Estatística
}

Área de Concentração: Estatística
Orientadora: Profa. Dra. Lúcia Pereira Barroso

-São Paulo, agosto de 2004- 


\section{Amostragem por Linhas Transectas \\ e Pontos Transectos: \\ uma comparação dos estimadores \\ da densidade populacional}

Este exemplar corresponde à redação final
da dissertação devidamente corrigida e
defendida por Diana Milena Galvis Soto
e aprovada pela comissão julgadora.

São Paulo, 2 de agosto de 2004.

Banca Examinadora:

- Profa. Dra. Lúcia Pereira Barroso (Orientadora) - IME - USP

- Prof. Dr. Wilton de Oliveira Bussab - IME - USP

- Profa. Dra. Maria Cecília Mendes Barreto - UFSCar 
A Dios,

a mi madre

y a la luz que hoy brilla dentro de mí, mi hijo. 


\section{Agradecimentos}

À minha orientadora Lúcia Pereira Barroso pela orientação, ajuda, amizade e a compreensão que me ofereceu durante o tempo em que trabalhamos juntas, porque embora tenha sido muito difícil trabalhar pela internet, chegamos até o final do trabalho.

Ao meu pai, minhas irmãs e meus sobrinhos, pelo amor, o apoio e as forças com que sempre me brindaram.

À "mi Hurtado" e à "Dolly María" porque sem eles este mestrado não teria sido possível; pelo apoio e o grande amor que me oferecem, por ter aberto para mim as portas de um mundo novo.

Aos professores Maria Cecília M. Barreto, Heleno Bolfarine e Wilton O. Bussab pela ajuda e sugestões que fizeram, com o objetivo de melhorar o trabalho.

À Dra. Fernanda Marques e ao Dr. Len Thomas, que embora não os conhecendo pessoalmente, esclareceram muitas dúvidas no estudo dos métodos aqui apresentados. Muito obrigada.

Ao Julian, pelo amor e o apoio que me ofereceu no momento que mais precisei.

Ao meu grande amigo Persé, pela grande amizade que me ofereceu e por ter estado comigo em todos os momentos.

Ao Elier e ao Juvencio, meus amigos e colegas no mestrado, pela amizade e a ajuda que sempre me ofereceram.

À Maria Do Carmo, Natalia, Nubia, Pao e Sandra, minhas amigas que sempre me escutaram e me ajudaram no momento que mais precisei.

À Dri e Valéria, minhas lindas amigas brasileiras, que sempre estiveram comigo. 
Aos meus grandes amigos com quem compartilhei muitos momentos da minha vida em São Paulo. Não os nomearei porque a lista seria muito grande. A todos muito obrigada pela amizade. À CAPES pelo financiamento econômico na realização dos meus estudos de mestrado. Aos funcionários do IME-USP, pela amizade e a colaboração que sempre me ofereceram.

À COSEAS, por terem me deixado morar no CRUSP.

A todos, muito obrigada. 


\section{Índice}

Introdução

1 Conceitos Fundamentais $\quad 8$

1.1 Função de Detecção . . . . . . . . . . . . . . . . . . . . . . . . . . 12

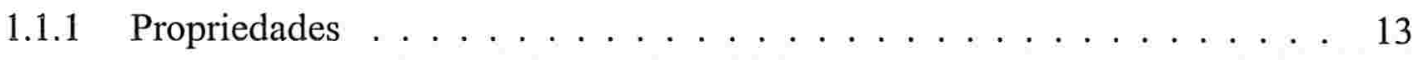

1.1.2 Modelagem . . . . . . . . . . . . . . . . . . . . . . . . . 14

1.2 Suposições . . . . . . . . . . . . . . . . . . . . . . . . 17

2 Os Métodos Amostrais $\quad 20$

2.1 Linhas Transectas . . . . . . . . . . . . . . . . . . 20

2.2 Pontos Transectos . . . . . . . . . . . . . . . . . . . . . 23

2.3 Análise da Função Densidade de Probabilidade das Distâncias dos Objetos Detec-

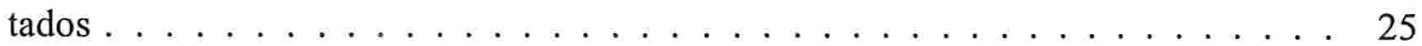

2.3.1 Estimação dos Parâmetros . . . . . . . . . . . . . . . . . 27

2.3.2 Seleção do Número $q$ de Termos na Expansão em Séries . . . . . . . . . . 32

2.3.3 Seleção do Modelo para a Função Densidade de Probabilidade das Distâncias dos Objetos Detectados . . . . . . . . . . . . . . . . . . 34

2.3.4 Teste de Bondade de Ajuste do Modelo . . . . . . . . . . . . . . . . . . . 39

2.3.5 Exatidão e Precisão dos Estimadores de $D$. . . . . . . . . . . . . . . 40 
3 Uma Ilustração e Comparação dos dois Métodos Amostrais 44

3.1 Descrição da Região e da População em Estudo . . . . . . . . . . . . . . . . . . . . 45

3.2 Metodologia Usada na Observação das Distâncias . . . . . . . . . . . . . . . 46

3.3 Ilustração de Análise das Distâncias dos Objetos Detectados . . . . . . . . . . . 50

3.4 Uma Comparação dos dois Métodos Amostrais . . . . . . . . . . . . . . . . 56

A Anexos dos Capítulos 1 e 2

A.1 Modelo Taxa de Risco . . . . . . . . . . . . . . . . . . . . . . . . 61

A.2 Polinômios Hermitianos $\ldots \ldots \ldots \ldots \ldots$. . . . . . . . . . . 64

A.3 Linhas Transectas . . . . . . . . . . . . . . . . 65

A.4 Pontos Transectos . . . . . . . . . . . . . . . . . . . . 66

B Programas Desenvolvidos em R para Geração das Amostras $\quad 70$

C Saída do Programa Distance na Análise de um Conjunto de Dados para Linhas Tran$\begin{array}{ll}\text { sectas } & 79\end{array}$

D Saída do Programa Distance na Análise de um Conjunto de Dados para Pontos Transectos

Referências Bibliográficas 


\section{Lista de Figuras}

1.1 Amostragem por figuras geométricas . . . . . . . . . . . . . . . . . 9

1.2 Linhas transectas: possiveis medidas a serem tomadas, uma vez detectado o objeto 10

1.3 Linhas transectas : região coberta pela amostragem de área $a=2 w L \ldots \ldots$

1.4 Pontos transectos: medida a ser tomada uma vez detectado o objeto . . . . . . . . 11

1.5 Pontos Transectos: região coberta pela amostragem . . . . . . . . . . . . . . . 12

1.6 Exemplo de função de detecção com forma de ombro . . . . . . . . . . . . . . . . 14

2.1 A região formada pela faixa que contém a linha transecta corresponde à região coberta pela amostragem. Os pontos pretos recheados correspondem aos objetos detectados. Neste caso, a proporção de objetos detectados é conhecida mas será ignorada para a aplicação da teoria das linhas transectas . . . . . . . . . . . . 21

3.1 Histogramas: (a) das distâncias à linha transecta de todos os objetos dentro da área coberta pela amostragem, (b) das distâncias à linha transecta dos objetos

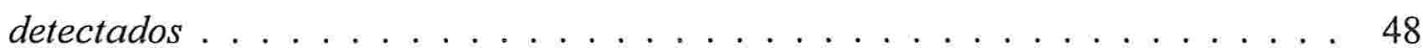

3.2 Histogramas: (a) das distâncias aos pontos transectos de todos os objetos dentro da região coberta pela amostragem, (b) das distâncias aos pontos transectos dos objetos detectados . . . . . . . . . . . . . . . . . . . . . . . . . . 50

3.3 Gráficos de barras: (a) proporção de objetos detectados em cada aro, (b) freqüências

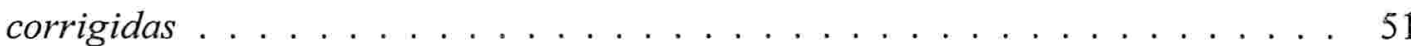


3.4 Histogramas das estimativas da densidade obtidas por linhas transectas e pontos transectos . . . . . . . . . . . . . . . . . 58

3.5 Boxplots das estimativas da densidade obtidas por linhas transectas e pontos tran-

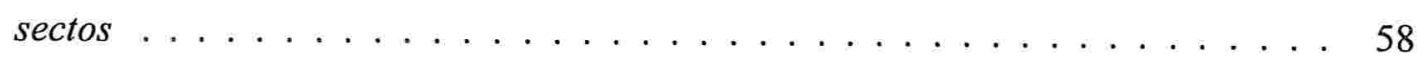

A.1 Ponto transecto, representação da notação usada na transformação de coordenadas 67

C.1 Detection Fct/Global/Plot: Detection Probability $1 \ldots \ldots$. . . . . . . . . . . . 91

C.2 Detection Fct/Global/Plot: Detection Probability $2 \ldots \ldots$. . . . . . . . . . 92

C.3 Detection Fct/Global/Plot: Detection Probability 3 . . . . . . . . . . . . . . . 93

D.1 Detection Fct/Global/Plot: Detection Probability 1 . . . . . . . . . . . . . 109

D.2 Detection Fct/Global/Plot: Pdf I . . . . . . . . . . . . . . . . . . 109

D.3 Detection Fct/Global/Plot: Detection Probability $2 \ldots \ldots$. . . . . . . . 110

D.4 Detection Fct/Global/Plot: Pdf $2 \ldots \ldots \ldots \ldots \ldots \ldots$. . . . . . . . . . . . . .

D.5 Detection Fct/Global/Plot: Detection Probability $3 \ldots \ldots$. . . . . . . . . . 112

D.6 Detection Fct/Global/Plot: Pdf 3 . . . . . . . . . . . . . . . . . . . 113 


\section{Lista de Tabelas}

1.1 Funções chaves para a função de deteç̧ão . . . . . . . . . . . . . . 15

1.2 Expansões em série na função de detecção . . . . . . . . . . . . . . . . . . 16

1.3 Funções de deteç̧ão . . . . . . . . . . . . . . . . . . . . . 16

2.1 Funções densidade de probabilidade das distâncias dos objetos detectados ajustadas aos dados do Exemplo 1 e os seus correspondentes valores de AIC . . . . . . 38

2.2 Alguns valores para $d_{n, \alpha} \ldots \ldots \ldots \ldots \ldots \ldots \ldots$. . . . . . . . . . 40

3.1 Modelos ajustados para linhas transectas . . . . . . . . . . . . . . 53

3.2 Modelos ajustados para pontos transectos . . . . . . . . . . . . . 54

3.3 Medidas de posição de $\hat{D} \ldots \ldots \ldots \ldots \ldots \ldots \ldots$. . . . . . . . . 57

3.4 Medidas de dispersão e vício de $\hat{D} \ldots \ldots \ldots \ldots \ldots \ldots \ldots$ 


\section{Resumo}

Nos estudos de Ecologia, freqüentemente é necessário estimar a densidade $(D)$ de populações biológicas (animais ou plantas), definida como o número de elementos por unidade de área.

Entre outros, a densidade é considerada como um parâmetro importante em pesquisas sobre a extinção de espécies e também para entidades governamentais que controlam a derrubada de árvores e a caça e pesca de animais.

Neste trabalho são apresentados estimadores da densidade populacional nos métodos amostrais linhas transectas e pontos transectos. A análise de dados obtidos por esses métodos de amostragem é ilustrada em dados de uma população com distribuição espacial uniforme, gerados via simulação e é apresentada uma comparação entre os estimadores sob os dois métodos. 


\section{Introdução}

O objetivo de muitas pesquisas em Ecologia é estimar a densidade de populações biológicas. A partir deste momento, o termo densidade fará referência ao parâmetro que representa o número de objetos por unidade de área.

Muitos métodos têm sido usados com esse propósito e entre eles estão os métodos amostrais linhas transectas e pontos transectos, que tiveram o seu desenvolvimento teórico a partir de 1968 e 1979 , respectivamente.

As idéias básicas de linhas transectas foram desenvolvidas, principalmente, por Eberhardt (1968) e Gates et al. (1968). Estas idéias foram de grande utilidade no desenvolvimento teórico que desde então tem sido alcançado em linhas transectas. Em 1970, Anderson e Pospahala usam aproximações paramétricas e introduzem as idéias básicas de aproximações semiparamétricas e não paramétricas na análise de dados obtidos com linhas transectas. Em 1976, Burnham e Anderson apresentam a formulação geral da amostragem por linhas transectas e obtêm bases para a construção de estimadores da densidade populacional. Burnham et al. (1980) publicam a maior monografia sobre teoria e aplicação em linhas transectas da época. A partir de 1980 muitos trabalhos sobre teoria e aplicação de linhas transectas têm sido publicados. Hayes e Buckland (1983) e Buckland (1985) fazem propostas para a análise de dois tipos de dados que podem ser coletados com base neste método amostral e Borchers et al. (1998b) propõem estimadores da densidade no caso em que as suposições básicas feitas em linhas transectas são violadas.

O formalismo estatístico em pontos transectos foi apresentado por Ramsey e Scott em 1979, 
que notaram uma relação próxima deste método com linhas transectas e fizeram um resumo das suposições e da teoria geral para a estimação da densidade populacional. Os pontos transectos são também chamados método gráfico de variáveis circulares. Burnham et al. em 1980 e Buckland em 1987 também notaram a relação existente entre linhas transectas e pontos transectos.

Os seguintes trabalhos tratam tanto de linhas transectas como de pontos transectos.

Buckland et al. (1993) escrevem o primeiro livro sobre teoria e aplicação destes métodos amostrais, atualizado por Buckland et al. (2001). Barry e Welsh (2001) avaliam as propriedades dos estimadores da densidade propostos por Buckland et al. (1993). Ramsey e Harrison (2004) propõem estimadores da densidade populacional levando em conta novas suposições.

Em amostragem por linhas transectas e pontos transectos, um observador percorre, respectivamente, uma série de linhas ou pontos posicionados aleatoriamente em uma região, procurando os objetos de interesse (usualmente animais ou plantas). Para cada objeto detectado é registrada a sua distância à linha ou ao ponto. Nem todos os objetos são detectados mas a suposição fundamental destes métodos é que os objetos sobre a linha ou ponto são sempre detectados. É de se esperar que quando se aumenta a distância do objeto à linha ou ao ponto seja mais difícil a detecção e isto resultaria em poucas detecções a grandes distâncias.

O objetivo neste trabalho é apresentar os estimadores da densidade populacional obtidos com cada um dos métodos, usando a metodologia proposta por Buckland et al. (1993) e fazer uma comparação entre eles. Essa comparação é feita via simulação, mediante a comparação dos erros quadráticos médios empíricos dos estimadores. Estes métodos são comparados levando em conta simultaneamente duas condições, a primeira que a população dentro da região é distribuída espacialmente de forma aleatória e desagrupada, ou seja, detectar um objeto não depende de se fazer a detecção de um outro próximo a ele e a segunda, que não existe movimentação dos animais em resposta ao observador.

O trabalho está dividido em três capítulos e quatro apêndices. O Capítulo 1 contém os conceitos necessários para o bom entendimento do desenvolvimento teórico dos dois métodos amostrais 
apresentados no Capítulo 2; no Capítulo 3 é feita uma ilustração de análise e a comparação dos dois métodos usando dados gerados via simulação. No Apêndice A encontram-se os anexos dos Capítulos 1 e 2, no Apêndice B os programas desenvolvidos em $\mathrm{R}$ para a geração dos dados usados no Capítulo 3 e nos Apêndices C e D as saídas do programa Distance na análise de um conjunto de dados para linhas transectas e pontos transectos, respectivamente. 


\section{Capítulo 1}

\section{Conceitos Fundamentais}

O objetivo fundamental nos dois primeiros capítulos deste trabalho é estimar a densidade de populações biológicas. Para isto, será considerada uma população de $N$ objetos distribuída aleatoriamente em uma região de área $A$. A densidade dessa população é $D=\frac{N}{A}$. Um método amostral usado tradicionalmente consiste em situar, de forma aleatória, figuras geométricas (quadrados, círculos, retângulos) dentro da região de área $A$ e recensear todos os objetos que se encontrem dentro destas figuras. Um estimador da densidade é dado por

$$
\hat{D}=\frac{n_{T}}{a}
$$

em que $n_{T}$ é o número de objetos contidos nas figuras geométricas e $a$ é a área total destas figuras. Como exemplo da aplicação deste método considere que em uma região de área $A$ são situados 4 quadrados onde cada quadrado tem uma área de $1 \mathrm{~m}^{2}$. Como pode-se observar na Figura 1.1, dentro destes quadrados encontram-se 12 objetos e portanto $\hat{D}=\frac{12 \text { objetos }}{4 \mathrm{~m}^{2}}=3$ objetos $/ \mathrm{m}^{2}$.

A dificuldade de se realizar este método amostral surge na condição de que todos os objetos dentro das figuras geométricas sejam recenseados pois na prática esta condição dificilmente é satisfeita.

Métodos amostrais como linhas transectas e pontos transectos também são utilizados para se 


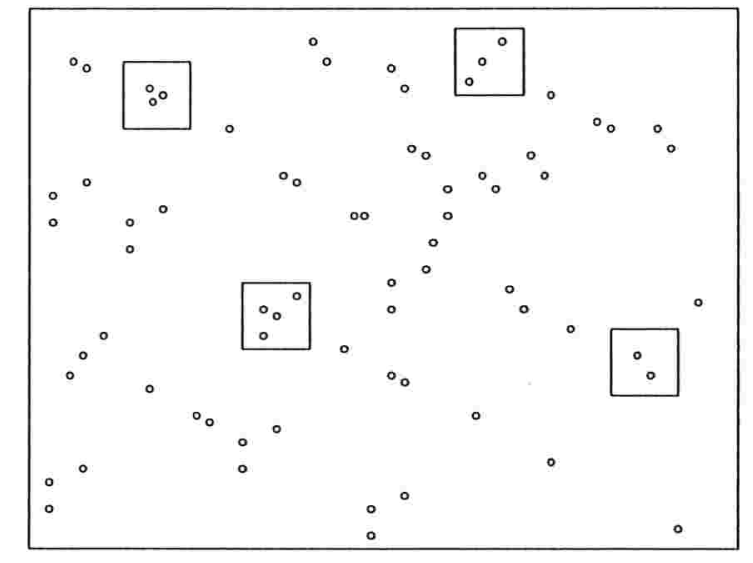

Figura 1.1: Amostragem por figuras geométricas

estimar a densidade de populações biológicas. Nestes métodos só uma proporção dos objetos contidos nas figuras geométricas é detectada. A seguir será apresentada a teoria destes métodos amostrais; para isto considere uma população de $N$ objetos distribuídos aleatoriamente em uma região de área $A$ (conhecida ou não).

Em amostragem por linhas transectas é posicionada aleatoriamente, dentro da região de área $A$, uma linha de comprimento $L$ ou várias de comprimento $l_{j}$, tais que $\sum_{j=1}^{k} l_{j}=L$, em que $k$ é o número de linhas nesta região. Uma vez posicionadas as linhas, elas são percorridas e, detectado o objeto de interesse, é tomada a distância perpendicular $(x)$ do objeto à linha, ou alternativamente, a distância $(r)$ do objeto ao observador e o ângulo $(\theta)$ formado entre a linha de visão do objeto e a linha transecta (Figura 1.2), para se obter por trigonometria a distância perpendicular $x(x=r \operatorname{sen} \theta)$.

Uma outra metodologia usada na realização da amostragem por linhas transectas é proposta por Zahl (1989).

Quando este método amostral é aplicado, é possível definir uma distância $x=w$ que será considerada como a máxima distância de observação dos objetos, a partir da qual os objetos são ignorados. Neste caso, $x=w$ definirá a área $a=2 w L$ da região coberta pela amostragem, em que $w$ é a metade da largura dessa região (ver Figura 1.3 ). No caso em que sejam usadas várias linhas, elas devem ser situadas de tal forma que a intersecção entre as faixas definidas por $x=w$ 


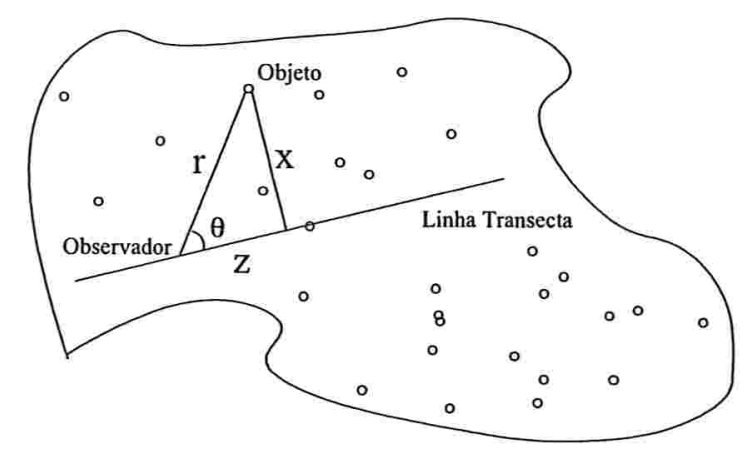

Figura 1.2: Linhas transectas: possiveis medidas a serem tomadas, uma vez detectado o objeto

seja vazia. Uma analogia com a amostragem por conglomerados poderia ser feita, considerando as áreas $a$, definidas pelas linhas transectas, como conglomerados.

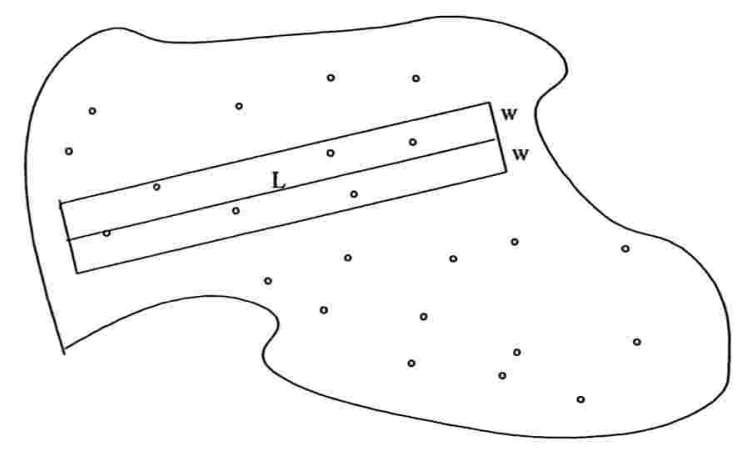

Figura 1.3: Linhas transectas : região coberta pela amostragem de área $a=2 w L$

Neste método amostral, existe uma relação entre o número esperado de objetos detectados, $E\left[n_{L}\right]$, a proporção desconhecida de objetos detectados na região de área $a, P_{a}$, e a densidade $D$, da qual surge uma nova expressão para o parâmetro de interesse $D$.

O número esperado de objetos detectados na área $a$ é o número esperado de objetos contidos na área $a$, ou seja, $\frac{N a}{A}$, pois a alocação da linha transecta é aleatória, multiplicado pela proporção de objetos detectados nessa área, isto é,

$$
E\left[n_{L}\right]=\frac{N a}{A} P_{a}=D a P_{a}
$$


de onde

$$
D=\frac{E\left[n_{L}\right]}{a P_{a}}
$$

Portanto,

$$
D=\frac{N}{A}=\frac{E\left[n_{L}\right]}{a P_{a}}=\frac{E\left[n_{L}\right]}{2 w L P_{a}}
$$

Em amostragem por pontos transectos são posicionados $k$ pontos de forma aleatória dentro da região de área $A$. Uma vez posicionados os pontos, um observador espera um tempo determinado em cada um deles e, detectado o objeto, é tomada a distância $(r)$ do objeto ao ponto (ver Figura 1.4).

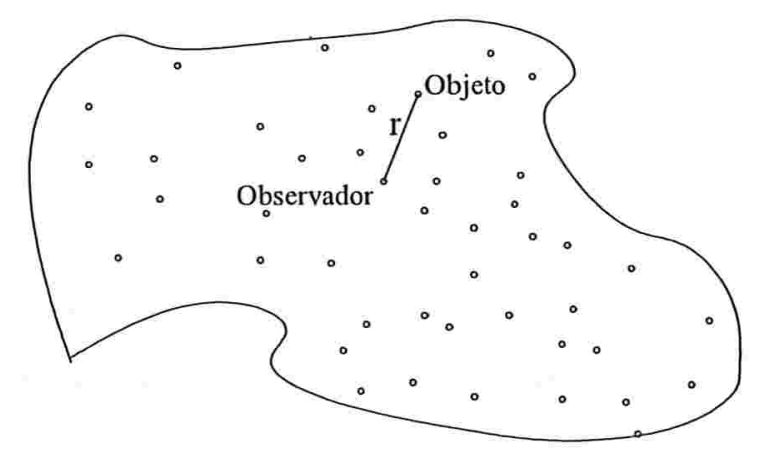

Figura 1.4: Pontos transectos: medida a ser tomada uma vez detectado o objeto

Quando este método amostral é aplicado, é possível definir uma distância $r=w$ que será considerada como a máxima distância de observação dos objetos, a partir da qual os objetos são ignorados. Em cada ponto esta máxima distância $(w)$ de observação dos objetos define um círculo de área $\pi w^{2}$. A região coberta pela amostragem terá então, uma área $a=k \pi w^{2}$ por existirem $k$ pontos na região de área $A$. Estes $k$ pontos são posicionados de tal forma que a intersecção entre os círculos definidos por $r=w$ seja vazia (ver Figura 1.5). Como na amostragem por linhas transectas, em amostragem por pontos transectos existe também uma relação do número esperado 


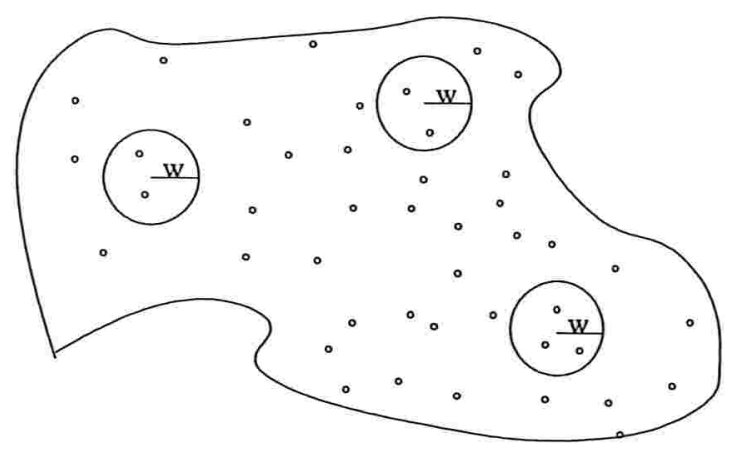

Figura 1.5: Pontos Transectos: região coberta pela amostragem

de objetos detectados, $E\left[n_{P}\right]$, a proporção desconhecida de objetos detectados na região de área $a$, $P_{a}$, e a densidade $D$, da qual surge uma nova expressão para o parâmetro de interesse $D$,

$$
D=\frac{E\left[n_{p}\right]}{k \pi w^{2} P_{a}}
$$

No planejamento amostral por linhas transectas e pontos transectos, o valor de $w$ é fixado com base na experiência do pesquisador ou com base em uma amostra piloto em que se desprezam os pontos mais distantes. As distâncias observadas devem ser truncadas para eliminar possíveis valores atípicos; uma regra simples pode ser, eliminar de 5 a 10\% das maiores distâncias (Buckland et al. (1993)).

Para se obter estimadores das expressões (1.1) e (1.2) será necessário introduzir o conceito da função de detecção, pois como poderá ser observado no próximo capítulo, os estimadores da densidade obtidos com base nestes métodos amostrais dependem diretamente desta função.

\subsection{Função de Detecção}

A função de detecção $g(y)$, em que $y$ é a distância $x$ em linhas transectas e a distância $r$ em pontos transectos, é definida como a probabilidade de se detectar um objeto dado que ele se 
encontra a uma distância $y$ da linha ou ponto, ou seja,

$$
g(y)=P(\text { detecção } \mid \text { distância } y), 0 \leq g(y) \leq 1 .
$$

É de se esperar que a probabilidade de detecção diminua à medida em que aumenta a distância do objeto à linha ou ao ponto. Uma das suposições feitas nestes métodos amostrais é que os objetos sobre a linha ou ponto são sempre detectados e $\operatorname{assim} g(0)=1$. A função $g(y)$ é, ademais, monótona decrescente (Burnham et al. (1980)). A partir dos dados coletados é possível conhecer a forma da função de detecção fazendo um gráfico de barras das distâncias para se obter uma representação do comportamento das detecções em relação às distâncias. Esta representação ajudará na escolha de um modelo para se estimar a função de deteç̧ão.

\subsubsection{Propriedades}

Buckland et al. (1993) propõem que os modelos para $g(y)$ levem em conta três propriedades: robustez do modelo, critério da forma e eficiência dos estimadores de tal forma que, quando satisfeitas, auxiliem na seleção do modelo.

As três propriedades desejadas de um modelo para $g(y)$ são dadas a seguir em ordem de importância (Burnham et al. (1980) e Buckland et al. (1993)).

\section{Robustez do modelo}

A propriedade mais importante que deve ser satisfeita por um modelo para $g(y)$ é a robustez no sentido de que garante que o modelo seja flexível e assuma um conjunto de formas possíveis da verdadeira função de detecção. A maioria dos modelos propostos para $g(y)$ possuem um número variável de parâmetros, o que facilita o cumprimento desta propriedade. Isto será observado na Seção 1.1.2.

\section{Critério da forma}

Este critério exige que o modelo para a função de detecção tenha "forma de ombro" nas 


\subsection{FUNÇÃO DE DETECÇÃO}

distâncias próximas de zero. Isto significa que a detecção permanece quase certa em pequenas distâncias da linha ou do ponto. A Figura 1.6 mostra um exemplo de função com essa forma.

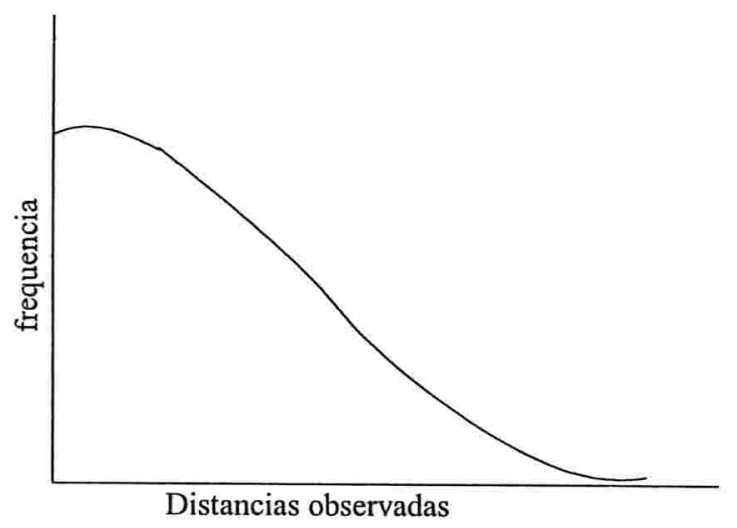

Figura 1.6: Exemplo de função de detecção com forma de ombro

Este critério exclui funções que são pontudas ao redor de zero, embora existam gráficos de barras que, por ter poucas classes ou classes muito amplas, apresentem esta forma. A pouca exatidão nas medições poderia também causar a forma pontuda do gráfico de barras.

\section{Eficiência dos estimadores}

É desejável selecionar um modelo que forneça estimadores relativamente precisos de seus parâmetros. A estimação será eficiente só quando os modelos forem robustos e tenham um ombro na distância próxima a zero. Em outros casos, a estimação poderia ser precisa mas viciada. Buckland et al. (1993) recomendam usar o método de máxima verossimilhança pois produz estimadores que possuem boas propriedades estatísticas.

\subsubsection{Modelagem}

Buckland (1992) propôs que a função de detecção tenha a seguinte forma

$$
g(y)=\text { função chave }\{1+\text { expansão em séries }\}
$$




\subsection{FUNÇÃO DE DETECÇÃO}

e sugere que o processo de modelagem seja feito em dois estágios. O primeiro estágio é selecionar uma função chave, $\alpha(y)$, logo depois que os valores atípicos tenham sido devidamente truncados e o segundo estágio é selecionar uma expansão em séries.

As funções chaves recomendadas por Buckland et al. (1993) são: a uniforme, a normal truncada à esquerda do zero (normal truncada) e a taxa de risco (hazard rate). A função uniforme não possui parâmetros a serem estimados, enquanto que a normal truncada e a taxa de risco possuem 1 e 2 , respectivamente.

Possivelmente só $\alpha(y)$ poderia se ajustar ao conjunto das distâncias se os dados fossem devidamente truncados, o tamanho da amostra fosse pequeno ou os dados fossem facilmente descritos por um modelo simples.

A função chave poderia ter uma das formas apresentadas na Tabela 1.1.

Tabela 1.1: Funções chaves para a função de detecção

\begin{tabular}{lll}
\hline Função & Forma & \\
\hline \hline Uniforme $[0, w]$ & $\alpha(y)=\frac{1}{w}$ & $0 \leq y \leq w$ \\
Normal truncada & $\alpha(y)=\exp \left(-\frac{y^{2}}{2 \sigma^{2}}\right)$ & $y \geq 0$ \\
Taxa de risco & $\alpha(y)=1-\exp \left(-\left(\frac{y}{\sigma}\right)^{-b}\right)$ & $y \geq 0$ \\
\hline$\sigma:$ parâmetro de escala, $(\sigma>0)$ & $b:$ parâmetro de forma, $(b \geq 1)$ &
\end{tabular}

Uma breve exposição sobre a última destas funções é feita no Apêndice A.1, em forma separada para linhas transectas e pontos transectos.

O segundo estágio é selecionar uma expansão em séries. Em Buckland et al. (1993) foram feitas as propostas para estas expansões apresentadas na Tabela 1.2 .

Nestas expansões, os $a_{j}$ 's são os coeficientes de cada termo e $q$ é o menor número de termos para o qual se obtém um bom ajuste. Este número é encontrado usando testes da razão de verossimilhanças ou o critério de informação de Akaike e o assunto será tratado com mais detalhes na Seção 2.3.2.

Os polinômios de ordem ímpar têm coeficiente zero já que a função densidade de probabilidade 
Tabela 1.2: Expansões em série na função de detecção

\begin{tabular}{ll}
\hline Expansão em séries & Forma \\
\hline \hline Séries cosseno & $\sum_{j=1}^{q} a_{j} \cos \left(\frac{j \pi y}{w}\right)$ \\
Polinômios simples & $\sum_{j=1}^{q} a_{j}\left(\frac{y}{w}\right)^{2 j}$ \\
Polinômios hermitianos & $\sum_{j=1}^{q} a_{j} H_{2 j}\left(\frac{y}{\sigma}\right)$ \\
\hline
\end{tabular}

das distâncias para pontos e linhas transectas é considerada como sendo simétrica ao redor do ponto ou da linha (Buckland (1985), Buckland (1992) e Buckland et al. (1993)).

Uma breve exposição sobre a última destas expansões é feita no Apêndice A.2.

Em Buckland et al. (1993) foram propostas para cada função chave duas expansões em séries, apresentadas na Tabela 1.3.

Tabela 1.3: Funções de detecção

\begin{tabular}{llll}
\hline Função chave & Forma & Expansão em séries & Forma \\
\hline \hline Uniforme & $\frac{1}{w}$ & Cosseno & $\sum_{j=1}^{q} a_{j} \cos \left(\frac{j \pi y}{w}\right)$ \\
Uniforme & $\frac{1}{w}$ & Polinômios simples & $\sum_{j=1}^{q} a_{j}\left(\frac{y}{w}\right)^{2 j}$ \\
Normal truncada & $\exp \left(-\frac{y^{2}}{2 \sigma^{2}}\right)$ & Cosseno & $\sum_{j=2}^{q} a_{j} \cos \left(\frac{j \pi y}{w}\right)$ \\
Normal truncada & $\exp \left(-\frac{y^{2}}{2 \sigma^{2}}\right)$ & Polinômios hermitianos & $\sum_{j=2}^{q} a_{j} H_{2 j}\left(\frac{y}{\sigma}\right)$ \\
Taxa de risco & $1-\exp \left(-\left(\frac{y}{\sigma}\right)^{-b}\right)$ & Cosseno & $\sum_{j=2}^{q} a_{j} \cos \left(\frac{j \pi y}{w}\right)$ \\
Taxa de risco & $1-\exp \left(-\left(\frac{y}{\sigma}\right)^{-b}\right)$ & Polinômios simples & $\sum_{j=2}^{q} a_{j}\left(\frac{y}{w}\right)^{2 j}$ \\
\hline
\end{tabular}

A função chave uniforme combinada com a expansão em séries cosseno produz o modelo conhecido como séries de Fourier, amplamente estudado por Burnham et al. (1980). Um método para redução do vício do estimador da densidade quando são usadas estas séries é apresentado por Quang (1990).

Outras formas de se estimar a função de detecção para linhas transectas são propostas por Melville e Welsh (2001), usando um estimador tipo Kernel. 


\subsection{Suposições}

As seguintes suposições são feitas quando são aplicados os métodos amostrais em estudo (Burnham et al. (1980), Buckland et al. (1993)).

1. os objetos são distribuídos na área de interesse segundo um processo estocástico com parâmetro $D$ (número de objetos por unidade de área);

2. as linhas ou pontos devem ser posicionados aleatoriamente. É mais importante que as linhas ou pontos sejam posicionados aleatoriamente com respeito à distribuição dos objetos que a distribuição aleatória dos mesmos na região de interesse, pois sob as suposições de posição aleatória da linha ou ponto e nenhuma movimentação dos objetos em reposta ao observador, a distribuição dos objetos na região coberta pela amostragem é uniforme (Burnham et al. (1980)).

As seguintes três suposições são relacionadas da mais a menos crítica, e são as que realmente produzem estimadores confiáveis da densidade:

1. os objetos sobre a linha ou ponto são sempre detectados $(g(0)=1)$ : é feita a suposição de que os objetos sobre ou próximos da linha ou ponto sejam sempre detectados, o que deve ser garantido por meio de procedimentos de campo. É importante que não se dê mais ênfase à detecção sobre a linha ou ponto do que à detecção dos objetos ao lado do observador, pois o número de objetos detectados poderia decrescer rapidamente após a distância zero e produzir uma forma pontuda na função de detecção, o que faria com que não fosse satisfeito o critério da forma mencionado na Seção 1.1.1, e portanto dificultar sua modelagem. No caso em que não possa ser garantido por procedimentos de campo que todos os objetos sobre a linha ou ponto sejam detectados foi proposto por Borchers et al. (1998a) o uso do método de captura-recaptura. Além desse método, podem ser usados também estimadores tipo HorvitzThompson, propostos em Borchers et al. (1998b); 
2. os objetos são detectados na sua posição inicial: em amostragem de animais, é possível que o animal se movimente antes de ser detectado. A distância é medida da linha ou ponto à posição do objeto no momento da detecção. Se os movimentos antes da detecção forem aleatórios não resultará em problemas sérios, mas se eles acontecerem em resposta à presença do observador isto implicará em um vício no estimador da densidade, que será grande se o animal afastar-se do observador e pequeno se o animal aproximar-se dele. Isto foi estudado mediante simulação para as linhas transectas por Turnock e Quinn (1991). No caso dos pontos transectos, uma possível solução aos movimentos dos animais, causados pela presença do observador pode ser, esperar um tempo predeterminado antes de se fazer as detecções;

3. as medições são exatas: as distâncias e os ângulos devem ser medidos com exatidão. Se as distâncias $x$ em linhas transectas e $r$ em pontos transectos são coletadas em forma de intervalos de distâncias, os objetos detectados devem ser corretamente designados à categoria. É importante que as medidas próximas à distância zero sejam exatamente medidas, especialmente no caso em que as distâncias e os ângulos sejam registrados pontualmente. Se os erros nas medições das distâncias são aleatórios e não muito grandes e o tamanho da amostra é grande então pode ser possível se obter uma estimação confiável da densidade.

Um estudo sobre o efeito dos erros nas medições em linhas transectas sob o estimador do número total de objetos em uma região foi apresentado por Chen (1998). Nesse artigo é feita uma proposta para correção desses erros usando como função de detecção séries de potência exponencial. Foi mostrado para esse caso que aumentar o comprimento $L$ da linha, chamado também de esforço da amostragem, não diminui o vício.

Freqüentemente, quando as distâncias são estimadas e não medidas pelo observador, ele pode arredondá-las a valores convenientes, por exemplo 5, 10,50 ou 100 unidades de medida. Isto é mais comum em ângulos, os quais são arredondados a 0, 15, 30, 45, 60 e 90 graus.

Em geral, os agrupamentos das distâncias podem melhorar os estimadores da densidade. Os 


\subsection{SUPOSIÇÕES}

extremos dos intervalos seriam definidos de tal forma que o ponto médio de cada intervalo contenha os valores mais freqüentes.

Os erros nas medições podem ser evitados medindo e não estimando as distâncias. 


\section{Capítulo 2}

\section{Os Métodos Amostrais}

A título de ilustração, será exibido ao longo do desenvolvimento deste capítulo, um exemplo da aplicação da teoria das linhas transectas aqui apresentada. É importante ressaltar que a aplicação da teoria para pontos transectos é similar à de linhas transectas e por tal motivo será omitida.

Exemplo 1: Considere uma população de tamanho $N=1000$ distribuída uniformemente em uma região de área $A=90000 \mathrm{~m}^{2}$ (ver Figura 2.1). O valor do parâmetro de interesse é $D=$

$\frac{1000 \text { objetos }}{90000 \mathrm{~m}^{2}}=0,0111$ objetos $/ \mathrm{m}^{2}$. Suponha uma amostra como sendo uma linha de comprimento $L=300 \mathrm{~m}$ situada dentro da região de área $A$ e definida a máxima distância de observação dos objetos como sendo $w=30 m$. O número de objetos detectados foi $n_{L}=67$.

\subsection{Linhas Transectas}

Como foi visto no Capítulo 1, a densidade em linhas transectas é dada por

$$
D=\frac{E\left[n_{L}\right]}{2 w L P_{a}}
$$

em que $P_{a}$ é a proporção desconhecida de objetos detectados dentro da região coberta pela amostragem. Uma forma para se estimar $P_{a}$ das distâncias é definí-la como a probabilidade de se detectar 


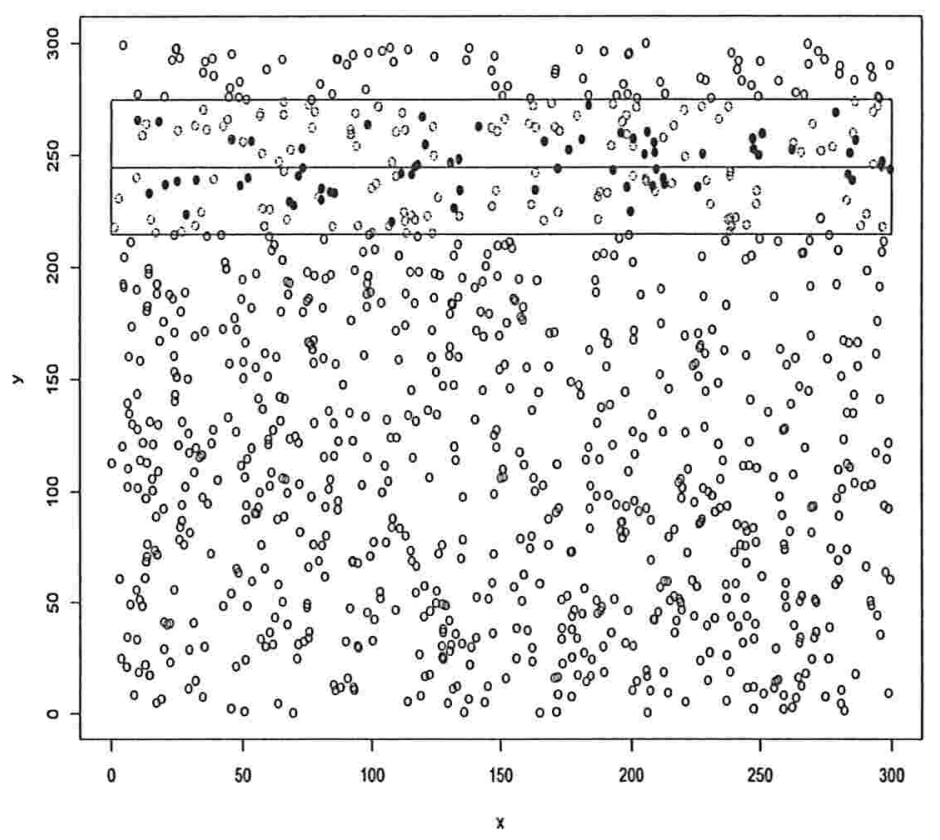

Figura 2.1: A região formada pela faixa que contém a linha transecta corresponde à região coberta pela amostragem. Os pontos pretos recheados correspondem aos objetos detectados. Neste caso, a proporção de objetos detectados é conhecida mas será ignorada para a aplicação da teoria das linhas transectas

um objeto dentro da região coberta pela amostragem. A expressão para $P_{a}$ (ver Apêndice A.3) é dada por

$$
P_{a}=\int_{0}^{w} g(x) \frac{1}{w} d x
$$

Substituindo a expressão (2.2) em (2.1) obtém-se,

$$
D=\frac{E\left[n_{L}\right]}{2 w L \int_{0}^{w} \frac{g(x)}{w} d x}=\frac{E\left[n_{L}\right]}{2 L \int_{0}^{w} g(x) d x} .
$$


Fazendo

$$
\int_{0}^{w} g(x) d x=\mu
$$

e substituindo em (2.3), a densidade ficaria

$$
D=\frac{E\left[n_{L}\right]}{2 L \mu}
$$

Uma interpretação para $\mu$ seria a probabilidade de se detectar um objeto dado que se encontra no intervalo de distância $[0, w]$.

Uma forma de se escrever $\mu$ será encontrada usando a função densidade de probabilidade das distâncias dos objetos detectados (a demonstração encontra-se no Apêndice A.3) dada por,

$$
f_{X \mid O}(x)=\frac{g(x)}{\int_{0}^{w} g(x) d x}
$$

em que $X$ é a variável aleatória que representa a distância perpendicular do objeto à linha e $O$ é o evento de se detectar um objeto.

Avaliando (2.6) em $x=0$, usando a suposição de que $g(0)=1$ e substituindo (2.4) em (2.6), obtém-se

$$
f_{X \mid O}(0)=\frac{g(0)}{\int_{0}^{w} g(x) d x}=\frac{1}{\int_{0}^{w} g(x) d x}=\frac{1}{\mu} .
$$

Substituindo a expressão (2.7) em (2.5), a nova expressão para $D$ é dada por

$$
D=\frac{E\left[n_{L}\right] f_{X \mid O}(0)}{2 L}
$$

Supondo distribuição espacial aleatória dos elementos da população na região de área $A, n_{L}$ teria uma distribuição de Poisson e $\widehat{E\left[n_{L}\right]}=n_{L}$. Fazendo a substituição dos parâmetros da expressão 
(2.8) pelos seus respectivos estimadores,

$$
\hat{D}=\frac{n_{L} \hat{f}_{X \mid O}(0)}{2 L}
$$

Pode-se observar na expressão (2.9) que o problema de se estimar a densidade de populações biológicas transformou-se no problema de se estimar a função densidade de probabilidade das distâncias dos objetos detectados, avaliada na distância zero. Por esta razão é feita uma análise desta função densidade de probabilidade e a forma da sua estimação na Seção 2.3.

\subsection{Pontos Transectos}

Como foi visto no Capítulo 1, a densidade em pontos transectos é dada por

$$
D=\frac{E\left[n_{p}\right]}{k \pi w^{2} P_{a}}
$$

em que $P_{a}$ é a proporção desconhecida de objetos detectados dentro da região coberta pela amostragem. Uma forma para se estimar $P_{a}$ das distâncias é definí-la como a probabilidade de se detectar um objeto dentro da região coberta pela amostragem. A expressão para $P_{a}$ (ver Apêndice A.4) é dada por

$$
P_{a}=\int_{0}^{w} g(r) \frac{2 r}{w^{2}} d r
$$

Substituindo a expressão (2.11) em (2.10) obtém-se,

$$
D=\frac{E\left[n_{p}\right]}{k \pi w^{2} \int_{0}^{w} \frac{2 r g(r)}{w^{2}} d r}=\frac{E\left[n_{p}\right]}{2 k \pi \int_{0}^{w} r g(r) d r} .
$$


Fazendo $v=2 \pi \int_{0}^{w} r g(r) d r$

$$
D=\frac{E\left[n_{P}\right]}{k v} .
$$

Uma forma de se escrever $v$ será encontrada usando a função densidade de probabilidade das distâncias dos objetos detectados (a demonstração encontra-se no Apêndice A.4), dada por,

$$
f_{R \mid O}(r)=\frac{2 \pi r g(r)}{2 \pi \int_{0}^{w} r g(r) d r}
$$

em que $R$ é a variável aleatória que representa a distância do objeto ao ponto e $O$ é o evento de se detectar um objeto.

Defina-se

$$
h(r)=\frac{f_{R \mid O}(r)}{r}=\frac{2 \pi g(r)}{v}
$$

e

$$
h(0)=\lim _{r \rightarrow 0} \frac{f_{R \mid O}(r)}{r}=\frac{2 \pi}{v}
$$

e portanto,

$$
v=\frac{2 \pi}{h(0)}
$$

Substituindo (2.16) em (2.13), obtém-se,

$$
D=\frac{E\left[n_{P}\right] h(0)}{2 k \pi}
$$

Supondo distribuição espacial aleatória dos objetos na região de área $A, n_{P}$ teria uma distribuição 
de Poisson e $\widehat{E\left[n_{P}\right]}=n_{P}$. Fazendo a substituição dos parâmetros em (2.17) pelos seus respectivos estimadores,

$$
\hat{D}=\frac{n_{P} \hat{h}(0)}{2 \pi k} \text {. }
$$

Pode-se observar na expressão (2.18), que de igual forma que para as linhas transectas, o problema de se estimar a densidade de populações biológicas transformou-se no problema de se estimar a função densidade de probabilidade das distâncias dos objetos detectados, pois $h(0)=$ $\lim _{r \rightarrow 0} \frac{f_{R \mid O}(r)}{r}$. Por esta razão é feita uma análise desta função densidade de probabilidade e a forma da sua estimação na Seção 2.3 .

Outros estimadores propostos na literatura para se estimar a densidade populacional usam estimadores tipo Horvitz-Thompson e estimadores tipo razão, que podem ser encontrados em Mack e Quang (1998), Barry e Welsh (2001), Ramsey e Harrison (2004). Estes últimos propuseram um estimador tipo Horvitz-Thompson para a densidade populacional, em que as probabilidades de inclusão dependem do local onde encontra-se o objeto em relação à posição da linha ou do ponto. Os estimadores dados em (2.9) e (2.18) são do tipo Horvitz-Thompson como demonstrado em Borchers et al. (2002).

\subsection{Análise da Função Densidade de Probabilidade das Distâncias dos Objetos Detectados}

Como pode-se observar nas expressões (2.9) e (2.18), o estimador da densidade é expresso em termos da função densidade de probabilidade das distâncias dos objetos detectados, que por sua vez depende da função de detecção. Por tal motivo será feita uma análise dessa função densidade de probabilidade, que inclui a estimação dos parâmetros da função chave e dos coeficientes da expansão em séries. 


\subsection{ANÁLISE DA FUNÇÃO DENSIDADE DE PROBABILIDADE DAS DISTÂNCIAS DOS OBJETOS DETECTADOS}

Em linhas transectas, a função densidade de probabilidade das distâncias dos objetos detectados, $f_{X \mid O}(x)$, é obtida substituindo a expressão para a função de detecção, dada na Seção 1.1.2, na expressão (2.6). Assim,

$$
f_{X \mid O}(x)=\frac{\alpha(x)\left\{1+\sum_{j=1}^{q} a_{j} P_{j}\left(x_{s}\right)\right\}}{\beta}
$$

em que

$$
P_{j}\left(x_{s}\right)= \begin{cases}\cos \left(j \pi x_{s}\right), & \text { em que } x_{s}=\frac{x}{w} \text { para as séries cosseno } \\ x_{s}^{2 j}, & \text { em que } x_{s}=\frac{x}{w} \text { para os polinômios simples } \\ H_{2 j}\left(x_{s}\right), & \text { em que } x_{s}=\frac{x}{\sigma} \text { para os polinômios hermitianos }\end{cases}
$$

$\beta=\int_{0}^{w} g(x) d x$ depende somente dos parâmetros de $\alpha(x)$ e dos coeficientes da expansão em séries e $a_{j}=0$ se o termo $j$ de $P_{j}\left(x_{s}\right)$ não é incluído no modelo.

Em pontos transectos, a função densidade de probabilidade das distâncias dos objetos detectados $f_{R \mid O}(r)$ é obtida substituindo a forma da função de detecção, dada na Seção 1.1.2, na expressão (2.14). Assim,

$$
f_{R \mid O}(r)=\frac{2 \pi r \alpha(r)\left\{1+\sum_{j=1}^{q} a_{j} P_{j}\left(r_{s}\right)\right\}}{\beta},
$$

em que $P_{j}\left(r_{s}\right)$ é definido como $P_{j}\left(x_{s}\right)$ em linhas transectas, substituindo $x$ por $r$ e tomando, neste caso, $\beta=2 \pi \int_{0}^{w} r g(r) d r$, que também depende somente dos parâmetros de $\alpha(r)$ e dos coeficientes da expansão em séries e $a_{j}=0$ se o termo $j$ de $P_{j}\left(r_{s}\right)$ não é incluído no modelo.

Assim, um estimador para $f_{X \mid O}(x)$ e para $f_{R \mid O}(r)$ é encontrado substituindo os estimadores dos parâmetros da função chave e dos coeficientes das expansões em séries nas expressões (2.19) e (2.20), respectivamente. A seguir será apresentada a forma de se estimar estes parâmetros e 


\subsection{ANÁLISE DA FUNÇÃO DENSIDADE DE PROBABILIDADE DAS DISTÂNCIAS DOS OBJETOS DETECTADOS}

coeficientes.

\subsubsection{Estimação dos Parâmetros}

A estimação dos parâmetros da função densidade de probabilidade das distâncias dos objetos detectados será feita levando em conta os dois tipos de dados que podem ser coletados com base nestes métodos amostrais. A seguir será feita uma descrição de cada tipo de dado e logo depois será apresentada a correspondente forma da estimação dos parâmetros.

Os dados coletados nestes métodos amostrais são classificados de acordo com a forma em que são registrados: se são registrados exatamente são chamados dados desagrupados e se são registrados em forma de intervalos são chamados dados agrupados.

\section{Estimação dos parâmetros para dados desagrupados}

Os dados desagrupados podem ser obtidos quando é registrada a distância $x$ ou a distância $r$ e o ângulo $\theta$ em linhas transectas e, a distância $r$ em pontos transectos. A estimação dos parâmetros da função densidade de probabilidade das distâncias detectadas é apresentada a seguir.

A estimação dos parâmetros da função de detecção em linhas transectas e pontos transectos é feita usando o método de máxima verossimilhança, como recomendado por Burnham et al. (1980) e Buckland (1992).

Uma vez obtida $f_{Y \mid O}(y)$, em que $Y$ é a distância $X$ em linhas transectas e $R$ em pontos transectos, pode-se obter a função de verossimilhança, dada por

$$
L(\eta)=\prod_{i=1}^{n} f_{Y \mid O}\left(y_{i}\right) .
$$

$\mathrm{O}$ vetor $\eta$ tem $p+q$ parâmetros onde os $p$ primeiros são os parâmetros da função chave e os $q$ restantes são os coeficientes da expansão em séries; $n$ é o número $n_{L}$ de objetos detectados em linhas transectas e $n_{P}$ em pontos transectos. 


\subsection{ANÁLISE DA FUNÇÃO DENSIDADE DE PROBABILIDADE DAS DISTÂNCIAS DOS OBJETOS DETECTADOS}

Buckland (1992) apresentou a derivada do $\log L(\eta)=l$ em relação ao $j$-ésimo parâmetro de $\eta$, dada por

$$
\frac{\partial l}{\partial \eta_{j}}=\sum_{i=1}^{n}\left(\frac{1}{f_{Y \mid O}\left(y_{i}\right) \beta} \frac{\partial f_{Y \mid O}\left(y_{i}\right) \beta}{\partial \eta_{j}}\right)-\frac{n}{\beta} \frac{\partial \beta}{\partial \eta_{j}}, j=1, \ldots, p+q
$$

em que

$$
\frac{\partial f_{Y \mid O}\left(y_{i}\right) \beta}{\partial \eta_{j}}=\left\{\begin{array}{l}
\alpha\left(y_{i}\right)\left\{\sum_{j^{\prime}=1}^{q} a_{j^{\prime}} \frac{\partial P_{j^{\prime}}\left(y_{i s}\right)}{\partial y_{i s}}\right\} \frac{\partial y_{i s}}{\partial \eta_{j}}+\left\{1+\sum_{j^{\prime}=1}^{q} a_{j^{\prime}} P_{j^{\prime}}\left(y_{i s}\right)\right\} \frac{\partial \alpha\left(y_{i}\right)}{\partial \eta_{j}}, \text { para } 1 \leq j \leq p \\
\alpha\left(y_{i}\right) P_{j-p}\left(y_{i s}\right), \text { para } a_{j-p} \neq 0 \text { e } p+1 \leq j \leq p+q .
\end{array}\right.
$$

A matriz de informação de Fisher é estimada pela matriz Hessiana avaliada no vetor $\hat{\eta}$, com o $j h$-ésimo elemento dado por

$$
H_{j h}(\hat{\eta})=\frac{1}{n}\left[\sum_{i=1}^{n} \frac{\partial \log f_{Y \mid O}\left(y_{i}\right)}{\partial \hat{\eta}_{j}} \frac{\partial \log f_{Y \mid O}\left(y_{i}\right)}{\partial \hat{\eta}_{h}}\right]
$$

em que $\frac{\partial z}{\partial \hat{\eta}_{j}}$ indica $\frac{\partial z}{\partial \eta_{j}}$ avaliada em $\hat{\eta}_{j}$.

Se uma função do vetor de parâmetros $\eta, m(\eta)$, fosse estimada por $m(\hat{\eta})$, então

$$
\widehat{\operatorname{Var}}(m(\hat{\eta}))=\frac{1}{n}\left[\frac{\partial m(\hat{\eta})}{\partial \hat{\eta}}\right]^{\top}[H(\hat{\eta})]^{-1}\left[\frac{\partial m(\hat{\eta})}{\partial \hat{\eta}}\right]
$$

No caso dos pontos transectos a estimação é feita substituindo $\alpha(y)$ por $r \alpha(r)$. A matriz Hessiana e um estimador da variância de $m(\hat{\eta})$ são obtidos pelas expressões (2.21) e (2.22), respectivamente.

\section{Estimação dos parâmetros para dados agrupados}

Os dados agrupados podem ser obtidos de duas formas: a primeira é obter as distâncias $x$ em linhas transectas e $r$ em pontos transectos e agrupá-las em intervalos antes que a análise seja feita; 


\subsection{ANÁLISE DA FUNÇÃO DENSIDADE DE PROBABILIDADE DAS DISTÂNCIAS DOS OBJETOS DETECTADOS}

a segunda é coletar no campo estas distâncias de forma agrupada; as distâncias seriam designadas a um intervalo ou categoria previamente definida. Se as distâncias perpendiculares $x$ em linhas transectas não são obtidas diretamente, existe um intervalo para as distâncias $r$ e um outro para o ângulo $\theta$. Embora existam técnicas para a análise, é recomendado que $r$ e $\theta$ não sejam coletados nem analisados de forma agrupada, já que isto dificulta a sua conversão a distâncias perpendiculares (Buckland et al. (1993)). O $i$-ésimo intervalo para $x$ em linhas transectas ou $r$ em pontos transectos seria $\left[c_{i-1}, c_{i}\right)$; por convenção $c_{0}=0$ e $c_{d}=w$, em que $w$ é a máxima distância em que seriam observados os objetos e $d$ é o número de intervalos em que são agrupadas as distâncias. Portanto, os dados coletados seriam o número de detecções $n_{i}$ em cada intervalo, em que $\sum_{i=1}^{d} n_{i}=n$, e $n$ é o número total de objetos detectados, $n_{L}$ para linhas transectas e $n_{P}$ para pontos transectos. A estimação dos parâmetros da função densidade de probabilidade das distâncias detectadas é apresentada a seguir.

Burnham et al. (1980) propõem uma distribuição multinomial para as freqüências $n_{1}, n_{2}, \ldots, n_{d}$ em dados agrupados. Assim, para $d$ intervalos existem $d$ probabilidades, $\pi_{1}, \ldots, \pi_{d}$, em que $\pi_{i}$ é a probabilidade de que a distância, perpendicular para linhas transectas e radial para pontos transectos, em que se encontra o objeto esteja no $i$-ésimo intervalo, $i=1, \ldots, d$. Portanto, no caso das linhas transectas,

$$
\pi_{i}=\int_{c_{i-1}}^{c_{i}} f_{X \mid O}(x) d x=\int_{c_{i-1}}^{c i} \frac{g(x)}{\beta} d x
$$

Fazendo $P_{i}=\int_{c_{i-1}}^{c_{i}} g(x) d x=\int_{c_{i-1}}^{c_{i}} f_{X \mid O}(x) \beta d x$, temos que $\beta=\sum_{i=1}^{d} P_{i}$. Isto faz com que $\pi_{i}=\frac{P_{i}}{\beta}$, o que implica em $P_{i}=\beta \pi_{i}$.

Logo,

$$
L(\eta)=\frac{n !}{n_{1} ! \ldots n_{d} !} \prod_{i=1}^{d} \pi_{i}^{n_{i}}
$$


ou

$$
l(\eta)=\log L(\eta)=\log \left(\frac{n !}{n_{1} ! \ldots n_{d} !}\right)+\sum_{i=1}^{d} n_{i} \log \pi_{i}
$$

e então

$$
\frac{\partial l(\eta)}{\partial \eta_{j}}=\sum_{i=1}^{d} \frac{n_{i}}{\pi_{i}} \frac{\partial \pi_{i}}{\partial \eta_{j}}
$$

em que

$$
\begin{aligned}
\frac{\partial \pi_{i}}{\partial \eta_{j}} & =\frac{\beta \frac{\partial P_{i}}{\partial \eta_{j}}-P_{i} \frac{\partial \beta}{\partial \eta_{j}}}{\beta^{2}} \\
& =\frac{\frac{\partial P_{i}}{\partial \eta_{j}}}{\beta}-\frac{\pi_{i} \beta \frac{\partial \beta}{\partial \eta_{j}}}{\beta^{2}} \\
& =\frac{1}{\beta}\left\{\frac{\partial P_{i}}{\partial \eta_{j}}-\pi_{i} \frac{\partial \beta}{\partial \eta_{j}}\right\}
\end{aligned}
$$

$\mathrm{e} \frac{\partial \beta}{\partial \eta_{j}}=\frac{\partial \sum_{i=1}^{d} P_{i}}{\partial \eta_{j}}=\sum_{i=1}^{d} \frac{\partial P_{i}}{\partial \eta_{j}}$

A matriz de informação de Fisher para uma observação, $I(\eta)$, tem como $j h$-ésimo elemento

$$
I_{j h}(\eta)=\sum_{i=1}^{d} \frac{1}{\pi_{i}} \frac{\partial \pi_{i}}{\partial \eta_{j}} \frac{\partial \pi_{i}}{\eta_{h}}, j, h=1, \ldots, p+q
$$

Se uma função do vetor de parâmetros $\eta, m(\eta)$, fosse estimada por $m(\hat{\eta})$, então

$$
\widehat{\operatorname{Var}}(m(\hat{\eta}))=\frac{1}{n}\left[\frac{\partial m(\hat{\eta})}{\partial \hat{\eta}}\right]^{\top}[I(\hat{\eta})]^{-1}\left[\frac{\partial m(\hat{\eta})}{\partial \hat{\eta}}\right]
$$


No caso dos pontos transectos, $\pi_{i}$ é definida como $\pi_{i}=\int_{c_{i-1}}^{c_{i}} f_{R \mid O}(r) d r=\int_{c_{i-1}}^{c i} \frac{2 \pi r g(r)}{\beta} d r$ e

$$
P_{i}=\int_{c_{i-1}}^{c_{i}} 2 \pi r g(r) d r=\int_{c_{i-1}}^{c_{i}} f_{R \mid O}(r) \beta d r
$$

A matriz de informação de Fisher e o estimador da variância de $m(\hat{\eta})$ são obtidos usando as expressões (2.23) e (2.24), respectivamente, levando em conta a definição de $\pi_{i}$ e $P_{i}$ para pontos transectos.

É requerido um processo iterativo para maximizar a verossimilhança quando os dados são agrupados ou desagrupados.

Uma vez obtidas as estimativas dos parâmetros da função chave e dos coeficientes da expansão em séries, estas são substituídas na função densidade de probabilidade das distâncias dos objetos detectados (expressão (2.19) para linhas transectas e (2.20) para pontos transectos). Assim, para se obter a estimativa de $f_{X \mid O}(0)$ ou $h(0)$ basta avaliar essas funções na distância zero.

É importante ressaltar que $m(\hat{\eta})$ faz referência a $\hat{f}_{X \mid O}(0)$ em linhas transectas e a $\hat{h}(0)$ em pontos transectos, pois estes dependem somente dos estimadores de máxima verossimilhança dos parâmetros da função chave e dos coeficientes na expansão em séries.

Continuação do Exemplo 1: Como ilustração, foi ajustada ao conjunto de dados do Exemplo 1 a função de deteç̧ão que possui como função chave a função uniforme, sem parâmetro a estimar, e como expansão em séries um termo na expansão cosseno. Os dados foram analisados de forma desagrupada. A estimativa obtida no aplicativo Distance para o coeficiente da expansão foi 0,7341 e a sua estimativa da variância foi 0,1334. Assim,

$$
\hat{f}_{X \mid O}(x)=\frac{\frac{1}{w}\left\{1+0,7341 \cos \left(\frac{\pi x}{w}\right)\right\}}{\int_{0}^{30} \frac{1}{w}\left\{1+0,7341 \cos \left(\frac{\pi x}{w}\right)\right\} d x}
$$

e

$$
\hat{f}_{X \mid O}(0)=\frac{\frac{1,7341}{w}}{\int_{0}^{30} \frac{1}{w}\left\{1+0,7341 \cos \left(\frac{\pi x}{w}\right)\right\} d x}=0,062670
$$




\subsection{ANÁLISE DA FUNÇÃO DENSIDADE DE PROBABILIDADE DAS DISTÂNCIAS DOS OBJETOS DETECTADOS}

A estimativa de $\operatorname{Var}\left(\hat{f}_{X \mid O}(0)\right)=2,323722 \times 10^{-5}$.

A estimativa da densidade é encontrada substituindo $\hat{f}_{X \mid O}(0)=0,06267, n_{L}=67$ objetos e $L=300 m$ na expressão (2.9). Portanto,

$$
\hat{D}=\frac{67 \text { objetos } \times 0,06267}{2 \times 300 \mathrm{~m}}=0,00699 \text { objetos } / \mathrm{m}^{2},
$$

ou alternativamente 6990 objetos $/ \mathrm{km}^{2}$.

Outras formas para se estimar a função densidade de probabilidade das distâncias dos objetos detectados, em linhas transectas e pontos transectos, são obtidas por meio do método Kernel. Algumas delas não levam em conta a forma da função de detecção e além disso, impõem que a probabilidade de detecção dependa não somente da distância que separa o objeto do observador como também de outras covariáveis como o tamanho, o volume ou a altura do objeto. Estas formas de estimação podem ser encontradas em Quang (1993), Chen (1996), Mack e Quang (1998) e Chen (2000).

$\mathrm{Na}$ continuação do Exemplo 1, nesta seção, foi dito que foi ajustado um termo na expansão cosseno. Ante isto surge a seguinte pergunta: o que foi feito para saber que somente um termo na expansão era necessário para o ajuste à função de detecção? A resposta é dada a seguir.

\subsubsection{Seleção do Número $q$ de Termos na Expansão em Séries}

É necessário se obter o número $q$ de termos na expansão em séries com o qual se obtém um bom ajuste ao conjunto de dados. Para a seleção do número $q$ de termos que serão ajustados na expansão em séries, é usado o teste da razão de verossimilhanças (Buckland et al. (1993)) da seguinte forma. Suponha que o Modelo 1 possui $q_{1}$ termos e o Modelo 2 possui $q_{1}+q_{2}$. Este teste avalia se a adição dos $q_{2}$ termos melhora o ajuste. A hipótese nula a ser testada é que o Modelo 1 se ajusta tão bem quanto o Modelo 2. 


\subsection{ANÁLISE DA FUNÇÃO DENSIDADE DE PROBABILIDADE DAS DISTÂNCIAS DOS OBJETOS DETECTADOS}

A estatística do teste é dada por

$$
\chi^{2}=-2\left[\log L_{1}-\log L_{2}\right]
$$

que tem distribuição assintótica $\chi^{2} \operatorname{com} q_{2}$ graus de liberdade, $L_{1}$ e $L_{2}$ são os valores máximos das funções de verossimilhança para os Modelos 1 e 2, respectivamente, definidas na Seção 2.3.1 para os dados agrupados e desagrupados.

Além do teste da razão de verossimilhanças, pode-se usar também o critério de informação de Akaike $(A I C)$, definido como

$$
A I C=-2 \log (L)+2 s
$$

em que $L=L_{1}$ e $s=q_{1}$ para o Modelo 1 e $L=L_{2}$ e $s=q_{1}+q_{2}$ para o Modelo 2. No $A I C$, o primeiro termo é uma medida do bom ajuste do modelo, enquanto que o segundo é uma penalidade pela adição dos parâmetros.

A forma de se selecionar o número $q$ de termos é calcular o $A I C$ para o Modelo 1 e para o Modelo 2; se o valor do $A I C$ aumenta com a adição dos $q_{2}$ termos, o número $q$ de coeficientes na expansão em séries será $q=q_{1}$.

Continuação do Exemplo 1: Para se encontrar que somente era necessário um termo na expansão em séries cosseno para se obter um bom ajuste no Exemplo 1 na seção anterior, foram usados os dois métodos apresentados nesta seção. A seguir são exibidos os resultados encontrados.

\section{Usando os testes da razão de verossimilhanças}

Primeiro foram ajustados o Modelo 1 contendo somente a função uniforme e o Modelo 2 contendo a função uniforme e um termo da expansão cosseno. O valor da estatística do teste foi 18,86404 , pois $\log L_{1}=-222,46449$ e $\log L_{2}=-213,03238$. Isto produz um $p$-valor $<0,001$ o que indica que o Modelo 2 se ajusta melhor do que o Modelo 1 e portanto foram redefinidos os Modelo 1 e 2 da seguinte forma: o Modelo 1 passou a conter a função uniforme e um termo da expansão cosseno e o Modelo 2 a função uniforme e dois termos da expansão cosseno. Procedendo 


\subsection{ANÁLISE DA FUNÇÃO DENSIDADE DE PROBABILIDADE DAS DISTÂNCIAS DOS OBJETOS DETECTADOS}

como no caso anterior, foi calculada a estatística do teste da razão de verossimilhanças; o valor obtido foi 0,17766 e o $p$-valor foi 0,673392 , indicando que o novo Modelo 1 está bem ajustado.

\section{Usando o Critério de Informação de Akaike}

Primeiro foram ajustados o Modelo 1 contendo somente a função uniforme e o Modelo 2 contendo a função uniforme e um termo da expansão cosseno. Uma vez ajustados os modelos, foram calculados o $A I C$ de 444,92899 para o Modelo 1 e de 428,06476 para o Modelo 2. Como o valor do $A I C$ diminuiu são ajustados o Modelo 1 agora sendo a função uniforme e um termo na expansão cosseno e o Modelo 2 contendo a função uniforme e dois termos na expansão em séries e calculado novamente o $A I C$ para os dois modelos. Os valores obtidos do $A I C$ foram 428,06476 e 429,88712, respectivamente. Como o valor do $A I C$ aumentou, foi escolhido o novo Modelo 1 contendo a função uniforme e um termo na expansão cosseno.

\subsubsection{Seleção do Modelo para a Função Densidade de Probabilidade das Distâncias dos Objetos Detectados}

Na modelagem de $f_{X \mid O}(x)$ ou $f_{R \mid O}(r)$ poderiam ser encontrados vários modelos que se ajustam bem ao conjunto de dados com base nos quais poderíamos obter vários estimadores para $f_{X \mid O}(0)$ ou $h(0)$. Portanto, é necessário escolher $f_{X \mid O}(x)$ ou $f_{R \mid O}(r)$ que mais se aproxime da verdadeira, que neste caso é desconhecida. Nesta seção, são apresentadas algumas propostas para se selecionar a "melhor" $f_{X \mid O}(x)$ ou $f_{R \mid O}(r)$.

A primeira proposta (Buckland et al. (1993)) é calcular o $A I C$ para cada modelo e aquele com o menor $A I C$ é o escolhido.

A segunda proposta é feita por Buckland et al. (1997), que apresentaram um estimador para $f_{X \mid O}(0)$ da seguinte forma

$$
\hat{f}_{X \mid O}(0)=\sum_{k=1}^{K} w_{k} \hat{f}_{k}(0)
$$




\subsection{ANÁLISE DA FUNÇÃO DENSIDADE DE PROBABILIDADE DAS DISTÂNCIAS DOS OBJETOS DETECTADOS}

em que $\hat{f}_{k}(0)$ é o estimador de $f_{X \mid O}(0)$ sob o $k$-ésimo modelo e $w_{k}$ é o peso designado ao $k$-ésimo modelo, $k=1, \ldots, K$, com $K$ sendo o número de modelos considerados. Formas para obtenção dos pesos $w_{k}$ são indicadas adiante nesta seção. Um estimador da variância de $\hat{f}_{X \mid O}(0)$, considerando que os $\hat{f}_{X \mid O}(0)$ são identicamente distribuídos com $E\left[\hat{f}_{X \mid O}(0)\right]=f_{X \mid O}(0)$ e pesos $w_{k}$ conhecidos, é

$$
\operatorname{Var}\left(\hat{f}_{X \mid O}(0)\right)=\sum_{k=1}^{K} w_{k}^{2} \operatorname{Var}\left(\hat{f}_{k}(0)\right)+2 \sum_{l<k} w_{k} w_{l} \operatorname{Cov}\left(\hat{f}_{k}(0), \hat{f}_{l}(0)\right) .
$$

O problema é como se estimar essa covariância. Buckland et al. (1997) argumentam que a covariância é alta pois cada modelo é ajustado ao mesmo conjunto de dados. Portanto ela é igualada ao seu máximo valor possível que é a média geométrica das variâncias dos estimadores sob os modelos $k$ e $l$. Em tal caso, obtemos o maior valor da $\operatorname{Var}\left(\hat{f}_{X \mid O}(0)\right)$,

$$
\begin{aligned}
& \operatorname{Var}\left(\hat{f}_{X \mid O}(0)\right) \leq \sum_{k=1}^{K} w_{k}^{2} \operatorname{Var}\left(\hat{f}_{k}(0)\right)+2 \sum_{l<k} w_{k} w_{l} \sqrt{\operatorname{Var}\left(\hat{f}_{k}(0)\right) \operatorname{Var}\left(\hat{f}_{l}(0)\right)} \\
& \operatorname{Var}\left(\hat{f}_{X \mid O}(0)\right) \leq\left(\sum_{k=1}^{K} w_{k} \sqrt{\operatorname{Var}\left(\hat{f}_{k}(0)\right)}\right)^{2} .
\end{aligned}
$$

Esta variância muda quando é incorporada uma componente que representa o vício que é produzido quando $f_{X \mid O}(0)$ é estimada de um modelo selecionado erradamente. A seguir será incorporada esta componente.

Defina-se $f_{k}(0)=f_{X \mid O}(0)+\gamma_{k}$, onde $\gamma_{k}$ é o vício não especificado que surge ao se estimar $f_{X \mid O}(0)$ sob o modelo $k$. Suponha que $E\left[\gamma_{k}\right]=0$, em que a esperança é tomada sob todos os possíveis modelos. Denote,

$$
E\left[\hat{f}_{k}(0) \mid \gamma_{k}\right]=f_{X \mid O}(0)+\gamma_{k}=f_{k}(0)
$$

Se a esperança é tomada sob todos os possíveis modelos,

$$
E\left[\hat{f}_{k}(0)\right]=E\left[E\left[\hat{f}_{k}(0) \mid \gamma_{k}\right]\right]=E\left[f_{X \mid O}(0)+\gamma_{k}\right]=E\left[f_{k}(0)\right]=f_{X \mid O}(0)
$$




\subsection{ANÁLISE DA FUNÇÃO DENSIDADE DE PROBABILIDADE DAS DISTÂNCIAS DOS}

\section{OBJETOS DETECTADOS}

Denote também

$$
\operatorname{Var}\left(\hat{f}_{k}(0) \mid \gamma_{k}\right)=E\left[\left(\hat{f}_{k}(0)-f_{k}(0)\right)^{2}\right]
$$

e

$$
\operatorname{Var}\left(\hat{f}_{k}(0)\right)=E\left[\left(\hat{f}_{k}(0)-f_{X \mid 0}(0)\right)^{2}\right]
$$

Sob o modelo $k, \gamma_{k}$ é constante e isto implica em

$$
\begin{aligned}
\operatorname{Var}\left(\hat{f}_{k}(0)\right) & =E\left[\left(\hat{f}_{k}(0)-f_{k}(0)+f_{k}(0)-f_{X \mid O}(0)\right)^{2}\right] \\
& =E\left[\left(\hat{f}_{k}(0)-f_{k}(0)\right)^{2}+2\left(\hat{f}_{k}(0)-f_{k}(0)\right)\left(f_{k}(0)-f_{X \mid O}(0)\right)+\left(f_{k}(0)-f_{X \mid O}(0)\right)^{2}\right] \\
& =E\left[\left(\hat{f}_{k}(0)-f_{k}(0)\right)^{2}\right]+2\left(f_{k}(0)-f_{X \mid O}(0)\right) E\left[\hat{f}_{k}(0)-f_{k}(0)\right]+\left(f_{k}(0)-f_{X \mid O}(0)\right)^{2} \\
& =\operatorname{Var}\left(\hat{f}_{k}(0) \mid \gamma_{k}\right)+\gamma_{k}^{2}
\end{aligned}
$$

Porém,

$$
\operatorname{Var}\left(\hat{f}_{X \mid O}(0)\right)=\sum_{k=1}^{K} w_{k}^{2} \operatorname{Var}\left(\hat{f}_{k}(0)\right)+\sum_{k} \sum_{l \neq k} w_{k} w_{l} \operatorname{Cov}\left(\hat{f}_{k}(0), \hat{f}_{l}(0)\right)
$$

Se assume-se a correlação perfeita entre $\hat{f}_{k}(0)$ e $\hat{f}_{l}(0)$, ou seja $\operatorname{Corr}\left(\hat{f}_{k}(0), \hat{f}_{l}(0)\right)=1$, a variância ficaria

$$
\begin{aligned}
\operatorname{Var}\left(\hat{f}_{X \mid O}(0)\right) & =\sum_{k=1}^{K} w_{k}^{2} \operatorname{Var}\left(\hat{f}_{k}(0)\right)+\sum_{k} \sum_{l \neq k} w_{k} w_{l} \sqrt{\operatorname{Var}\left(\hat{f}_{k}(0)\right) \operatorname{Var}\left(\hat{f}_{l}(0)\right)} \\
& =\left(\sum_{k=1}^{K} w_{k} \sqrt{\operatorname{Var}\left(\hat{f}_{k}(0)\right)}\right)^{2}
\end{aligned}
$$

Substituindo (2.27) em (2.30) obtém-se

$$
\operatorname{Var}\left(\hat{f}_{X \mid O}(0)\right)=\left\{\sum_{k=1}^{K} w_{k} \sqrt{\operatorname{Var}\left(\hat{f}_{k}(0) \mid \gamma_{k}\right)+\gamma_{k}^{2}}\right\}^{2}
$$




\subsection{ANÁLISE DA FUNÇÃO DENSIDADE DE PROBABILIDADE DAS DISTÂNCIAS DOS OBJETOS DETECTADOS}

Esta variância pode ser estimada substituindo $\gamma_{k}$ por $\hat{\gamma}_{k}=\hat{f}_{k}(0)-\hat{f}_{X \mid O}(0)$ e $\operatorname{Var}\left(\hat{f}_{k}(0) \mid \gamma_{k}\right)$ por $\widehat{\operatorname{Var}}\left(\hat{f}_{k}(0) \mid \gamma_{k}\right)$. O estimador $\hat{f}_{X \mid O}(0)$ é encontrado usando a expressão (2.25) e $\widehat{\operatorname{Var}}\left(\hat{f}_{k}(0) \mid \gamma_{k}\right)$ é encontrado usando a expressão (2.22) para dados desagrupados e a expressão (2.24) para dados agrupados, supondo que o modelo $k$ é o verdadeiro.

A independência dos $f_{k}(0)^{\prime} s$ pode ser obtida se existir um número grande de dados, dividindoos em $K$ grupos iguais ou quase iguais, em que $K$ é o número de modelos. Cada modelo é ajustado a um dos $K$ conjuntos de dados para se obter os estimadores de $f_{k}(0)$ e de $\operatorname{Var}\left(\hat{f}_{k}(0) \mid \gamma_{k}\right)$. Os $w_{k}$ são estimados do conjunto inteiro de dados como indicado abaixo.

O estimador da variância, usando a independência agora obtida com a divisão do conjunto de dados, é obtido fazendo $\operatorname{Corr}\left(\hat{f}_{k}(0), \hat{f}_{l}(0)\right)=0 \mathrm{em}(2.28)$. Assim,

$$
\operatorname{Var}\left(\hat{f}_{X \mid O}(0)\right)=\sum_{k=1}^{K} w_{k}^{2} \operatorname{Var}\left(\hat{f}_{k}(0)\right)
$$

Substituindo (2.27) em (2.31), temos

$$
\operatorname{Var}\left(\hat{f}_{X \mid O}(0)\right)=\sum_{k=1}^{K} w_{k}^{2}\left\{\operatorname{Var}\left(\hat{f}_{k}(0) \mid \gamma_{k}\right)+\gamma_{k}^{2}\right\}
$$

A primeira proposta para se encontrar os pesos $w_{k}$ é usar o $A I C$ ou o $B I C$ (critério de informação de Bayes), que são definidos como $I=-2 \log L+s \log n_{L}$, em que $n_{L}$ é o número de deteç̧ões. Para cada modelo $I_{k}=-2 \log L_{k}+t_{k}$, em que $t_{k}=2 s$ no caso do $A I C$ e $t_{k}=s \log n_{L}$ no caso do $B I C$ ( $s$ é o número de parâmetros do modelo).

Define-se o peso $w_{k}$ como

$$
w_{k}=\frac{\exp \left(-\frac{I_{k}}{2}\right)}{\sum_{k=1}^{K} \exp \left(-\frac{I_{k}}{2}\right)} .
$$

Definindo $w_{k}$ desta forma assegura-se que os modelos com igual valor para $I$ tenham o mesmo 


\subsection{ANÁLISE DA FUNÇÃO DENSIDADE DE PROBABILIDADE DAS DISTÂNCIAS DOS OBJETOS DETECTADOS}

peso.

A segunda proposta é feita baseada no bootstrap, em que para cada reamostra é avaliada $f_{k}(x)$ $k=1, \ldots, K$ e selecionado o melhor modelo entre estes. Esta seleção é feita usando o $A I C$ ou $B I C$. Os pesos $w_{k}$ são estimados como a proporção de reamostras em que o modelo $k$ é selecionado como o melhor.

No caso dos pontos transectos a seleção do melhor modelo é feita do mesmo modo que para linhas transectas substituindo $f_{X \mid O}(0)$ por $h(0)$ e $n_{L}$ por $n_{P}$.

Continuação do Exemplo 1: Como foi visto na Seção 1.1.2 existem várias propostas para a modelagem da função de detecção e portanto existem várias propostas para a função densidade de probabilidade das distâncias dos objetos detectados. No caso do exemplo 1, foram ajustadas 5 funções densidade de probabilidade das distâncias dos objetos detectados. As funções chaves e as expansões em série de cada função densidade de probabilidade e os seus correspondentes valores de $A I C$ são apresentados na Tabela 2.1. O número de termos ajustados na expansão em séries aparece entre parênteses. Este número foi selecionado usando testes da razão de verossimilhanças.

Tabela 2.1: Funções densidade de probabilidade das distâncias dos objetos detectados ajustadas aos dados do Exemplo 1 e os seus correspondentes valores de AIC.

\begin{tabular}{ll}
\hline Função chave e expansão em séries & Valor do $A I C$ \\
\hline \hline Uniforme e Cosseno(1) & 428,06476 \\
Uniforme e Polinômios Simples(2) & 429,90109 \\
Normal truncada e Cosseno(0) & 428,23315 \\
Normal truncada e Polinômios hermitianos(0) & 428,23315 \\
Taxa de risco e Cosseno(0) & 429,35022 \\
\hline
\end{tabular}

A seleção do modelo foi feita baseada no mínimo valor do $A I C$ e portanto o modelo selecionado como o melhor foi a função chave uniforme e um termo na expansão em séries cosseno. 


\subsection{ANÁLISE DA FUNÇÃO DENSIDADE DE PROBABILIDADE DAS DISTÂNCIAS DOS OBJETOS DETECTADOS}

\subsubsection{Teste de Bondade de Ajuste do Modelo}

Para se avaliar o ajuste do modelo selecionado como o melhor para $f_{X \mid O}(x)$ ou $f_{R \mid O}(r)$ ao conjunto de dados, são usados os testes $\chi^{2}$ de bondade de ajuste e o teste de Kolmogorov-Smirnov.

O teste $\chi^{2}$ compara as freqüências $n_{i}$ do $i$-ésimo intervalo das distâncias com as distâncias esperadas estimadas sob o modelo selecionado. No caso em que os dados sejam desagrupados é necessário que estes sejam agrupados em intervalos antes da utilização do teste.

A estatística do teste é dada por

$$
\chi^{2}=\sum_{i=1}^{d} \frac{\left(n_{i}-\hat{E}\left[n_{i}\right]\right)^{2}}{\hat{E}\left[n_{i}\right]}
$$

que tem aproximadamente uma distribuição $\chi^{2} \operatorname{com} d-(p+q)-1$ graus de liberdade, em que $d$ é o número de intervalos das distâncias, $p+q$ é o número de parâmetros do modelo e $\hat{E}\left[n_{i}\right]=$ $n\left(F_{i+1}-F_{i}\right)$, em que $F_{i}\left(F_{i+1}\right)$ é a função de distribuição acumulada do modelo selecionado avaliada no valor mínimo (máximo) do $i$-ésimo intervalo.

O teste de Kolmogorov-Smirnov (Dudewicz (1988)), calcula a máxima diferença entre a função de distribuição empírica $F_{n}(y)$ e a função de distribuição de probabilidade do modelo selecionado.

A hipótese nula é $H_{0}: F(y)=F_{Y \mid O}(y)$, em que $F(y)$ representa a função de distribuição de probabilidade de onde provêm as distâncias e $F_{Y \mid O}(y)$ a função de distribuição de probabilidade do modelo selecionado.

A estatística do teste é dada por

$$
D_{n}=\sup _{y}\left|F_{n}(y)-F_{Y \mid O}(y)\right|,
$$

em que $F_{n}(y)$ é a função de distribuição de probabilidade empírica. O teste rejeita $H_{0}$ a um nível $\alpha$ se $D_{n} \geq d_{n, \alpha}$, em que $d_{n, \alpha}$ é tal que $P_{H_{0}}\left(D_{n} \geq d_{n, \alpha}\right)=\alpha$.

Alguns valores assintóticos para $d_{n, \alpha}$ são apresentados na Tabela 2.2. 


\subsection{ANÁLISE DA FUNÇÃO DENSIDADE DE PROBABILIDADE DAS DISTÂNCIAS DOS OBJETOS DETECTADOS}

Tabela 2.2: Alguns valores para $d_{n, \alpha}$

\begin{tabular}{llll}
\hline$\alpha$ & 0,01 & 0,05 & 0,10 \\
\hline$d_{n, \alpha}$ & $\frac{1,63}{\sqrt{n}}$ & $\frac{1,36}{\sqrt{n}}$ & $\frac{1,22}{\sqrt{n}}$ \\
\hline
\end{tabular}

Valores exatos para $d_{n, \alpha}$ e $n \leq 40$ aparecem em Gibbons (1985).

Continuação do Exemplo 1: O teste de bondade de ajuste para o modelo selecionado como o melhor foi feito para diferentes agrupamentos do conjunto de dados, pois como foi dito anteriormente os dados foram analisados de forma desagrupada e portanto estes agrupamentos foram possíveis.

Os dados foram agrupados em 5, 8 e 12 intervalos, a estatística do teste resultou nos seguintes valores: 1,7861 com 3 graus de liberdade, 1,3058 com 6 graus de liberdade e 3,0999 com 10 graus de liberdade, com correspondentes $p$-valores dados por 0,61797, 0,97134 e 0,97898, indicando que o modelo selecionado como o melhor na seção anterior está bem ajustado.

O valor da estatística do teste de Kolmogorov-Smirnov foi $D_{n}=0,0763$ e o $p$-valor foi $p=$ 0,8305 , indicando um bom ajuste do modelo.

\subsubsection{Exatidão e Precisão dos Estimadores de $D$}

Para linhas transectas, o vício de $\hat{D}$ é dado por

$$
\begin{aligned}
E[\hat{D}]-D & =E\left[\frac{n_{L} \hat{f}_{X \mid O}(0)}{2 L}\right]-\frac{E\left[n_{L}\right] f_{X \mid O}(0)}{2 L} \\
& =\frac{E\left[n_{L}\right] E\left[\hat{f}_{X \mid O}(0)\right]}{2 L}-\frac{E\left[n_{L}\right] f_{X \mid O}(0)}{2 L}
\end{aligned}
$$

pois é feita a suposição de correlação zero entre $\hat{f}_{X \mid O}(0)$ e $n_{L}$ (Buckland et al. (1993)). 


\subsection{ANÁLISE DA FUNÇÃO DENSIDADE DE PROBABILIDADE DAS DISTÂNCIAS DOS OBJETOS DETECTADOS}

Para pontos transectos, o vício é dado por

$$
\begin{aligned}
E[\hat{D}]-D & =E\left[\frac{n_{P} \hat{h}(0)}{2 \pi k}\right]-\frac{E\left[n_{P}\right] h(0)}{2 \pi k} \\
& =\frac{E\left[n_{P}\right] E[\hat{h}(0)]}{2 \pi k}-\frac{E\left[n_{P}\right] h(0)}{2 \pi k}
\end{aligned}
$$

pois como em linhas transectas, também é feita a suposição de correlação zero entre $\hat{h}(0)$ e $n_{P}$.

Assim, $\hat{D}$ é não viciado para $D$ se $\hat{f}_{X \mid O}(0)$ é não viciado para $f_{X \mid O}(0)$ em linhas transectas e $\hat{h}(0)$ é não viciado para $h(0)$ em pontos transectos. Como foi mostrado na Seção 2.3 , não existe um modelo único para $f_{X \mid O}(x)$ em linhas transectas nem para $h(r)$ em pontos transectos, o que faz com que não exista uma forma fechada para o vício do estimador de $f_{X \mid O}(0)$ nem para o vício do estimador de $h(0)$.

A estimação da $\operatorname{Var}(\hat{D})$ será feita usando o método delta como proposto por Seber (1982). Usando este método, a variância de uma função de variáveis $v(t)$, em que $t$ é um vetor de variáveis, é dada por

$$
\operatorname{Var}(v(t))=\sum_{i=1}^{n} \operatorname{Var}\left(t_{i}\right)\left(\frac{\partial v(t)}{\partial t_{i}}\right)^{2}+2 \sum \sum_{i<j} \operatorname{Cov}\left(t_{i}, t_{j}\right)\left(\frac{\partial v(t)}{\partial t_{i}}\right)\left(\frac{\partial v(t)}{\partial t_{j}}\right) .
$$

Para se estimar a variância de $\hat{D}$, será feita a suposição de que a correlação entre $n_{L}$ e $\hat{f}_{X \mid O}(0)$ para linhas transectas e entre $n_{P}$ e $\hat{h}(0)$ para pontos transectos é zero.

Assim, um estimador da variância para linhas transectas é dado por

$$
\begin{aligned}
\widehat{\operatorname{Var}}(\hat{D}) & =\widehat{\operatorname{Var}}\left(n_{L}\right)\left(\frac{\hat{f}_{X \mid O}(0)}{2 L}\right)^{2}+\widehat{\operatorname{Var}}\left(\hat{f}_{X \mid O}(0)\right)\left(\frac{n_{L}}{2 L}\right)^{2} \\
& =\widehat{\operatorname{Var}}\left(n_{L}\right)\left(\frac{\hat{D}}{n_{L}}\right)^{2}+\widehat{\operatorname{Var}}\left(\hat{f}_{X \mid O}(0)\right)\left(\frac{\hat{D}}{\hat{f}_{X \mid O}(0)}\right)^{2} \\
& =\hat{D}^{2}\left\{\frac{\widehat{\operatorname{Var}}\left(n_{L}\right)}{n_{L}^{2}}+\frac{\widehat{\operatorname{Var}}\left(\hat{f}_{X \mid O}(0)\right)}{\left(\hat{f}_{X \mid O}(0)\right)^{2}}\right\}
\end{aligned}
$$




\subsection{ANÁLISE DA FUNÇÃO DENSIDADE DE PROBABILIDADE DAS DISTÂNCIAS DOS OBJETOS DETECTADOS}

e para pontos transectos por

$$
\widehat{\operatorname{Var}}(\hat{D})=\hat{D}^{2}\left\{\frac{\widehat{\operatorname{Var}}\left(n_{P}\right)}{n_{P}^{2}}+\frac{\widehat{\operatorname{Var}}(\hat{h}(0))}{(\hat{h}(0))^{2}}\right\}
$$

Se os objetos são distribuídos espacialmente de forma aleatória, o número de objetos detectados $n$ têm uma distribuição de Poisson e $\widehat{\operatorname{Var}}(n)=n$, em que $n$ representa o número de objetos detectados $n_{L}$ em linhas transectas e $n_{P}$ em pontos transectos.

Se os dados são registrados usando $k$ linhas transectas, o número de objetos detectados na linha $i$ é $n_{i} i=1, \ldots, k$, com $\sum_{i=1}^{k} n_{i}=n_{L}$. Um estimador de $\operatorname{Var}\left(n_{L}\right)$, quando as linhas têm comprimentos diferentes (Buckland et al. (1993)) é

$$
\widehat{\operatorname{Var}}\left(n_{L}\right)=L \sum_{i=1}^{k} \frac{l_{i}\left(\frac{n_{i}}{l_{i}}-\frac{n_{L}}{L}\right)^{2}}{k-1}
$$

em que $\sum_{i=1}^{k} l_{i}=L$.

No caso em que as linhas tenham mesmo comprimento, o estimador da variância é dado por

$$
\widehat{\operatorname{Var}}\left(n_{L}\right)=k \sum_{i=1}^{k} \frac{\left(n_{i}-\frac{n_{L}}{k}\right)^{2}}{k-1}
$$

Quando a mesma linha é percorrida mais do que uma vez (réplicas no tempo), o estimador de $\operatorname{Var}\left(n_{L}\right)$ é

$$
\widehat{\operatorname{Var}}\left(n_{L}\right)=T_{L} \sum_{i=1}^{k} \frac{t_{i} l_{i}\left(\frac{n_{i}}{t_{i} l_{i}}-\frac{n_{L}}{T_{L}}\right)^{2}}{k-1}
$$

em que $T_{L}=\sum_{i=1}^{k} t_{i} l_{i}$ e $t_{i}$ é o número de vezes que a linha $i$ foi percorrida.

Para pontos transectos, quando o ponto $i$ é amostrado $t_{i}$ vezes e um número $n_{i}$ de objetos é detectado na $i$-ésima vez, com $\sum_{i=1}^{k} n_{i}=n_{P}$, o estimador da variância do número de objetos detectados é dado por 


$$
\widehat{\operatorname{Var}}\left(n_{P}\right)=T \sum_{i=1}^{k} \frac{t_{i}\left(\frac{n_{i}}{t_{i}}-\frac{n_{P}}{T}\right)^{2}}{k-1}
$$

em que $T=\sum_{i=1}^{k} t_{i}$.

Os estimadores de $f_{X \mid O}(0), \operatorname{Var}\left(\hat{f}_{X \mid O}(0)\right), h(0)$ e de $\operatorname{Var}(\hat{h}(0))$ são obtidos usando a teoria de máxima verossimilhança como proposto por Buckland et al. (1997) e descrito na Seção 2.3.3.

Continuação do Exemplo 1: Com os dados do Exemplo 1 obtidos até este momento é possível calcular uma estimativa da variância de $\hat{D}$. Esta estimativa é encontrada substituindo as estimativas de $\hat{f}_{X \mid O}(0)=0,006267, \operatorname{Var}\left(\hat{f}_{X \mid O}(0)\right)=2,323 \times 10^{-5}, \hat{D}=0,00699, n_{L}=67, \widehat{\operatorname{Var}}\left(n_{L}\right)=67$ na expressão (2.33). Assim, $\hat{D}=0,00699^{2}\left\{\frac{1}{67}+\frac{2,323 \times 10^{-5}}{0,06267^{2}}\right\}=1,018 \times 10^{-6}$. 


\section{Capítulo 3}

\section{Uma Ilustração e Comparação dos dois}

\section{Métodos Amostrais}

O objetivo neste capítulo é apresentar uma ilustração da análise de dados obtidos por intermédio dos dois métodos de amostragem aqui descritos e fazer uma comparação dos estimadores da densidade $D$ de uma população simulada.

Existem na literatura alguns trabalhos que fazem comparações sob vários aspectos da amostragem por linhas transectas e pontos transectos. Buckland et al. (1993) apresentam alguns deles, que resumimos a seguir.

Bollinger et al. (1988) compararam as estimativas da densidade conhecida de uma espécie de pássaro, obtidas por linhas transectas e pontos transectos em duas regiões do Estado de Nova Iorque. As regiões tinham 17,6 e 12,6 hectares de área. Foram situadas 12 linhas e 18 pontos na primeira região e 10 linhas e 14 pontos na segunda região. O pesquisador esperou 4 minutos antes de fazer as medições para que os pássaros voltassem às atividades habituais e permaneceu em cada ponto por outros 4 minutos para realizar a coleta das distâncias. Foram calculadas estimativas da densidade para machos e fêmeas em linhas transectas e somente para machos em pontos transectos. Ambos apresentaram estimativas para os machos maiores que os valores verdadeiros, sendo o vício relativo de pontos transectos de $140 \%$ e de linhas transectas de $76 \%$. A estimativa da densidade 


\subsection{DESCRIÇÃO DA REGIÃO E DA POPULAÇÃO EM ESTUDO}

das fêmeas foi aproximadamente igual ao verdadeiro valor.

Anderson e Ohmart (1981) compararam as estimativas de densidades de várias espécies de pássaros obtidas por linhas transectas e pontos transectos ao longo do Rio Colorado. Mais pássaros foram detectados em linhas transectas porque o tempo de deslocamento de um ponto a outro é um "tempo morto", de não observação. As diferenças entre as estimativas encontradas por linhas transectas e pontos transectos foram relativamente baixas.

Edwards et al. (1981) compararam os dois métodos estimando densidades de pássaros em uma ilha do Rio Columbia. Foram detectados mais pássaros em pontos transectos que em linhas transectas, entretanto o valor de $w$ para linhas foi de $50 \mathrm{~m}$ e para pontos de $150 \mathrm{~m}$. As estimativas das densidades foram similares nos dois métodos embora algumas em pontos transectos tenham sido maiores. Os métodos não foram padronizados e por isso a comparação entre eles é difícil.

Neste trabalho, uma população com distribuição geográfica uniforme aleatória em uma região de área $A$, com densidade $D$ fixada, foi simulada. Foram sorteadas 500 amostras por linhas transectas e 500 amostras por pontos transectos, todas elas totalizando áreas cobertas pela amostragem aproximadamente iguais. A densidade $D$ foi estimada em cada amostra e as distribuições empíricas das densidades obtidas dos dois métodos amostrais foram comparadas.

\subsection{Descrição da Região e da População em Estudo}

A região usada na comparação dos dois métodos amostrais foi definida como sendo uma região com 300 metros de largura por 300 metros de comprimento, ou seja, a área $A$ da região amostrada é $A=90000 m^{2}$.

Foi gerada uma população distribuída espacialmente de forma aleatória com tamanho $N=$ 1000 (ver Figura 2.1). Portanto, o valor do parâmetro de interesse é $D=1000 / 90000 m^{2}=0,0111$ objetos $/ \mathrm{m}^{2}$ ou aproximadamente $D=11100$ objetos $/ \mathrm{km}^{2}$.

Os objetos da população simulada na região de área $A$ foram situados aleatoriamente usando coordenadas $(x, y)$ em que cada componente foi gerada de uma distribuição Uniforme com parâmetros 
0 e 300, ou seja, $X_{i} \sim U[0,300]$ e $Y_{i} \sim U[0,300], i=1, \ldots, 1000$.

\subsection{Metodologia Usada na Observação das Distâncias}

Na obtenção das amostras correspondentes às distâncias dos objetos detectados em linhas transectas e pontos transectos foram usados programas desenvolvidos no aplicativo $R$. Estes programas encontram-se no Apêndice B deste trabalho. Uma descrição da forma como estas amostras foram obtidas é feita a seguir.

Em linhas transectas, foi colocada aleatoriamente e em forma horizontal na região de área $A$, uma linha de 300 metros de comprimento (ver Figura 2.1), usando uma distribuição Uniforme [30, 270], pois foi fixado um valor de $w=30$ (máxima distância em que serão detectados os objetos). O comprimento da linha e o valor de $w$ definem a área $a$ da região a ser coberta pela amostragem; no caso esta área é $a=2 \times 30 \times 300=18000 \mathrm{~m}^{2}$.

Os objetos foram detectados com base nos valores positivos gerados de uma distribuição Normal com média 0 e variância 0,5 , transformados de tal forma a se obter distâncias entre 0 e 30 metros e armazenados em um vetor denominado Distanger, de dimensão $110 \times 1$ (110 foi o número máximo de objetos dentro das regiões cobertas pela amostragem e foi obtido simulando várias amostras). A transformação usada para obter distâncias entre 0 e 30 metros foi,

$$
\text { Distanger }=\text { Distanger } \times \frac{30}{\max (\text { Distanger })} \text {. }
$$

Foram calculadas as distâncias de cada objeto da população à linha transecta e as distâncias menores ou iguais a $w=30$ foram armazenadas em um vetor denominado Distan.

Cada valor do novo vetor Distanger, obtido mediante a transformação acima, foi comparado a todos os valores armazenados no vetor Distan, ou seja, a todas as distâncias dos objetos da população dentro da região coberta pela amostragem.

Foram considerados objetos detectados aqueles cujas distâncias da linha transecta fossem pró- 


\subsection{METODOLOGIA USADA NA OBSERVAÇÃO DAS DISTÂNCIAS}

ximas a uma das distâncias geradas contidas no vetor Distanger. Como critério de proximidade consideramos arbitrariamente $\frac{\mid(\text { Distanger }[j]-D i s t a n[i]) \mid}{\max (\text { Distan })} \leq 0,003, i$ varia entre 1 e o número de objetos na região coberta pela amostragem, $j=1, \ldots, 110$. Este critério implica em que a probabilidade de se detectar um objeto da população seja maior para objetos mais próximos da linha transecta. Outros critérios poderiam ter sido usados.

Na Figura 3.1 são apresentados, como ilustração, três pares de histogramas correspondentes a três das amostras selecionadas. A coluna (a) contém os histogramas das distâncias à linha dos objetos da população localizados na região coberta pela amostragem. Como esperado, esses gráficos apresentam distribuição aproximadamente uniforme; a coluna (b) contém os histogramas das distâncias dos objetos detectados à linha. Estes gráficos são uma representação da função densidade de probabilidade das distâncias dos objetos detectados e também da função de detecção, devido à relação existente entre $g(x)$ e $f_{X \mid O}(x)$, pois $g(x) \propto f_{X \mid O}(x)$,

$$
f_{X \mid O}(x)=\frac{g(x)}{\mu}
$$

Conforme ilustrado nos histogramas da coluna (b), a maioria das amostras satisfaz o critério da forma (Seção 1.1.1).

Em pontos transectos foram colocados aleatoriamente 6 pontos na região de área $A$. A distância máxima em que foram detectados os objetos foi fixada em $w=30$ metros, o que define a área $a=6 \times \pi \times 30^{2}=16964 m^{2}$ da região coberta pela amostragem. Estes pontos foram situados de tal forma que a intersecção das regiões definidas pelo valor de $w=30$ fosse vazia para evitar que um objeto fosse detectado duas vezes. A forma de se detectar os objetos foi análoga à usada para linhas transectas.

Na coluna (a) da Figura 3.2 são apresentados os histogramas das distâncias dos objetos da população contidos nos círculos de raio 30 metros em torno dos pontos transectos, correspondentes a três das amostras selecionadas. As classes dos histogramas correspondem a aros em torno dos pontos transectos. Quanto mais próximo do ponto, menor é a área do aro e portanto menor é 
(a)
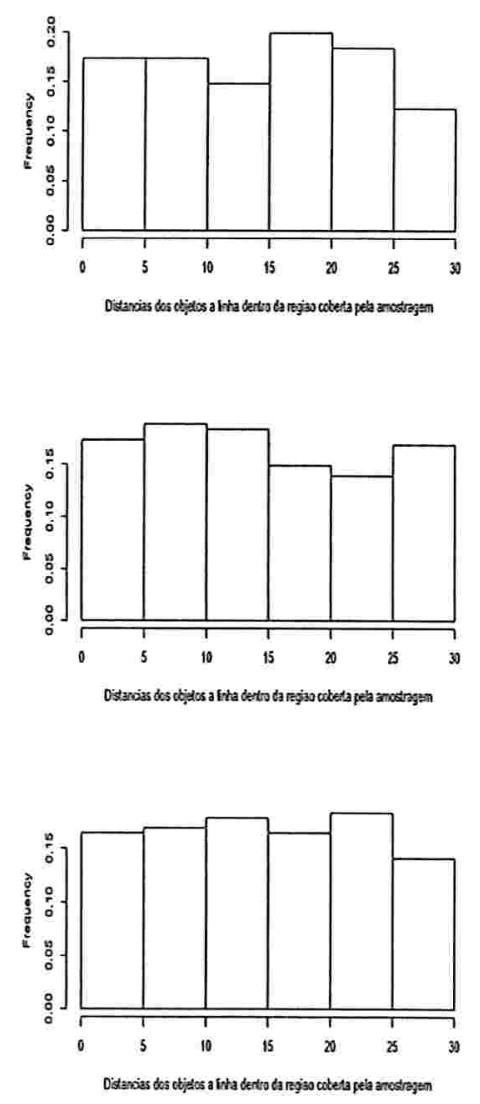

(b)
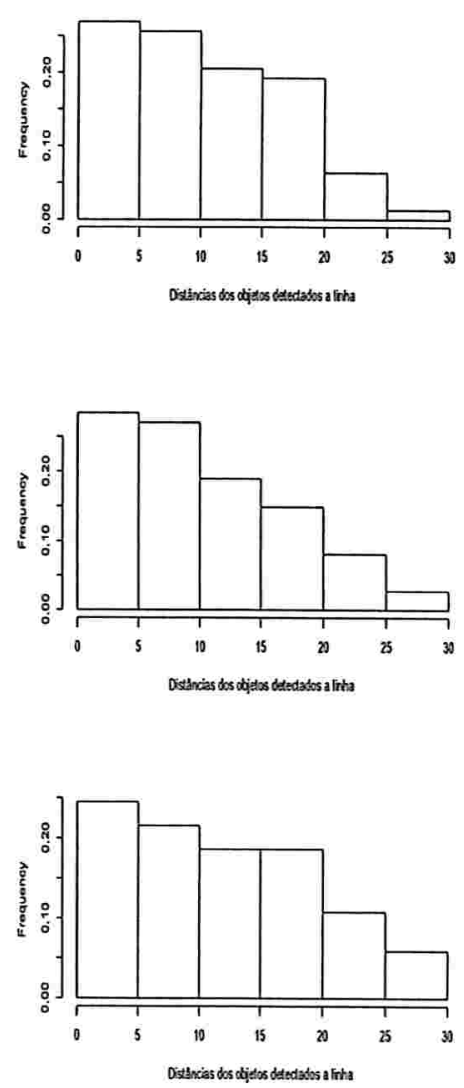

Figura 3.1: Histogramas: (a) das distâncias à linha transecta de todos os objetos dentro da área coberta pela amostragem, (b) das distâncias à linha transecta dos objetos detectados

o número de objetos ali contidos, uma vez que a distribuição espacial da população na região toda é uniforme. Por esse motivo os histogramas apresentam freqüências mais baixas nas faixas correspondentes às distâncias menores.

Na coluna (b) da Figura 3.2 são apresentados os histogramas das distâncias dos objetos detectados. Esses gráficos são uma estimativa da função densidade de probabilidade das distâncias dos objetos detectados, mas não da função de detecção pois, no caso de pontos transectos, a relação entre elas depende de $r$. Para a obtenção do gráfico de barras que representa a função de detecção é necessário fazer uma "correção" das freqüências em cada intervalo de distâncias, pois, como visto 
no Capítulo 2, $g(r)$ é proporcional a $\frac{f_{R \mid O}}{r}$, ou seja,

$$
f_{R \mid O}(r)=\frac{2 \pi r g(r)}{v}
$$

o que implica em

$$
g(r)=\frac{v f_{R \mid O}(r)}{2 \pi r}
$$

e assim

$$
g(r) \propto \frac{f_{R \mid O}(r)}{r}
$$

A "freqüência corrigida" para o $j$-ésimo intervalo das distâncias, $f_{j}$, é obtida da seguinte forma

$$
f_{j}=\sum_{r_{i} \in j} \frac{1}{r_{i}}
$$

em que $r_{i} \in j$ quer dizer que a distância radial $r_{i}$ pertence ao $j$-ésimo intervalo das distâncias.

Na Figura 3.3, coluna (a), são apresentados os gráficos de barras correspondentes aos histogramas da Figura 3.2. Nesses gráficos, a altura é igual à proporção de objetos detectados em cada aro em relação ao número de objetos da população naquele aro, isto é, é o número de objetos detectados no aro dividido pelo número de objetos no aro. Esses gráficos são estimativas da função de detecção e satisfazem o critério da forma, entretanto, sua construção não é possível na prática pois o número de objetos da população em cada aro é desconhecido. Aqui, sua construção é possível devido a geração dos dados ser feita via simulação e, portanto, serem conhecidos. Na coluna (b) são apresentados os gráficos de barras que representam a função de detecção, em que a altura é igual às freqüências corrigidas como indicado acima. Nota-se que estes também satisfazem o critério da forma e podem ser construídos na prática pois só dependem dos valores da amostra.

Estes procedimentos foram realizados até se obter 500 conjuntos de dados, em que um conjunto em linhas correspondesse a um conjunto em pontos, relacionados segundo o número de detecções para evitar que os resultados fossem influenciados por estes valores. 
(a)
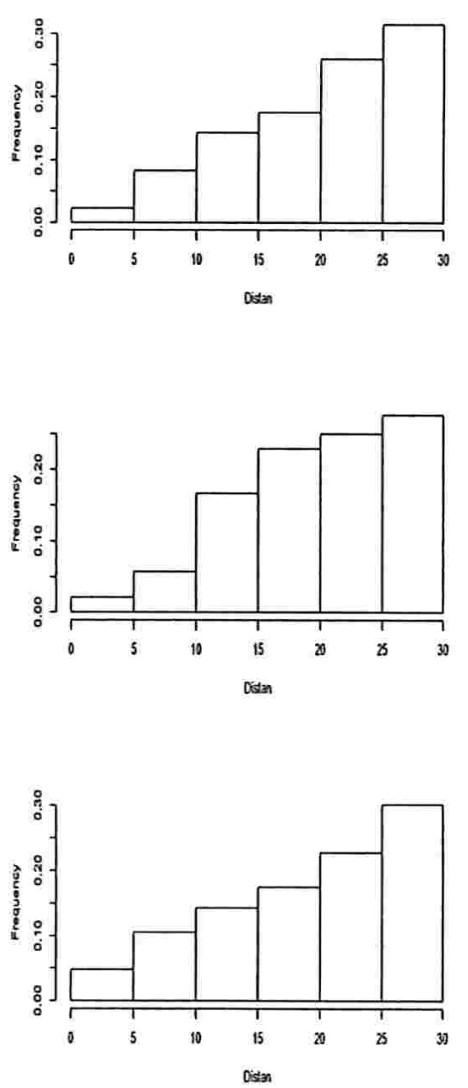

(b)
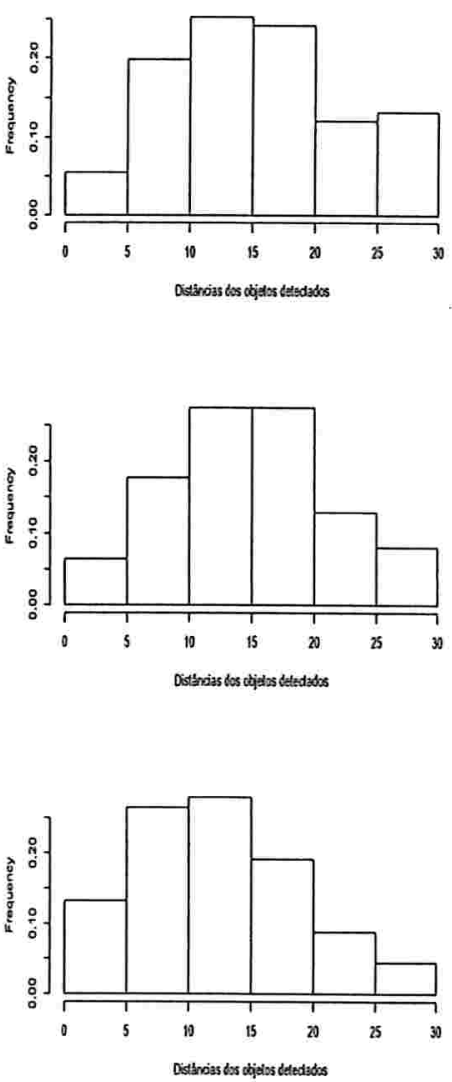

Figura 3.2: Histogramas: (a) das distâncias aos pontos transectos de todos os objetos dentro da região coberta pela amostragem, (b) das distâncias aos pontos transectos dos objetos detectados

\subsection{Ilustração de Análise das Distâncias dos Objetos Detecta- dos}

Apresentamos nesta seção, a título de ilustração, a análise de uma das amostras obtida por linhas transectas e uma obtida por pontos transectos. O aplicativo computacional utilizado na análise foi o Distance (Thomas et al. (2003)), elaborado por um grupo de pesquisadores dos dois métodos amostrais, da Research Unit for Wildlife Population Assesment e da Universidade de St. Andrews, UK. O Distance encontra-se disponível para download na internet (http://www.ruwpa.st- 
(a)
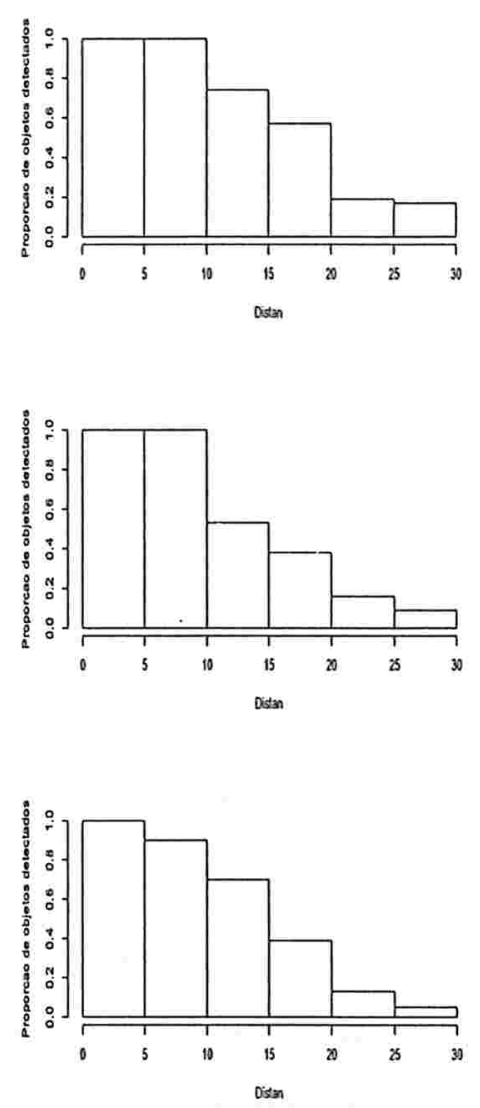

(b)
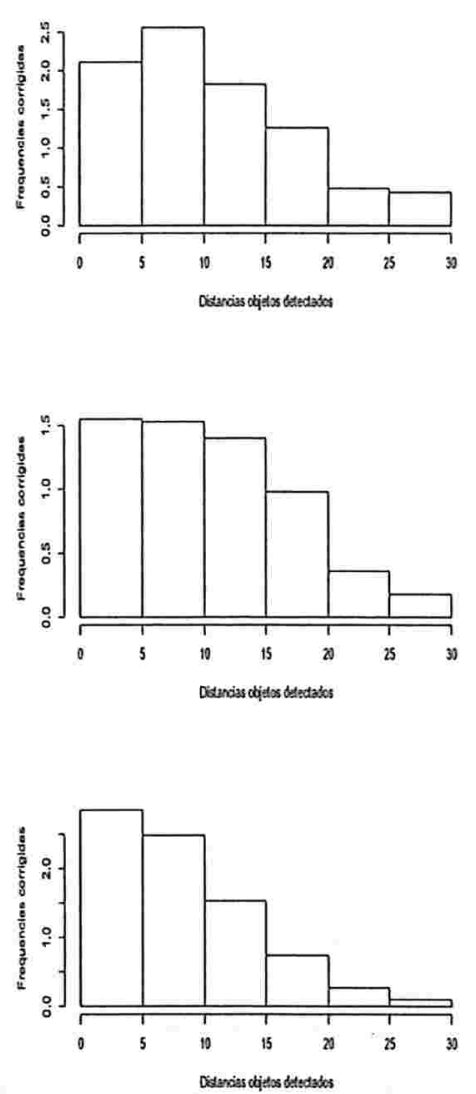

Figura 3.3: Gráficos de barras: (a) proporção de objetos detectados em cada aro, (b) freqüências corrigidas

and.ac.uk/distance/distance41download.html).

Os dados foram analisados de forma desagrupada, pois as distâncias foram medidas da posição do objeto à linha ou ao ponto e não em intervalos de distância.

Nos Apêndices C e D são apresentadas as saídas do aplicativo Distance para linhas transectas e pontos transectos, respectivamente. Para facilitar a interpretação dos resultados, estes foram divididos em 5 partes, tanto para linhas transectas como para pontos transectos, e serão analisados conjuntamente dada a similaridade entre eles.

Na primeira parte são apresentadas as funções de detecção ajustadas ao conjunto das distâncias. 
Essas funções são escolhidas pelo usuário. Para linhas transectas, as funções chave e as expansões em séries ajustadas foram: 1. uniforme e cosseno, 2. uniforme e polinômios simples, 3. normal truncada e cosseno, 4. normal truncada e polinômios hermitianos e 5. taxa de risco e polinômios simples. Para pontos transectos, foram as quatro primeiras e também a taxa de risco e cosseno. $\mathrm{O}$ critério para seleção do modelo que melhor se ajusta foi baseado no $A I C$. O modelo escolhido é aquele que tem o menor $A I C$. Além disso, são apresentadas as variáveis e uma descrição do que elas representam dentro da análise. A $\operatorname{Var}(n)$ é estimada sob a suposição de que $n$ tem distribuição de Poisson e $\operatorname{Var}(\hat{f}(0))$ e $\operatorname{Var}(\hat{h}(0))$ são estimadas com base na expressão (2.22).

Na segunda parte são apresentados o comprimento da linha, em linhas transectas, e o número de pontos em pontos transectos, os quais aparecem como esforço da amostragem. O valor de $w$ aparece como a largura e o número de detecções, $n_{L}$ em linhas transectas e $n_{P}$ em pontos transectos, aparece como número de observações. A saída mostra também, para cada uma das combinações de função chave e expansão em séries relacionadas na primeira parte, a seleção do número $q$ de termos na expansão em séries, usando para isto testes da razão de verossimilhanças e o $A I C$. A forma de fazer esta seleção é apresentada a seguir. Para cada combinação é ajustado o Modelo 1 só com a função chave e o Modelo 2 com a função chave e uma expansão em séries de ordem baixa. Os dois são comparados com base no teste da razão de verossimilhanças e no critério de Akaike. Se os dois modelos têm o mesmo $A I C$, um deles é escolhido aleatoriamente. Se o Modelo 1 é escolhido, a seqüência de testes é interrompida; se o Modelo 2 é escolhido, ajusta-se o Modelo 3 composto pela função chave e uma expansão em séries de ordem mais alta do que a do Modelo 2. Os Modelos 2 e 3 são então comparados. Se o de ordem mais baixa é escolhido (Modelo 2), a seqüência de testes é interrompida, caso contrário ajusta-se um modelo de ordem mais alta para ser comparado com o Modelo 3. Em resumo, para cada combinação de função chave e expansão em séries, os modelos são comparados seqüencialmente, de 2 em 2 , em ordem crescente e a seqüência de testes é interrompida quando o modelo de ordem menor é escolhido.

As Tabelas 3.1 e 3.2 mostram um resumo dos resultados obtidos com o ajuste desses modelos 


\subsection{ILUSTRAÇÃO DE ANÁLISE DAS DISTÂNCIAS DOS OBJETOS DETECTADOS}

Tabela 3.1: Modelos ajustados para linhas transectas

\begin{tabular}{|c|c|c|c|}
\hline $\begin{array}{l}\text { Função chave e } \\
\text { expansão em séries }\end{array}$ & Modelo 1 & Modelo 2 & Modelo 3 \\
\hline $\begin{array}{l}\text { 1. Uniforme e } \\
\text { cosseno }\end{array}$ & $\begin{array}{c}\text { uniforme } \\
\text { AIC }=604,20 \\
p<0,001\end{array}$ & $\begin{array}{c}\text { uniforme } e \\
\text { cosseno (1) } \\
\text { AIC }=\mathbf{5 9 1 , 0 5} \\
p=0,666\end{array}$ & $\begin{array}{c}\text { uniforme e } \\
\text { cosseno }(1,2) \\
\text { AIC }=592,87\end{array}$ \\
\hline $\begin{array}{l}\text { 2. Uniforme e } \\
\text { polinômio simples }\end{array}$ & $\begin{array}{c}\text { uniforme } \\
\text { AIC }=604,20 \\
p<0,001\end{array}$ & $\begin{array}{c}\text { uniforme e } \\
\text { polinômio simples (2) } \\
\text { AIC }=\mathbf{5 9 1}, \mathbf{2 1} \\
p=0,475\end{array}$ & $\begin{array}{c}\text { uniforme e } \\
\text { polinômio simples }(2,4) \\
A I C=592,70\end{array}$ \\
\hline $\begin{array}{l}\text { 3. Normal truncadae } \\
\text { cosseno }\end{array}$ & $\begin{array}{l}\text { normal truncada } \\
\begin{array}{c}\text { AIC }=\mathbf{5 9 0}, \mathbf{7 0} \\
p=0,942\end{array}\end{array}$ & $\begin{array}{c}\text { normal truncada } e \\
\text { cosseno (2) } \\
A I C=592,70\end{array}$ & \\
\hline $\begin{array}{l}\text { 4. Normal truncada e } \\
\text { polinômio hermitiano }\end{array}$ & $\begin{array}{l}\text { normal truncada } \\
\begin{array}{c}A I C=\mathbf{5 9 0}, \mathbf{7 0} \\
p=0,902\end{array}\end{array}$ & $\begin{array}{c}\text { normal truncada e } \\
\text { polinômio hermitiano (4) } \\
\text { AIC }=592,69\end{array}$ & \\
\hline $\begin{array}{l}\text { 5. Taxa de risco e } \\
\text { polinômio simples }\end{array}$ & $\begin{array}{c}\text { taxa de risco } \\
\begin{array}{c}A I C=\mathbf{5 9 2}, \mathbf{8 1} \\
p=0,924\end{array}\end{array}$ & $\begin{array}{c}\text { taxa de risco e } \\
\text { polinômio simples (4) } \\
A I C=594,80\end{array}$ & \\
\hline
\end{tabular}

para linhas transectas e pontos transectos, respectivamente. Essas tabelas mostram os modelos ajustados com os respectivos $A I C$ e os $p$-valores dos testes da razão de verossimilhanças.

Tomemos como exemplo a combinação 2 de linhas transectas (Tabela 3.1). Nessa combinação é considerada a função chave uniforme e a expansão em séries polinômios simples. O Modelo 1 contém apenas a função chave uniforme e o $A I C$ correspondente é 604,20. O Modelo 2 é composto pela função chave uniforme e a expansão em séries polinômios simples de ordem 2 $(A I C=591,21)$. Entre os dois é escolhido o Modelo 2 pois tem o menor $A I C$ e o $p$-valor do teste da razão de verossimilhanças é menor do que 0,001 , indicando que o Modelo 2 se ajusta melhor do que o Modelo 1. O modelo seguinte ajustado (Modelo 3) é composto pela função chave uniforme e a expansão em séries polinômios simples com termos de graus 2 e 4 . Entre os Modelos 2 e 3, o 
Tabela 3.2: Modelos ajustados para pontos transectos

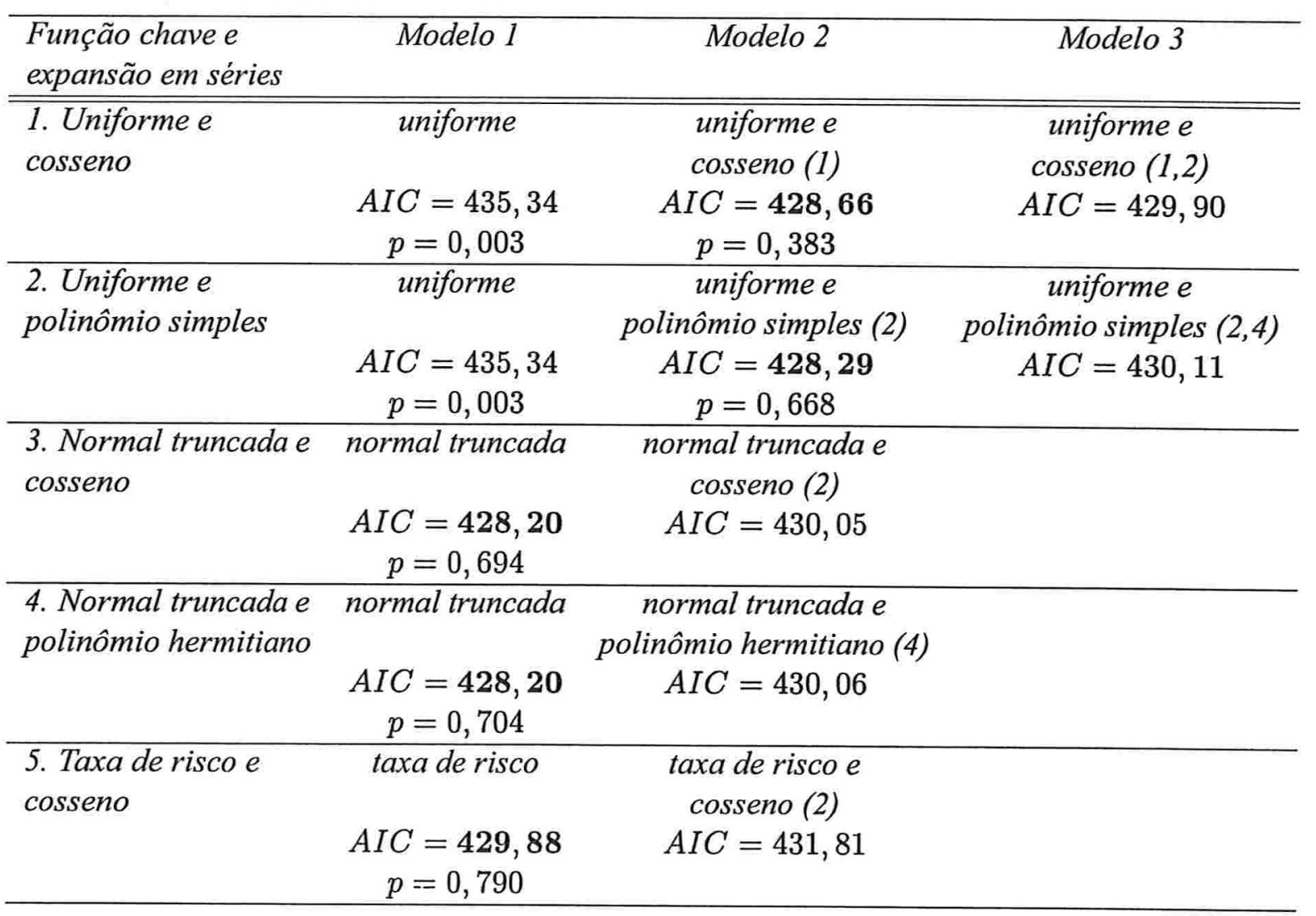

Modelo 2 é escolhido pois tem o menor $A I C(591,21$ versus 592,70) e o $p$-valor do teste da razão de verossimilhanças é 0,475 . Portanto o número $q$ de termos selecionado foi $q=1$.

Nesse ponto da análise temos um modelo escolhido para cada função densidade de probabilidade das distâncias dos objetos detectados, obtida com cada uma das combinações de função chave e expansão em séries. Resta agora eleger um modelo entre eles.

Na terceira parte é selecionado o melhor modelo para a função densidade de probabilidade das distâncias dos objetos detectados dentre as cinco escolhidas na segunda parte, levando em conta o menor $A I C$ dos modelos obtidos anteriormente. São apresentados os estimadores dos parâmetros da função de detecção correspondente à função densidade de probabilidade das distâncias dos objetos detectados selecionada como a melhor, em que $A(i), i=1, \ldots, p$ são as estimativas dos 


\subsection{ILUSTRAÇÃO DE ANÁLISE DAS DISTÂNCIAS DOS OBJETOS DETECTADOS}

parâmetros da função chave e os $A(i), i=p+1, \ldots, p+q$ são as estimativas dos coeficientes na expansão em séries. Estes valores são calculados usando a teoria de máxima verossimilhança apresentada na Seção (2.3.1). As estimativas de $f(0)$ e $h(0)$, para linhas transectas e pontos transectos, respectivamente, são obtidas como foi indicado na Seção 2.3.

Na saída para linhas transectas (Apêndice C), o modelo selecionado foi o que contém apenas a função chave normal truncada, em que $A(1)$ é a notação para $\sigma$. Assim, o modelo estimado foi

$$
f_{X \mid O}(x)=\frac{\exp \left(\frac{-x^{2}}{2(16,7)^{2}}\right)}{\int_{0}^{30} \exp \left(\frac{-x^{2}}{2(16,7)^{2}}\right) d x}
$$

pois $\hat{\sigma}=16,7$. A estimativa do erro padrão de $\hat{\sigma}$ é 2,318 , de $f_{X \mid O}(0)$ é 0,052 com erro padrão de 0,0049 e coeficiente de variação de $9,53 \%$. O intervalo de confiança para $f_{X \mid O}(0)$ com coeficiente de confiança de $95 \%$ é $(0,043 ; 0,062)$.

Para pontos transectos (Apêndice D), o mesmo modelo foi escolhido, ou seja, aquele que contém somente a função chave normal truncada $(A I C=428,20)$. O modelo foi estimado por

$$
f_{R \mid O}(r)=\frac{\exp \left(-r^{2} / 619,52\right)}{\int_{0}^{30} \exp \left(-r^{2} / 619,52\right) d r}
$$

pois $\hat{\sigma}=17,60$, com erro padrão de 3,034 . A estimativa de $h(0)$ é 0,0044 , com erro padrão 0,00079 e coeficiente de variação de $17,96 \%$. O intervalo de confiança de $95 \%$ para $h(0)$ é $(0,0031 ; 0,0063)$.

Na quarta parte são apresentados os testes de bondade de ajuste de Kolmogorov-Smirnov, que testa se existe alguma fuga significante entre a função de distribuição empírica e a função de distribuição acumulada ajustada, e o teste de Cramer-von Mises (Stephens (1986)), que é uma sequiência de testes qui-quadrado (ver Seção 2.3.4), calculados para diferentes agrupamentos dos dados. Para esses testes são apresentados vários gráficos ilustrando o ajuste. Para linhas transectas são mostrados os gráficos de proporções, que são estimativas da função de detecção e, para pontos transectos, os gráficos de proporções, que são estimativas da função de detecção e da função 


\subsection{UMA COMPARAÇÃO DOS DOIS MÉTODOS AMOSTRAIS}

densidade das distâncias dos objetos detectados. No caso de linhas transectas, os dois gráficos têm formas similares pois, como já foi dito anteriormente na Seção 3.2, são proporcionais. Por isso somente um deles é exibido.

Nas amostras analisadas todos os testes indicam que o modelo está bem ajustado, tanto para linhas transectas como para pontos transectos.

Na quinta parte da saída são apresentadas as estimativas de diversos parâmetros com seus respectivos erros padrão, coeficientes de variação e intervalos de confiança. Também é apresentado um resumo das estimativas sob o modelo escolhido. No exemplo, a estimativa da densidade populacional para a amostra de linhas transectas é de 0,0077 e o intervalo de confiança correspondente é de $(0,0058 ; 0,0102)$. Para pontos transectos, a estimativa de $D$ é 0,0076 com intervalo de confiança de $(0,0049 ; 0,0117)$. Esses intervalos são calculados sob a suposição de que $\hat{D}$ têm uma distribuição log-normal, isto é, um intervalo de confiança aproximado com $95 \%$ de confiança para $D$ é dado por $[\hat{D} / C, \hat{D} . C]$, em que

$$
C=\exp \left[1,96 \sqrt{\widehat{\operatorname{Var}}\left(\log _{e} \hat{D}\right)}\right]
$$

e

$$
\widehat{\operatorname{Var}}\left(\log _{e} \hat{D}\right)=\log _{e}\left[1+\frac{\widehat{\operatorname{Var}}(\hat{D})}{\hat{D}^{2}}\right]
$$

\subsection{Uma Comparação dos dois Métodos Amostrais}

Nesta seção, um estudo descritivo dos resultados para $\hat{D}$ das 500 amostras simuladas é feito para cada um dos métodos.

A Tabela 3.3 mostra o mínimo, o máximo, a média e os quartis das 500 estimativas de $\hat{D}$ obtidas por linhas transectas e pontos transectos. Nas Figuras 3.4 e 3.5 são apresentados os histogramas e boxplots dessas estimativas.

Embora as médias e medianas das densidades em pontos transectos sejam mais próximas da verdadeira densidade $D(0,0111)$, a variância nesse método amostral é maior (ver Tabela 3.4). O 
Tabela 3.3: Medidas de posição de $\hat{D}$

\begin{tabular}{lllllll}
\hline Método Amostral & Mínimo & $Q_{1}$ & Mediana & Média & $Q_{3}$ & Máximo \\
\hline \hline Linhas transectas & 0,0042 & 0,0066 & 0,0073 & 0,0074 & 0,0080 & 0,0117 \\
Pontos transectos & 0,0005 & 0,0082 & 0,0103 & 0,0107 & 0,0123 & 0,0571 \\
\hline
\end{tabular}

Intervalo com $95 \%$ de confiança para a média de $\hat{D}$ é $[0,0073 ; 0,0075]$ em linhas transectas e $[0,0103 ; 0,0111]$ em pontos transectos, indicando que o intervalo de confiança para a média de $\hat{D}$ em pontos transectos cobre o valor do parâmetro, que neste caso é $D=0,0111$, não ocorrendo o mesmo em linhas transectas.

Tabela 3.4: Medidas de dispersão e vício de $\hat{D}$

\begin{tabular}{llllll}
\hline Método Amostral & Variância & Vício & $E Q M$ & $C V$ & $E Q M /(\bar{X})^{2}$ \\
\hline \hline Linhas transectas & $1,3 \mathrm{e}-06$ & $-0,0037$ & $1,499 \mathrm{e}-05$ & 0,1541 & 0,2737 \\
Pontos transectos & $2,1 \mathrm{e}-05$ & $-0,0004$ & $2,116 \mathrm{e}-05$ & 0,4283 & 0,1848 \\
\hline
\end{tabular}

Da Tabela 3.4 pode-se concluir que a variância em pontos transectos é aproximadamente 16 vezes a variância em linhas transectas e o vício em linhas transectas é aproximadamente 9 vezes o vício em pontos transectos e, havendo uma certa compensação, os erros quadráticos médios não são tão diferentes (o EQM em pontos transectos é 1,4 vezes o EQM em linhas transectas). O coeficiente de variação em pontos transectos é 3 vezes o coeficiente de variação em linhas transectas. Essa medida, entretanto, ignora o vício dos estimadores. Dividindo-se o EQM pelo quadrado da média, a amostragem por linhas transectas passa a ter pior desempenho que a amostragem por pontos transectos. A diferença porém, não é acentuada.

Na Figura 3.4 nota-se que existe uma assimetria à direita mais acentuada para pontos transectos. Na Figura 3.5, podemos notar que a densidade é subsestimada em linhas transectas, mas existem estimativas muito maiores que a densidade em pontos transectos. 

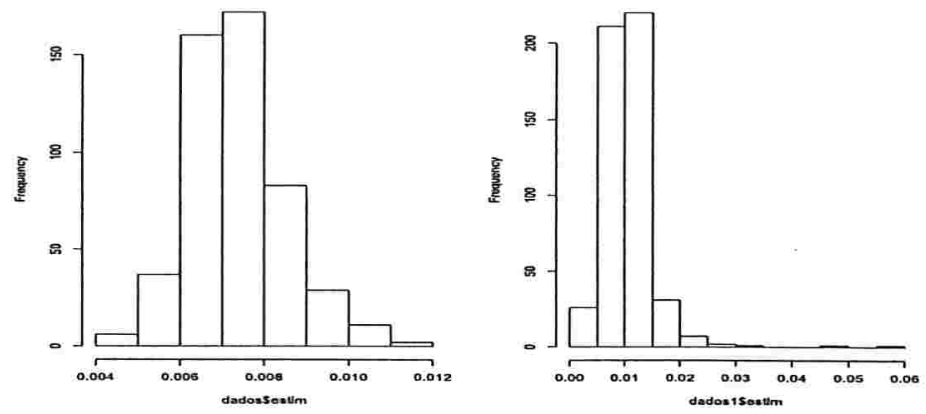

Figura 3.4: Histogramas das estimativas da densidade obtidas por linhas transectas e pontos transectos

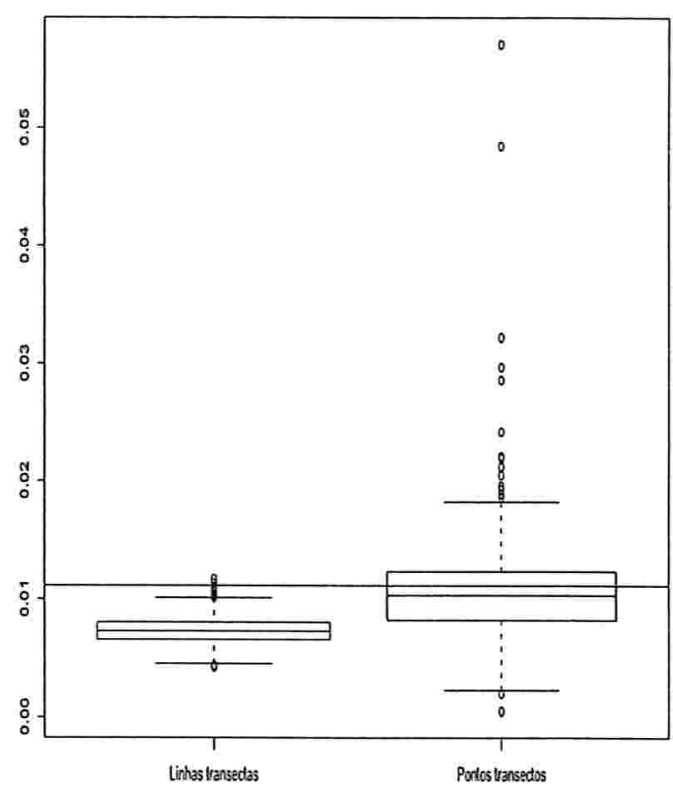

Figura 3.5: Boxplots das estimativas da densidade obtidas por linhas transectas e pontos transectos 


\section{Conclusões}

Levando em conta a distribuição uniforme aleatória dos objetos e nenhuma movimentação deles em resposta ao observador, pode-se concluir da comparação das estimativas obtidas em linhas transectas e pontos transectos para o caso simulado que:

1. a variância em linhas transectas é menor do que a variância em pontos transectos;

2. o vício, em valor absoluto, produzido em linhas transectas é maior do que o correspondente em pontos transectos;

3. o erro quadrático médio em linhas transectas é menor do que o erro quadrático médio em pontos transectos;

4. o desempenho da amostragem por linhas transectas foi melhor do que o da amostragem por pontos transectos.

Essas conclusões têm que ser avaliadas com cuidados pois são restritas exclusivamente a uma situação específica. Como exemplificado no início do Capítulo 3, as conclusões podem ser diferentes dependendo do caso em estudo. Bollinger et al. (1988) encontraram vício maior para pontos transectos, o oposto do que ocorreu em nossas simulações. Estudos de simulação mais amplos deveriam ser efetuados, variando o tamanho da área amostrada, o tamanho da área coberta pela amostragem e também a densidade populacional.

Como propostas para futuros estudos, sugerimos: 


\subsection{UMA COMPARAÇÃO DOS DOIS MÉTODOS AMOSTRAIS}

1. a ampliação das simulações;

2. o estudo da estimação da densidade populacional considerando outras distribuições espaciais dos objetos, como por exemplo, quando animais andam em bando;

3. o estudo da estimação da densidade por outros métodos, como por exemplo, por estimadores do tipo razão ou Horvitz-Thompson. 


\section{Apêndice A}

\section{Anexos dos Capítulos 1 e 2}

\section{A.1 Modelo Taxa de Risco}

\section{Linhas transectas}

O modelo taxa de risco foi definido por Buckland et al. (1993) para linhas transectas como

$$
\alpha(x)=1-\exp \left(-\int_{0}^{\infty} h(z, x) d z\right)
$$

em que $z$ representa a distância do observador ao ponto de mínima distância entre a linha e o objeto (Figura 1.2); $z$ decresce de $\infty$ a zero pois é considerado que o observador aproxima-se do objeto desde um ponto remoto ou distante e

$h(z, x) d z=P$ (observar um objeto no intervalo $(z, z-d z) \mid$ não foi observado em $(\infty, z))$.

Fazendo uma mudança na variável de integração de $z$ para $r$ e levando em conta que $r$ satisfaz $r^{2}=x^{2}+z^{2}$, temos

$$
h(z, x) d z=k(r, x) \frac{r}{\sqrt{r^{2}-x^{2}}} d r
$$


em que $k(r, x) \equiv h\left(\sqrt{r^{2}-x^{2}}, x\right)$

Portanto,

$$
\alpha(x)=1-\exp \left(-\int_{x}^{\infty} \frac{r}{\sqrt{r^{2}-x^{2}}} k(r, x) d r\right)
$$

em que $k(r, x)$ é conhecida como a função de risco. A escolha de $k(r, x)$ deve ser feita de tal modo a se obter simplicidade matemática (Skaug e Schweder (1999)).

Vários modelos têm sido propostos para $k(r, x)$. Hayes e Buckland (1983) fizeram duas propostas para $k(r, x)$ que pertencem à família

$$
\int_{x}^{\infty} \frac{r}{\sqrt{r^{2}-x^{2}}} k(r, x) d r=\left(\frac{x}{\sigma}\right)^{-b}
$$

para algum $\sigma$ e $b$, em que $\sigma$ é um parâmetro de escala e $b$ é um parâmetro de forma.

Na primeira proposta,

$$
k(r, x)=c r^{-d}, r \geq x
$$

em que $c$ e $d$ são constantes positivas, $c$ é um parâmetro de escala, $b=d-1$ e $\sigma=\left(\frac{c \Gamma\left(\frac{d-1}{2}\right) \Gamma(0,5)}{2 \Gamma\left(\frac{d}{2}\right)}\right)^{\frac{1}{d-1}}$.

Este modelo é proposto quando o observador procura igualmente em todas as direções por objetos imóveis (como plantas, por exemplo) ou, quando a resposta do animal ao observador depende só da distância entre eles.

Na segunda proposta,

$$
k(r, x)=c r^{-d} \cos (\theta),
$$

em que $c$ e $d$ são constantes positivas, $c$ é um parâmetro de escala, $\cos (\theta)=\frac{\left(x^{2}-r^{2}\right)^{\frac{1}{2}}}{r}$, de tal forma que $b=d-1$ e $\sigma=\left(\frac{c}{d-1}\right)^{\frac{1}{d-1}}$.

Este modelo é proposto quando é mais provável que os objetos, neste caso animais, fujam quando o observador aproxima-se deles. 


\section{Pontos transectos}

Em pontos transectos (Buckland et al. (1993)), a função de detecção depende não só da distância $r$, mas também do tempo $T$ de espera em cada ponto. A função de risco $k(r, t)$ é definida de tal forma que

$k(r, t)=P$ (objeto na distância $r$ seja detectado durante $(t, t+d t) \mid$ não foi detectado durante $(0, t)), t \leq T$.

A função chave é definida como

$$
\alpha(r)=1-\exp \left(-\int_{0}^{T} k(r, t) d t\right)
$$

Se o tempo de espera em cada ponto é o mesmo, $k(r, t)=k(r) \mathrm{e}$

$$
\alpha(r)=1-\exp [-k(r) T]
$$

Assumindo $k(r)=c r^{-d}$,

$$
\alpha(r)=1-\exp \left(-\left(\frac{r}{\sigma}\right)^{-b}\right)
$$

em que $c$ e $d$ são constantes positivas, $c$ é um parâmetro de escala, $b=d$ e $\sigma=(c T)^{\frac{1}{b}}$.

Neste caso, $\sigma$ depende diretamente do tempo de espera no ponto, ou seja quanto maior for o tempo de espera maior é o parâmetro de escala, o que faz com que seja mais fácil o ajuste da função de detecção. Porém, se o tempo é muito grande o número de detecções decresce rapidamente (Buckland et al. (1993)) e isto poderia afetar a forma da função de detecção.

Maiores detalhes sobre a função taxa de risco podem ser encontrados em Hayes e Buckland (1983), Buckland (1985), Zahl (1989), Buckland et al. (1993) e Skaug e Schweder (1999). 


\section{A.2 Polinômios Hermitianos}

Os polinômios hermitianos são derivados da seguinte maneira (Stuart e Ord (1987)). Seja

$$
\alpha(y)=\frac{1}{\sqrt{2 \pi}} \exp \left(-\frac{1}{2} y^{2}\right)
$$

e considerando derivadas sucessivas de $\alpha(y)$ em relação a $y$, obtém-se

$$
\begin{aligned}
\frac{d \alpha(y)}{d y} & =-\frac{y}{\sqrt{2 \pi}} \exp \left(-\frac{1}{2} y^{2}\right)=-y \alpha(y), \\
\frac{d^{2} \alpha(y)}{d y^{2}} & =\left(y^{2}-1\right) \alpha(y), \\
\frac{d^{3} \alpha(y)}{d y^{3}} & =\left(3 y-y^{3}\right) \alpha(y) .
\end{aligned}
$$

Pode-se notar que as derivadas resultam em um polinômio em $y$, vezes $\alpha(y)$. Define-se, portanto, o polinômio hermitiano, $H_{r}(y)$, como:

$$
\left(\frac{-d}{d y}\right)^{r} \alpha(y)=H_{r}(y) \alpha(y)
$$

em que $H_{r}(y)$ tem grau $r$ e o coeficiente de $y^{r}$ é 1 . Por convenção $H_{0}=1$.

Os primeiros cinco polinômios de ordem par são dados por:

$$
\begin{aligned}
& H_{2}=y^{2}-1 \\
& H_{4}=y^{4}-6 y^{2}+3 \\
& H_{6}=y^{6}-15 y^{4}+45 y^{2}-15 \\
& H_{8}=y^{8}-28 y^{6}+210 y^{4}-40 y^{2}+105 \\
& H_{10}=y^{10}-45 y^{8}+630 y^{6}-3150 y^{4}+4725 y^{2}-945
\end{aligned}
$$




\section{A.3 Linhas Transectas}

\section{Probabilidade de se detectar um objeto dentro da região coberta pela amos- tragem}

Para se encontrar a probabilidade de se detectar um objeto dentro da região coberta pela amostragem, $P_{a}$, são definidos o evento $O$ de se detectar um objeto e $X$ a variável aleatória que representa a distância perpendicular do objeto à linha. Sob as suposições de posição aleatória da linha e nenhuma movimentação dos objetos em reposta ao observador, a distribuição dos objetos na região coberta pela amostragem seria uniforme $[0, w]$ (Burnham et al. (1980)). Portanto,

$$
f_{X}(x)=\frac{1}{w}
$$

e

$$
\begin{aligned}
P_{a}=P(O) & =E[P(O \mid X)] \\
& =\int_{-\infty}^{\infty} P(O \mid X) f_{X}(x) d x \\
& =\int_{0}^{w} P(O \mid X) \frac{1}{w} d x .
\end{aligned}
$$

Usando a definição da função de detecção, $g(x)=P(O \mid X=x)$ e portanto

$$
P_{a}=\int_{0}^{w} g(x) \frac{1}{w} d x .
$$




\section{Função densidade de probabilidade das distâncias dos objetos detectados}

A distribuição condicional de $X$ dado que o objeto foi detectado é encontrada da seguinte forma:

$$
F_{X \mid O}(x)=P(X \leq x \mid O)=\frac{P(X \leq x, O)}{P(O)} .
$$

Agora,

$$
\begin{aligned}
P(X \leq x, O) & =\int_{0}^{x} P(O \mid X=u) f_{X}(u) d u \\
& =\int_{0}^{x} g(u) \frac{1}{w} d u=\frac{1}{w} \int_{0}^{x} g(u) d u
\end{aligned}
$$

Substituindo em (A.3), o numerador por (A.4) e o denominador por (A.2), obtém-se

$$
F_{X \mid O}(x)=\frac{\frac{1}{w} \int_{0}^{x} g(u) d u}{\frac{1}{w} \int_{0}^{w} g(x) d x}
$$

e portanto,

$$
f_{X \mid O}(x)=\frac{g(x)}{\int_{0}^{w} g(x) d x}
$$

\section{A.4 Pontos Transectos}

\section{Probabilidade de se detectar um objeto dentro da região coberta pela amos-} tragem

Para se encontrar a probabilidade de se detectar um objeto dentro da região coberta pela amostragem, $P_{a}$, são definidos o evento $O$ de se detectar um objeto e $R$ a variável aleatória que representa a distância do objeto ao ponto. Sob as suposições de posição aleatória dos pontos e nenhuma 
movimentação dos objetos em resposta ao observador, os objetos dentro do círculo são distribuídos segundo uma distribuição uniforme $\left[0, \pi w^{2}\right]$ (Burnham et al. (1980)). Assim,

$$
P_{a}=P(O)=E[P(O \mid R)]=\int_{-\infty}^{\infty} P(O \mid R) f_{R}(r) d r
$$

Para se encontrar a função densidade de probabilidade das distâncias dos objetos na área coberta pela amostragem ao ponto, $f_{R}(r)$, será usada a suposição feita no parágrafo anterior e a transformação de variáveis a seguir,

Sejam $(u, v)$ as coordenadas cartesianas correspondentes à distância $r$, (ver Figura A.1).

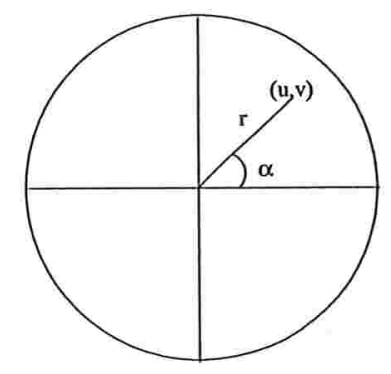

Figura A.1: Ponto transecto, representação da notação usada na transformação de coordenadas

Portanto, a função densidade de probabilidade conjunta de $U, V$ é dada por

$$
f_{U, V}(u, v)=\left\{\begin{array}{cl}
\frac{1}{\pi w^{2}}, & \text { se } \sqrt{u^{2}+v^{2}} \leq w \\
0, & \text { cc }
\end{array}\right.
$$

A distribuição marginal de $R$ será encontrada fazendo a transformação em coordenadas polares, $U=R \cos \alpha$ e $V=R \operatorname{sen} \alpha$. A distribuição conjunta de $R$ e $\alpha$ é então dada por $f_{R, \alpha}(r, \alpha)=\frac{1}{\pi w^{2}}|J|$, em que $|J|$ é o determinante do jacobiano da transformação dado por

$$
J=\left[\begin{array}{ll}
\frac{\partial u}{\partial r} & \frac{\partial u}{\partial \alpha} \\
\frac{\partial v}{\partial r} & \frac{\partial v}{\partial \alpha}
\end{array}\right]=\left[\begin{array}{cc}
\cos (\alpha) & -r \operatorname{sen}(\alpha) \\
\operatorname{sen}(\alpha) & r \cos (\alpha)
\end{array}\right]
$$




$$
\begin{aligned}
\Rightarrow|J| & =r \cos ^{2}(\alpha)+\operatorname{rsen}^{2}(\alpha) \\
& =r\left[\cos ^{2}(\alpha)+\operatorname{sen}^{2}(\alpha)\right] \\
& =r .
\end{aligned}
$$

Deste modo, obtém-se a distribuição conjunta de $R$ e $\alpha$;

$$
f_{R, \alpha}(r, \alpha)=\frac{1}{\pi w^{2}} r
$$

o que implica em que a função densidade de probabilidade marginal das distâncias dos objetos ao ponto é dada por

$$
f_{R}(r)=\int_{0}^{2 \pi} \frac{1}{\pi w^{2}} r d \alpha=\frac{2 r}{w^{2}}
$$

Substituindo (A.7) em (A.5) e usando a definição da função de detecção, $g(r)=P(O \mid R=r)$ obtém-se

$$
P_{a}=\int_{0}^{w} g(r) \frac{2 r}{w^{2}} d r
$$

\section{Função densidade de probabilidade das distâncias dos objetos detectados}

A distribuição condicional de $R$ dado que o objeto foi detectado é encontrada da seguinte forma:

$$
F_{R \mid O}(r)=P(R \leq r \mid O)=\frac{P(R \leq r, O)}{P(O)}
$$


Agora,

$$
\begin{aligned}
P(R \leq r, O) & =\int_{0}^{r} P(O \mid R=u) f_{R}(u) d u \\
& =\int_{0}^{r} g(u) \frac{2 u}{w^{2}} d u .
\end{aligned}
$$

Substituindo em (A.9), o numerador por (A.10) e o denominador por (A.8), obtém-se

$$
F_{R \mid O}(r)=\frac{2 \pi \int_{0}^{r} u g(u) d u}{2 \pi \int_{0}^{w} r g(r) d r}
$$

e portanto,

$$
f_{R \mid O}(r)=\frac{2 \pi r g(r)}{2 \pi \int_{0}^{w} r g(r) d r}
$$




\section{Apêndice B}

\section{Programas Desenvolvidos em $\mathbf{R}$ para}

\section{Geração das Amostras}

Os programas apresentados aqui foram feitos usando o aplicativo R. Programa usado na geração da amostra em linhas transectas.

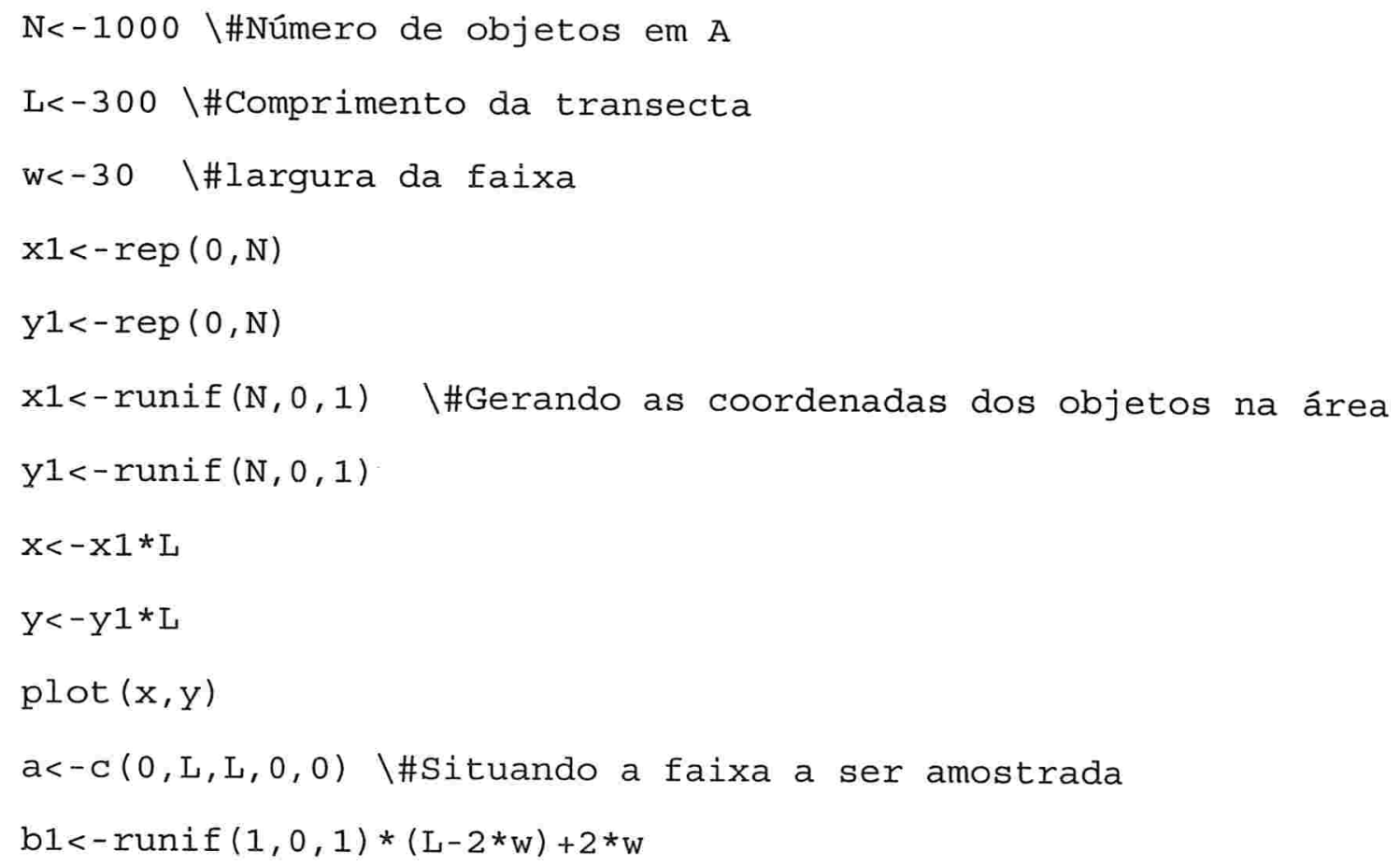




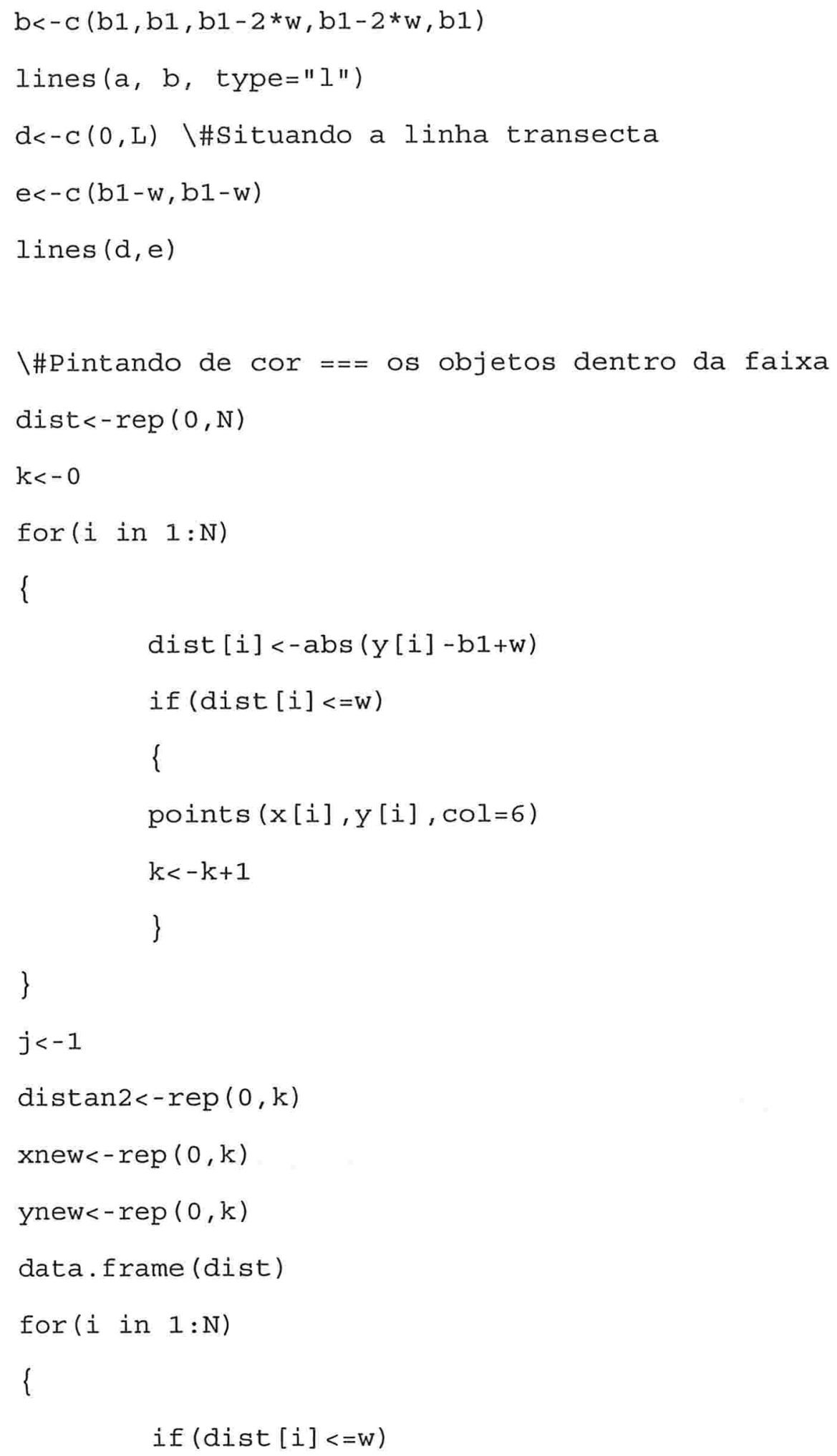




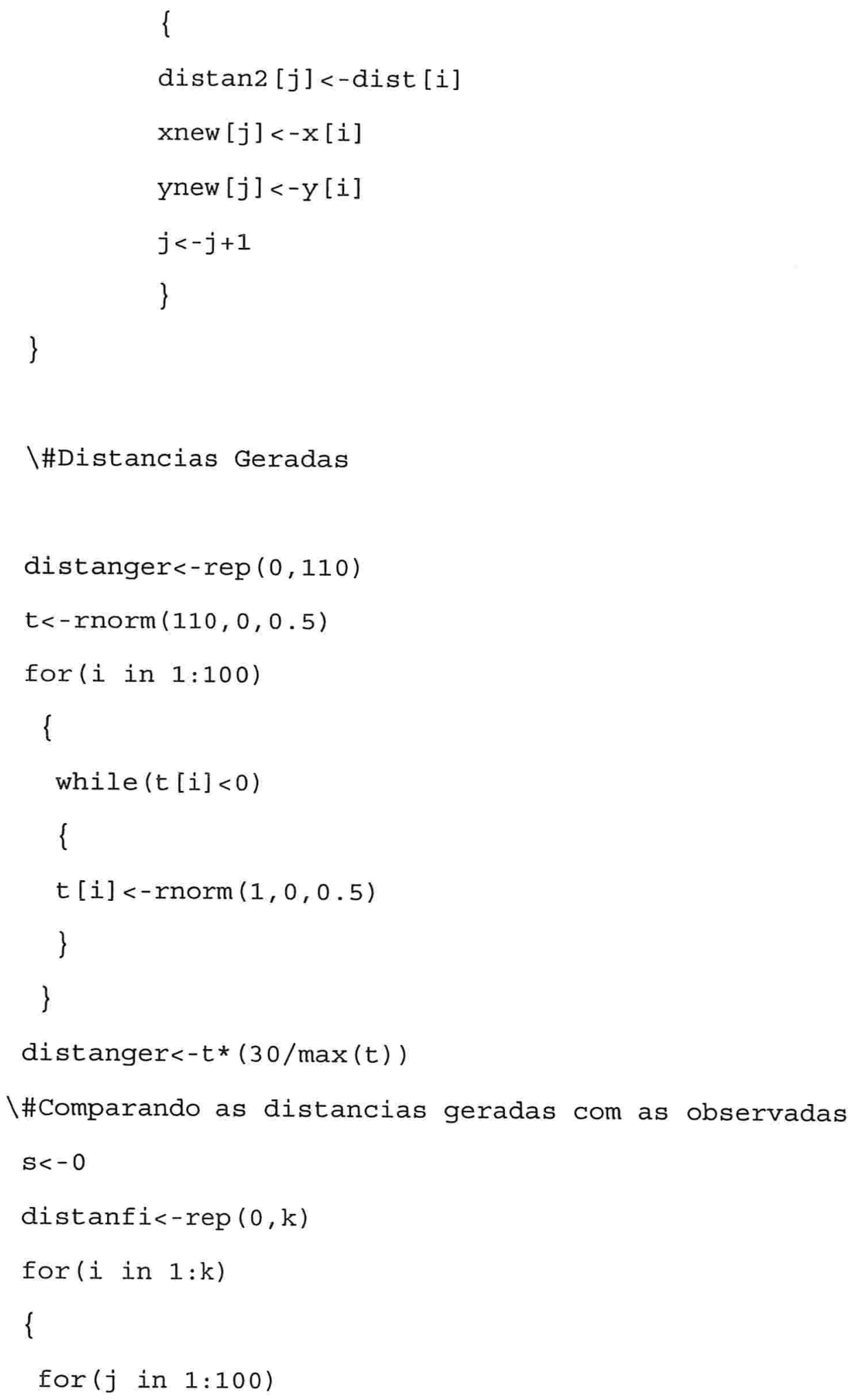




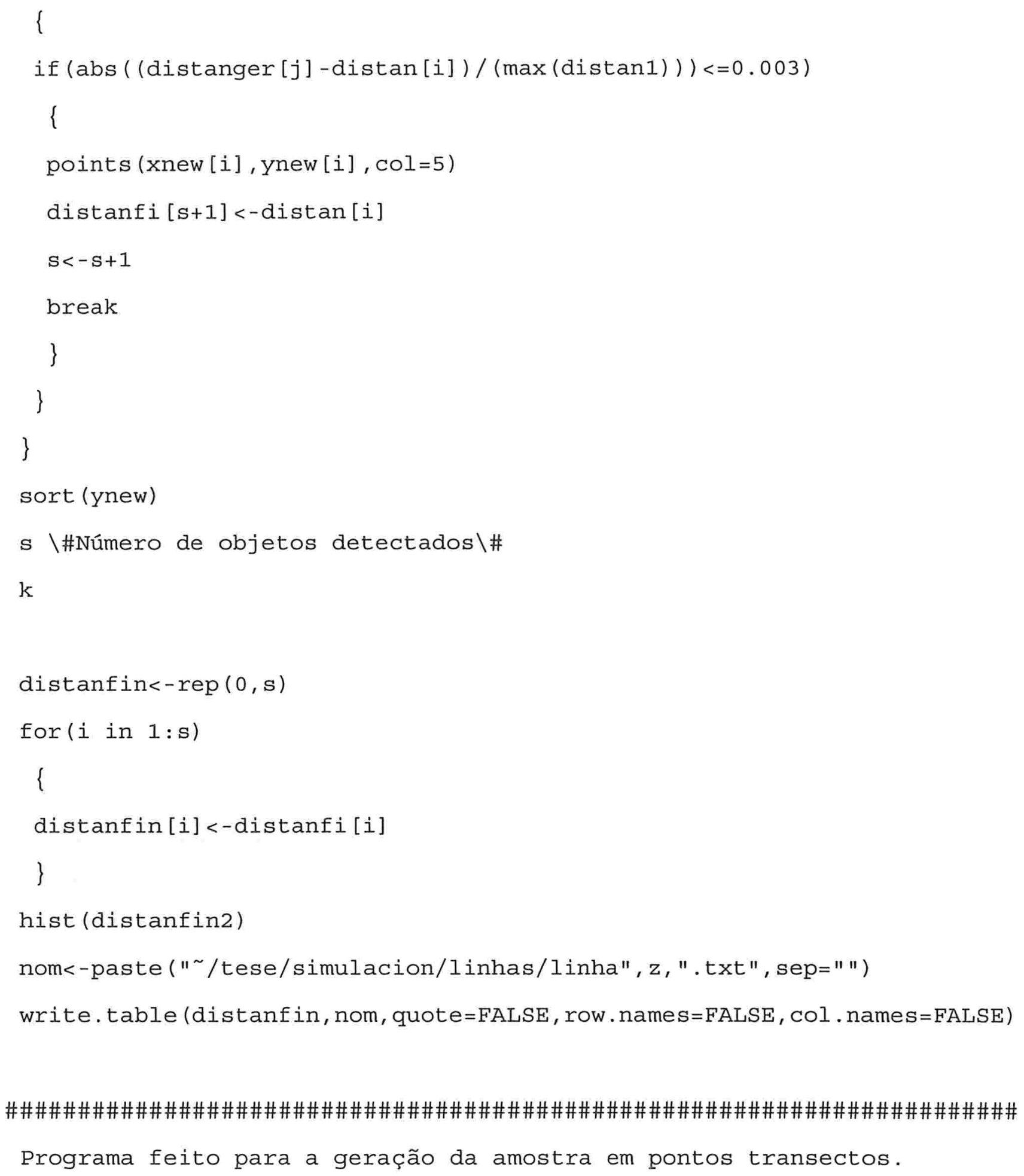




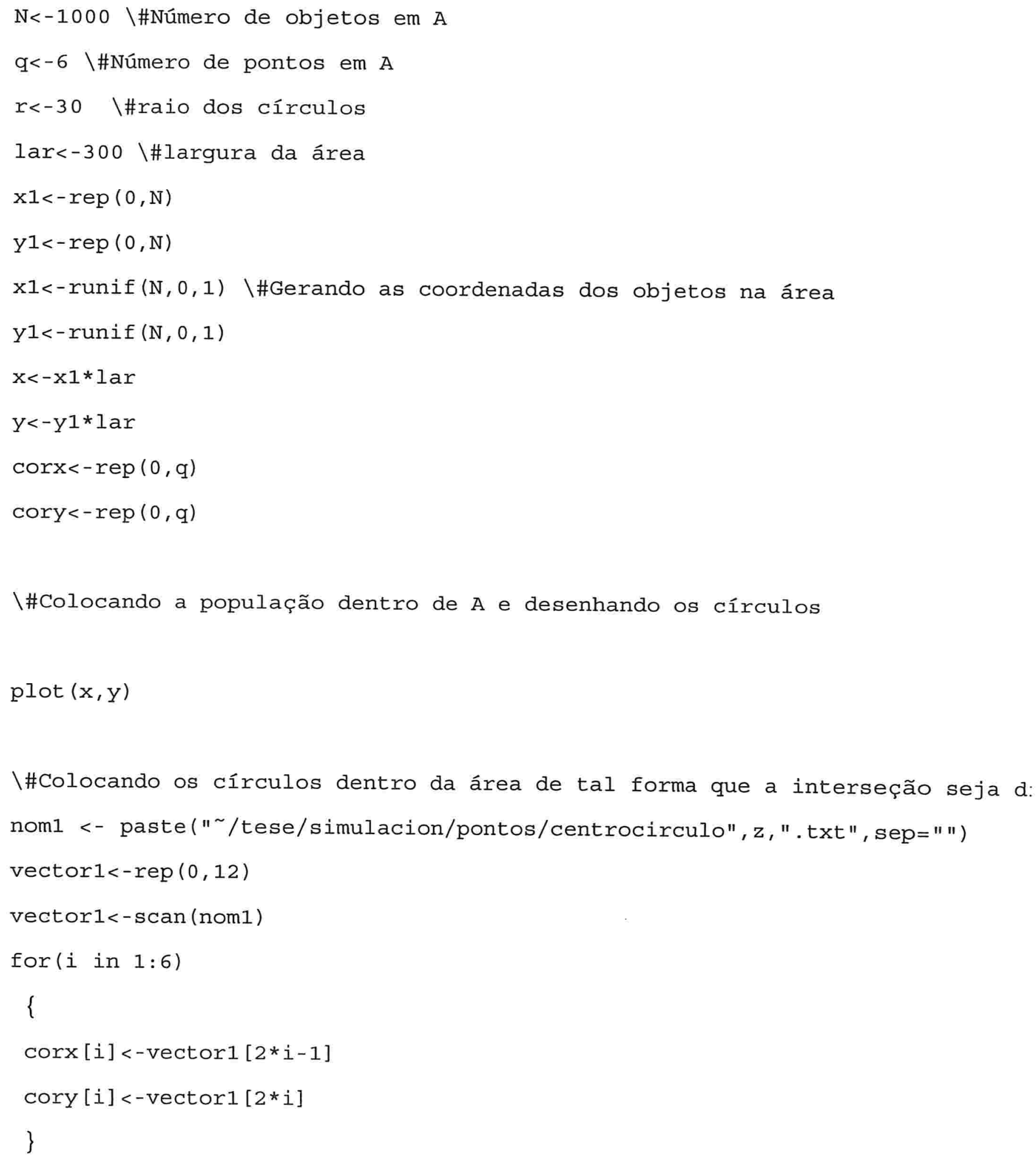




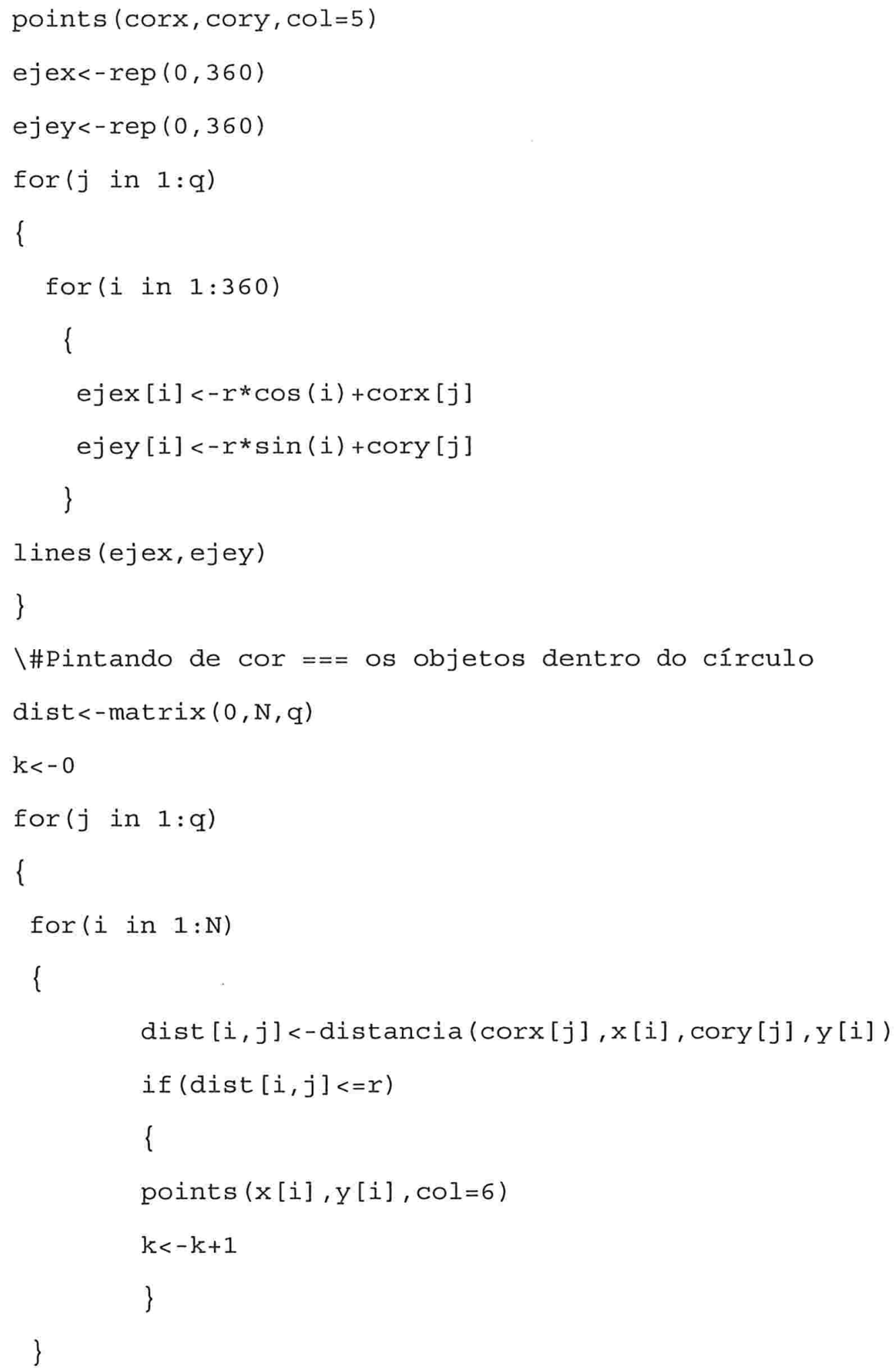




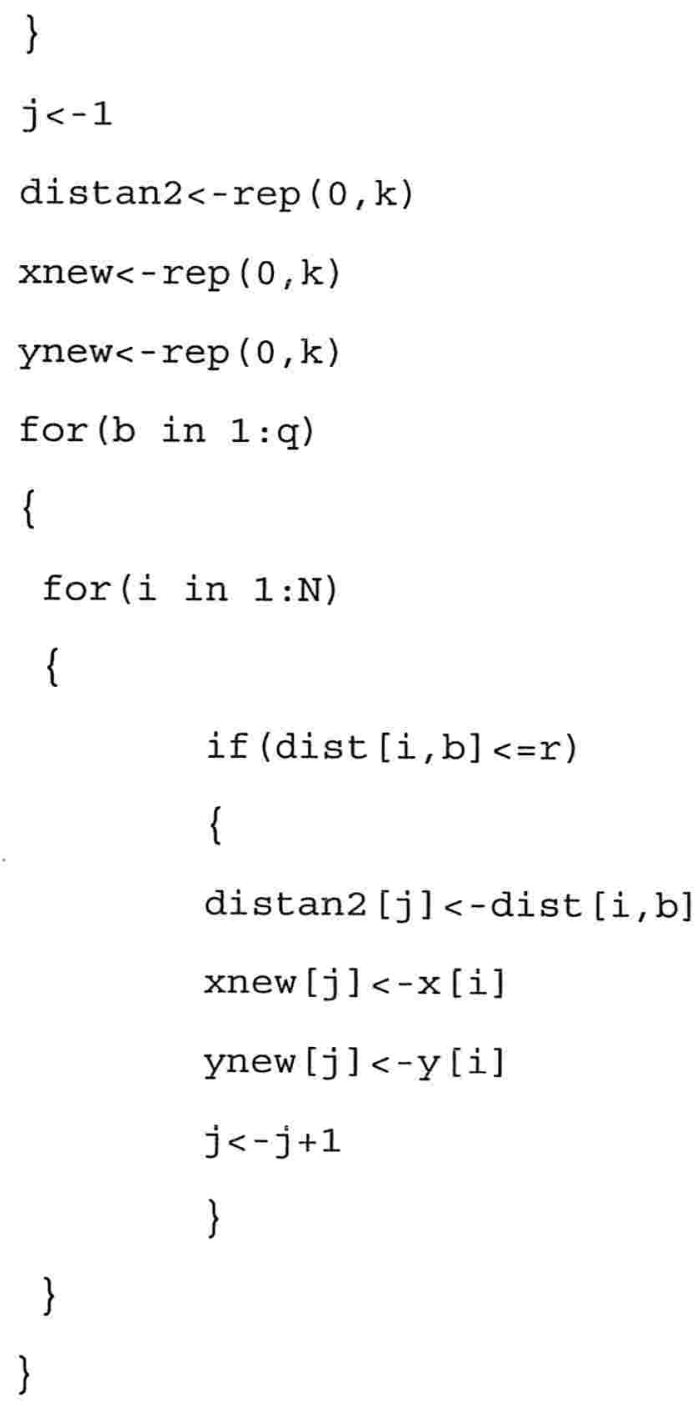




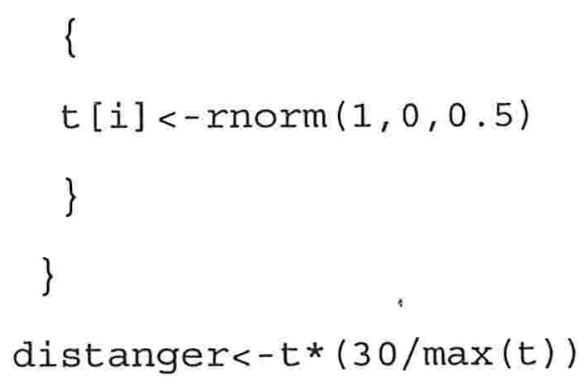




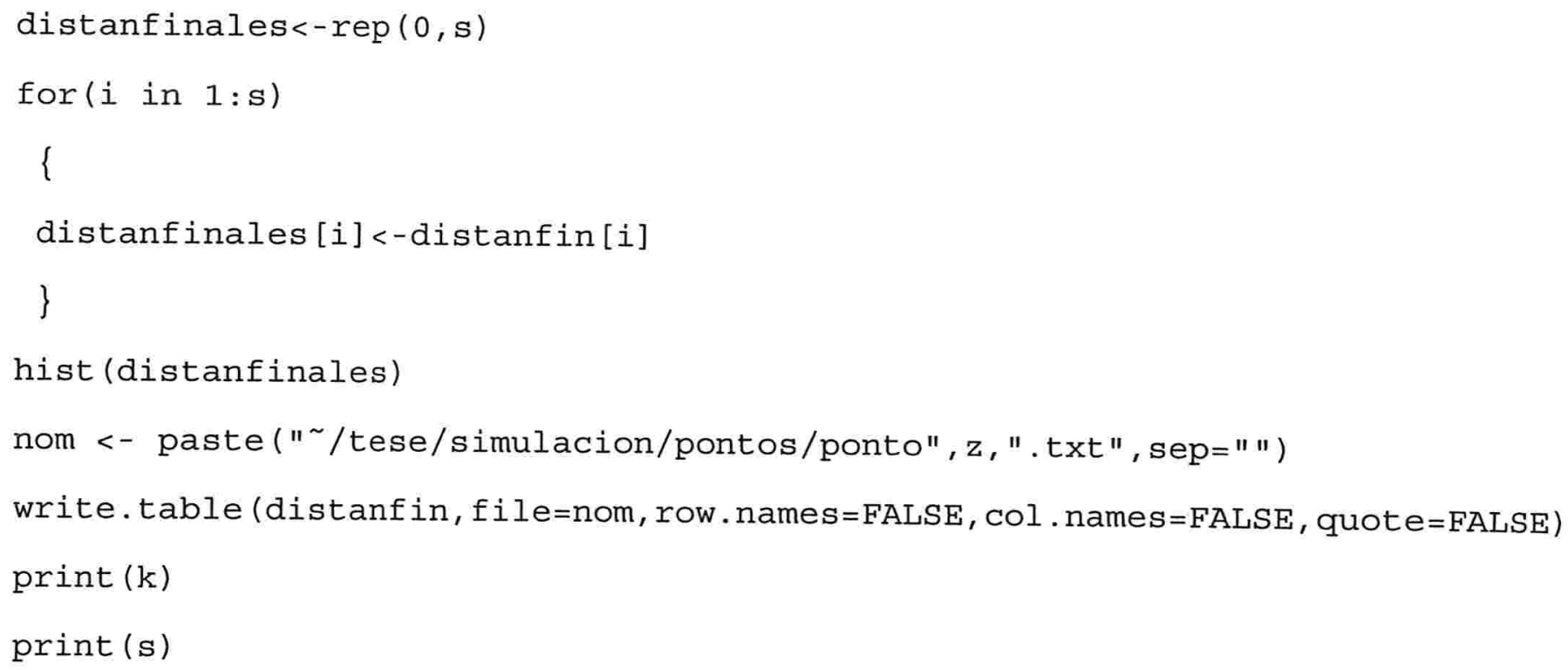




\section{Apêndice C}

\section{Saída do Programa Distance na Análise de um Conjunto de Dados para Linhas}

\section{Transectas}

Saída para Linhas Transectas

Primeira parte

Estimation Options Listing

Parameter Estimation Specification

Encounter rate for all data combined

Detection probability for all data combined

Density for all data combined

Distances :

Analysis based on exact distances

Width: use largest measurement/last interval endpoint 


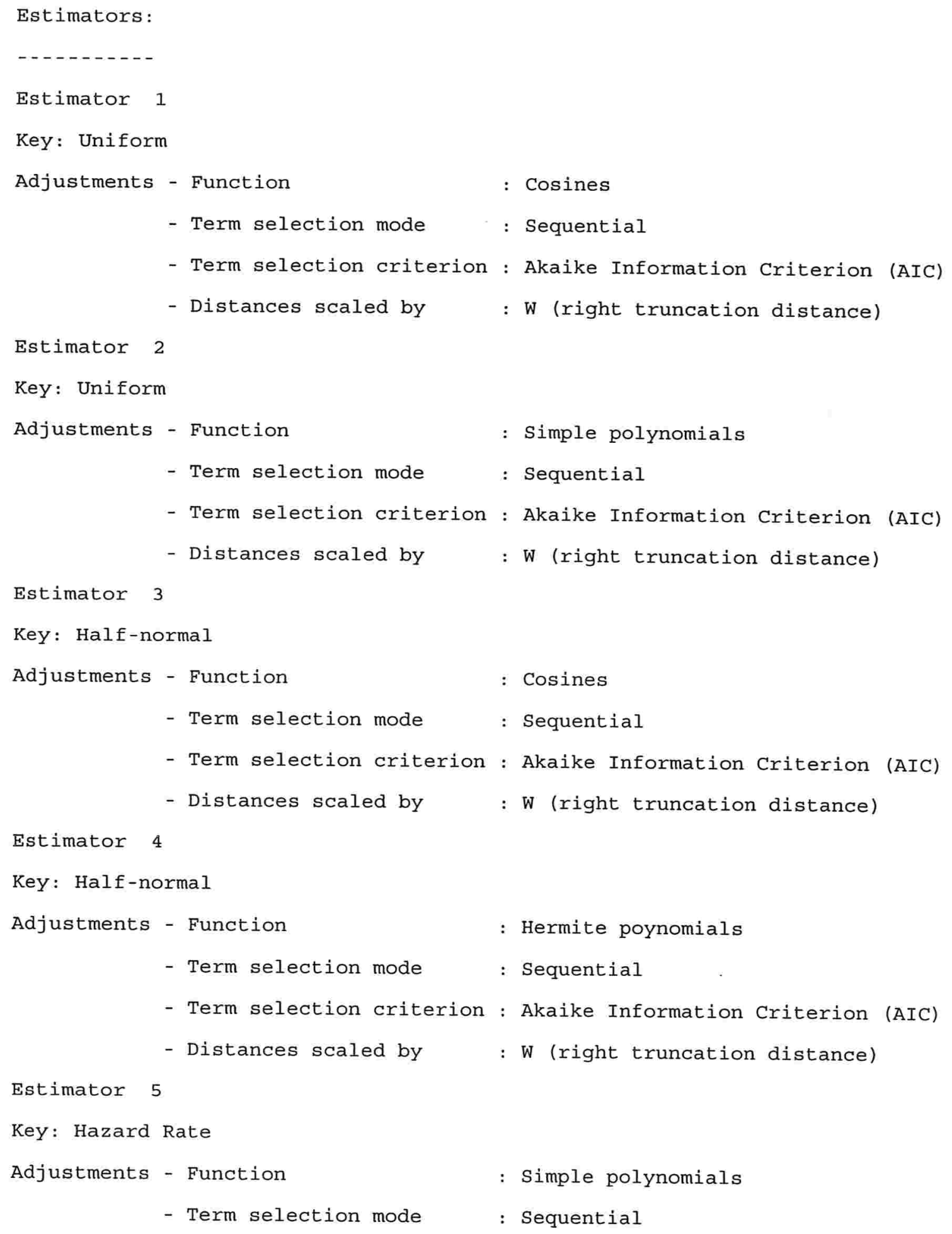




\section{- Term selection criterion : Akaike Information Criterion (AIC) \\ - Distances scaled by : W (right truncation distance)}

Estimator selection: Choose estimator with minimum AIC

Estimation functions: constrained to be nearly monotone non-increasing

Variances :

Variance of $\mathrm{n}$ : Assume Poisson distribution

Variance of $f(0)$ : MLE estimate

Goodness of fit:

Cut points chosen by program

Glossary of terms

Data items :

n - number of observed objects (single or clusters of animals)

L - total length of transect line(s)

k - number of samples

$\mathrm{K}$ - point transect effort, typically $\mathrm{K}=\mathrm{k}$

$\mathrm{T}$ - length of time searched in cue counting

ER - encounter rate ( $\mathrm{n} / \mathrm{L}$ or $\mathrm{n} / \mathrm{K}$ or $\mathrm{n} / \mathrm{T}$ )

W - width of line transect or radius of point transect

$x(i)$ - distance to i-th observation

s(i) - cluster size of i-th observation

$r-p$ - probability for regression test 
chi-p- probability for chi-square goodness-of-fit test

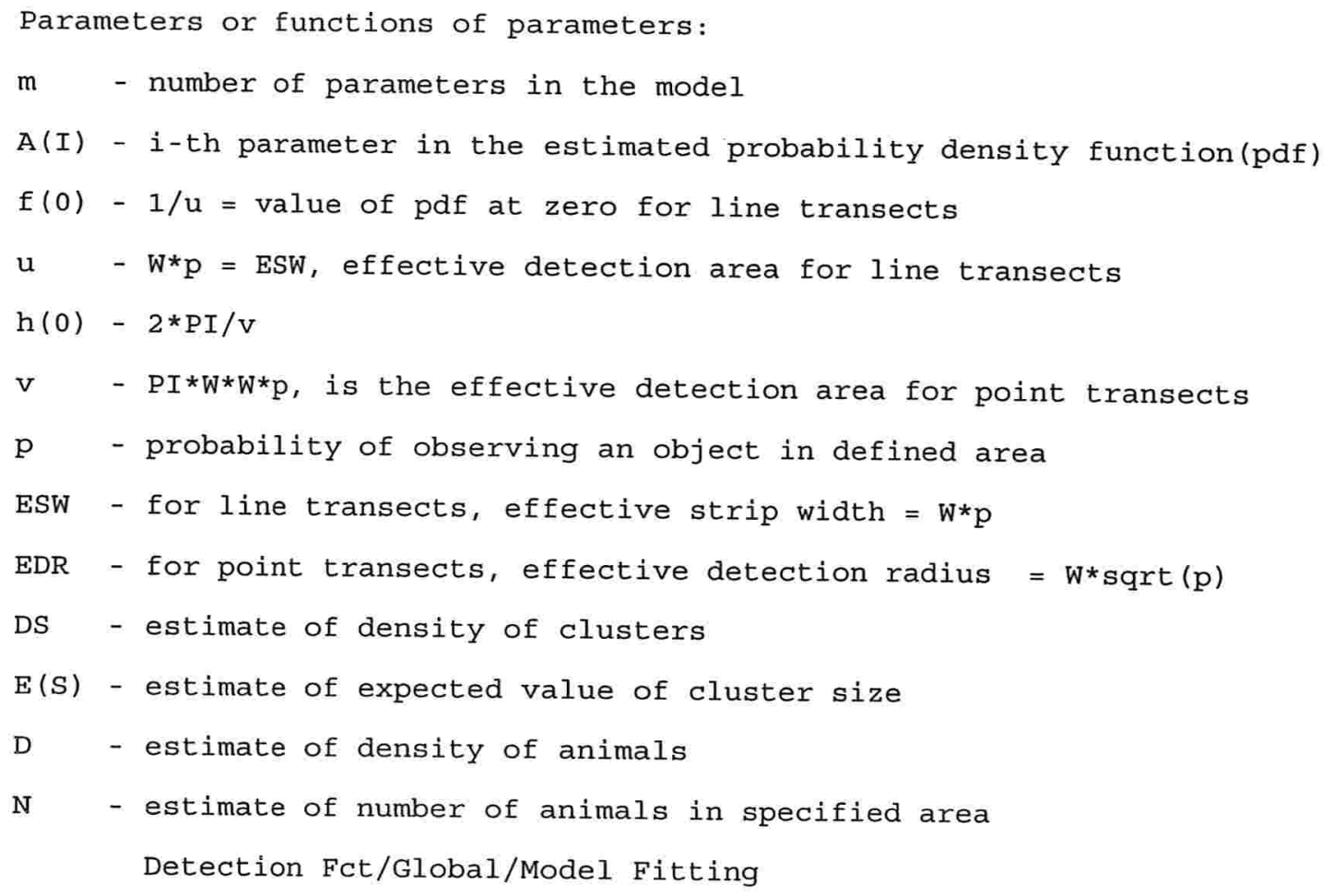

\section{Segunda parte}

$\begin{array}{lcc}\text { Effort } & : & 300.0000 \\ \text { \# samples } & : & 1 \\ \text { Width } & 29.79632 \\ \text { \# observations: } & 89\end{array}$

Model 1

Uniform key, $k(y)=1 / \mathrm{W}$

Results:

Convergence was achieved with 1 function evaluations.

Final Ln(likelihood) value $=-302.10025$ 


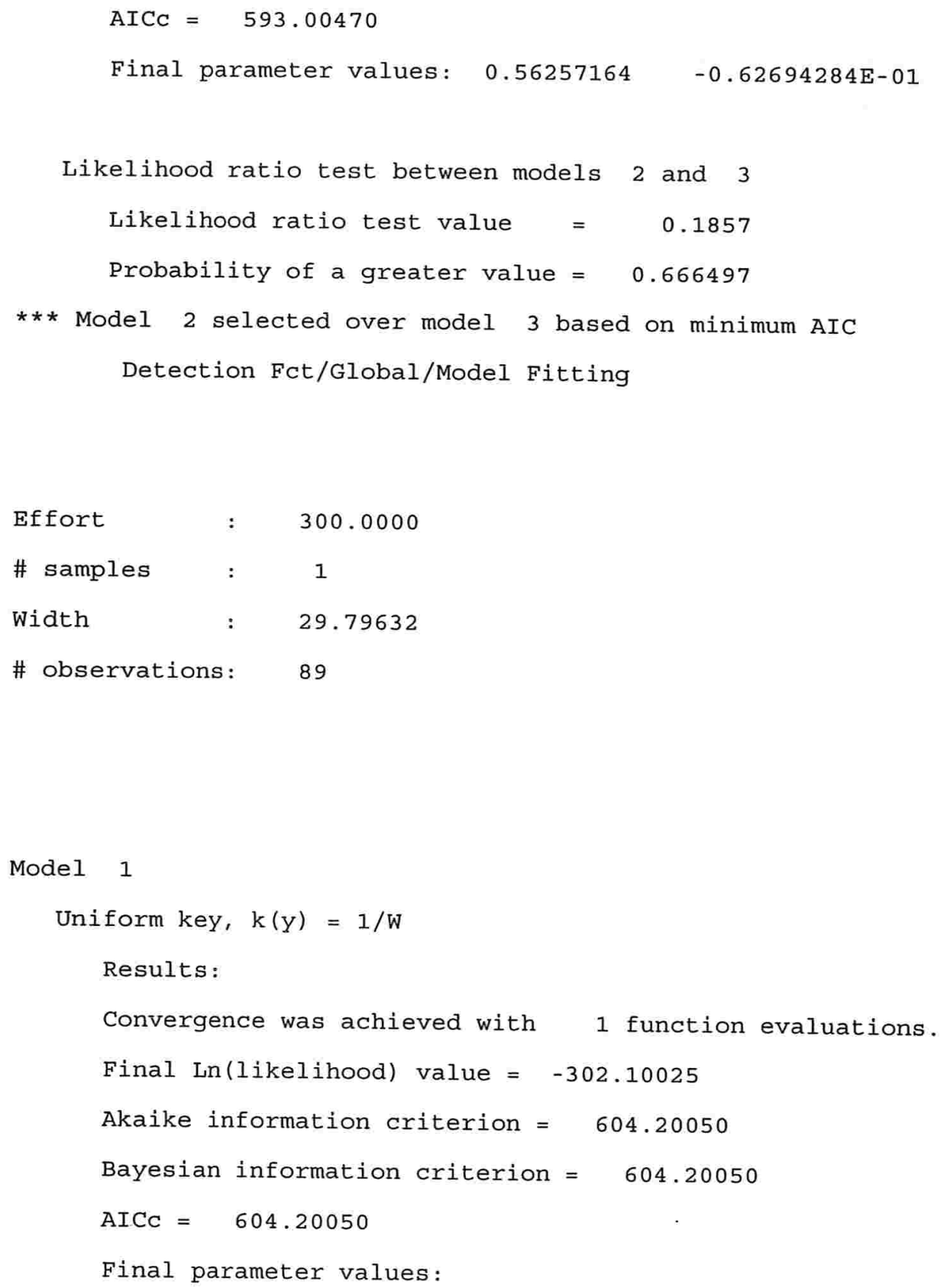




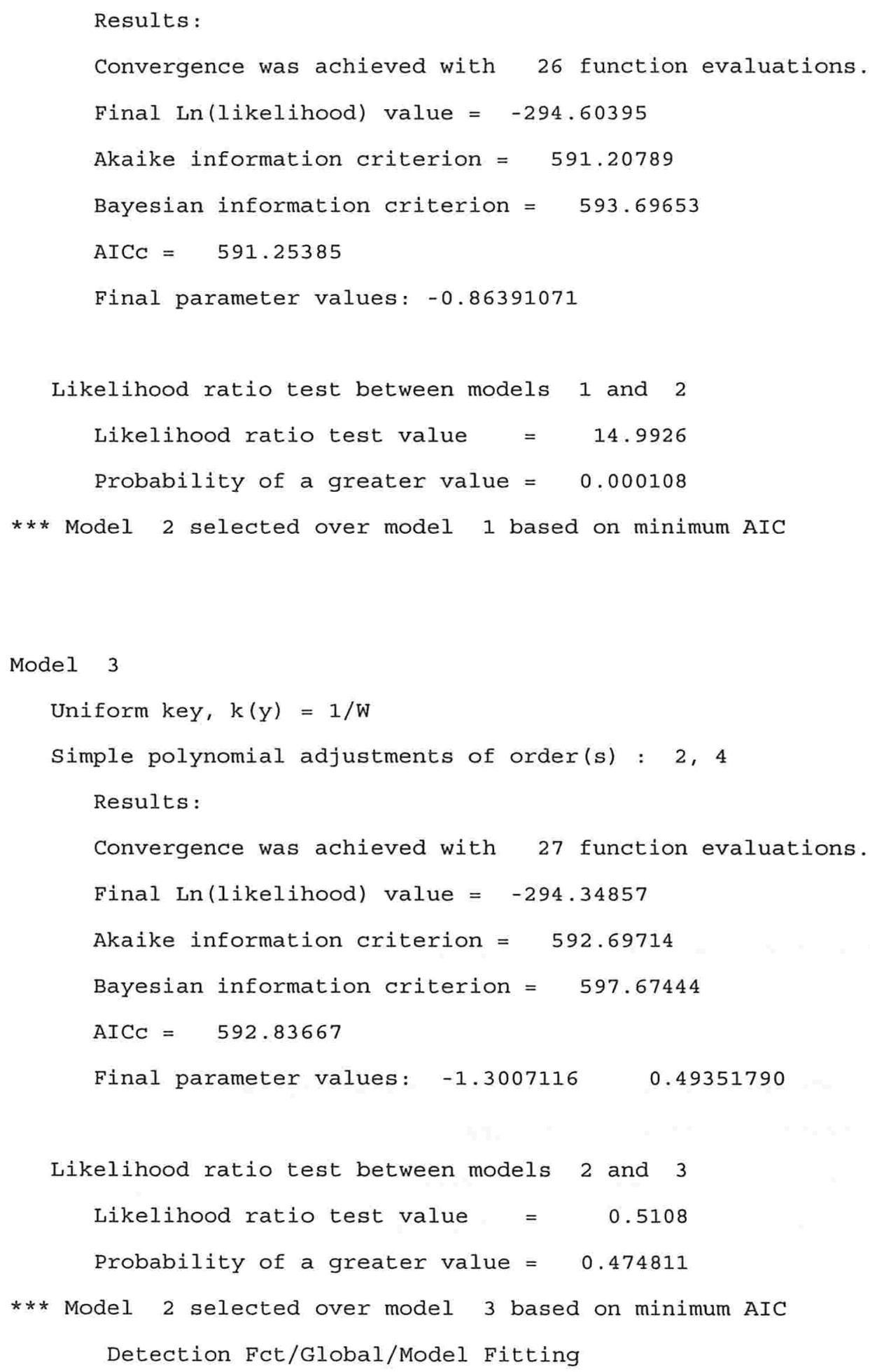




$\begin{array}{lcc}\text { Effort } & : & 300.0000 \\ \text { \# samples } & : & 1 \\ \text { Width } & : & 29.79632 \\ \text { \# observations: } & 89\end{array}$

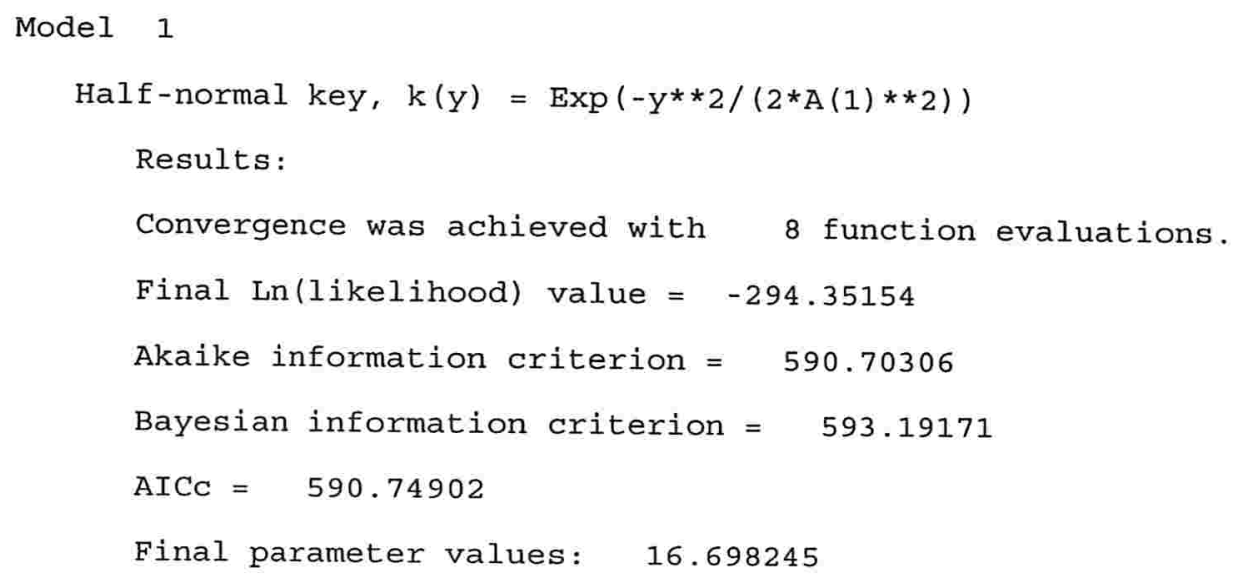




Likelihood ratio test value $=0.0053$
Probability of a greater value $=0.942013$

*** Model 1 selected over model 2 based on minimum AIC

Detection Fct/Global/Model Fitting

$\begin{array}{lcc}\text { Effort } & : & 300.0000 \\ \text { \# samples } & : & 1 \\ \text { Width } & : & 29.79632 \\ \text { \# observations: } & 89\end{array}$

Model 1

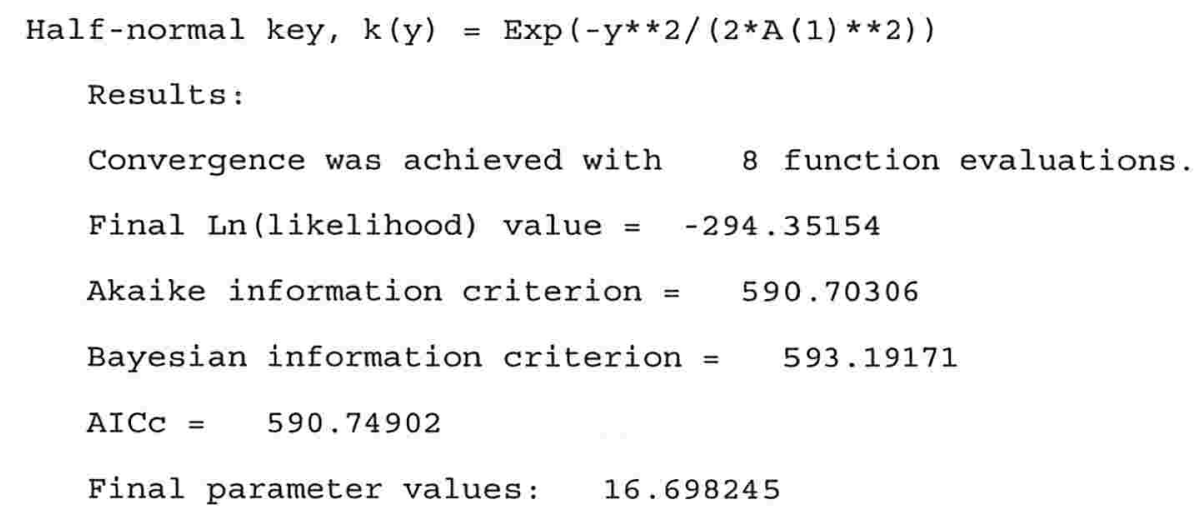

Model 2

Half-normal key, $\mathrm{k}(\mathrm{y})=\operatorname{Exp}(-\mathrm{y} * * 2 /(2 * \mathrm{~A}(1) * * 2))$

Hermite polynomial adjustments of order(s) : 4 Results:

Convergence was achieved with 26 function evaluations.

Final Ln(likelihood) value $=-294.34389$

Akaike information criterion $=592.68781$ 


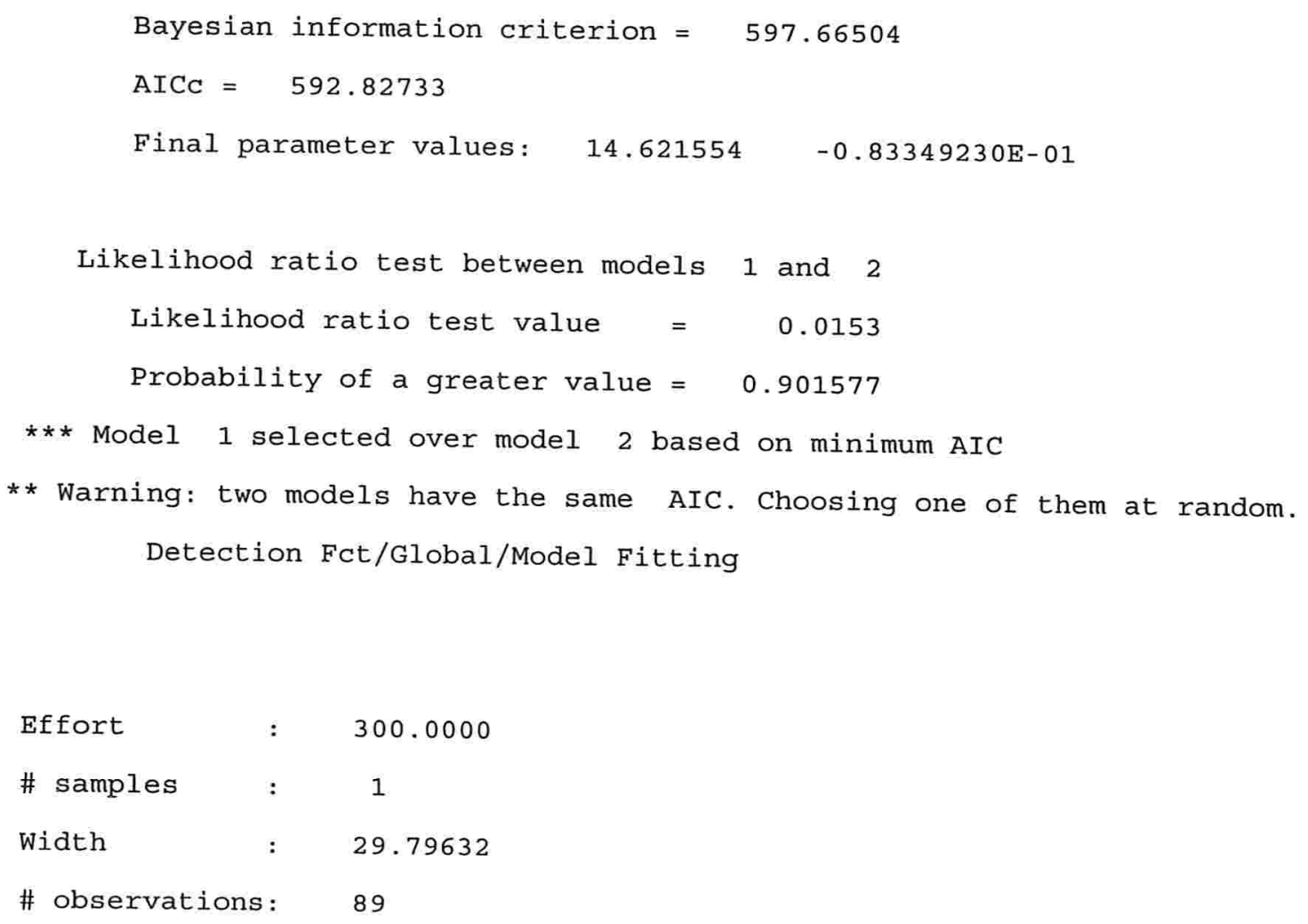




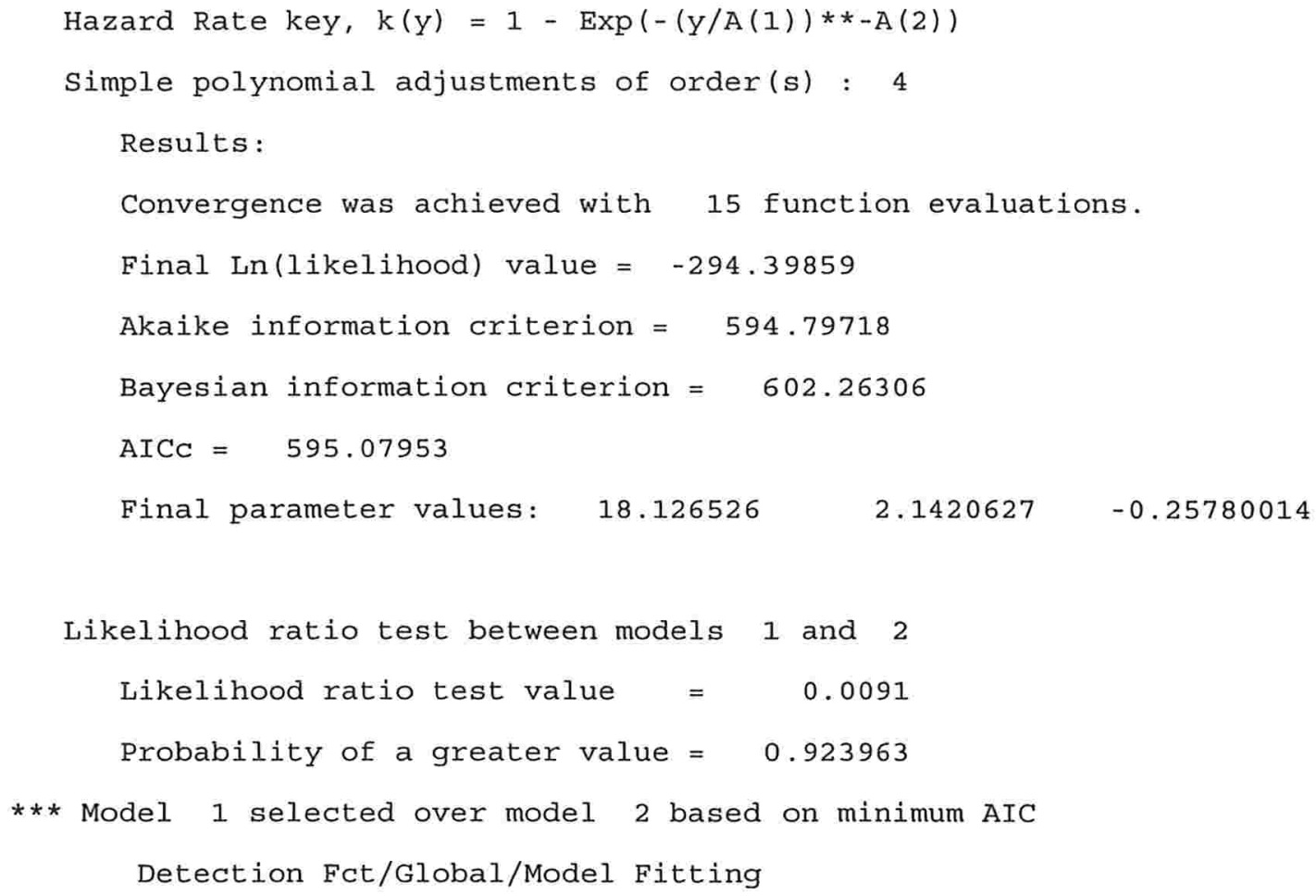

\section{Terceira parte}

$\begin{array}{lcc}\text { Effort } & : & 300.0000 \\ \text { \# samples } & : & 1 \\ \text { Width } & : & 29.79632 \\ \text { \# observations: } & 89\end{array}$

Model Selection

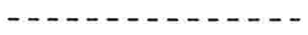

Minimum $\mathrm{AIC}=590.7031$

Estimator chosen based on minimum AIC : Model

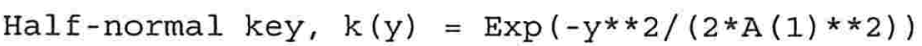

Detection Fct/Global/Parameter Estimates 


$\begin{array}{lcc}\text { Effort } & : & 300.0000 \\ \text { \# samples } & : & 1 \\ \text { Width } & : & 29.79632 \\ \text { \# observations : } & 89\end{array}$

Model

Half-normal key, $k(y)=\operatorname{Exp}(-y * * 2 /(2 * A(1) * * 2))$

\begin{tabular}{|c|c|c|c|c|}
\hline & Point & Standard & Percent Coef. & 95 Percent \\
\hline Parameter & Estimate & Error & of Variation & Confidence Interval \\
\hline$-\cdots-\cdots$ & $-\cdots-\cdots-1$ & $-\cdots------$ & $----1----1$ & $\cdots-\cdots$ \\
\hline$A(1)$ & 16.70 & 2.318 & & \\
\hline$f(0)$ & $0.51621 \mathrm{E}-01$ & $0.49220 \mathrm{E}-02$ & 9.53 & $0.42729 \mathrm{E}-01$ \\
\hline
\end{tabular}

Detection Fct/Global/Plot: Qq-plot

Detection Fct/Global/K-S GOF Test

\section{Quarta parte}

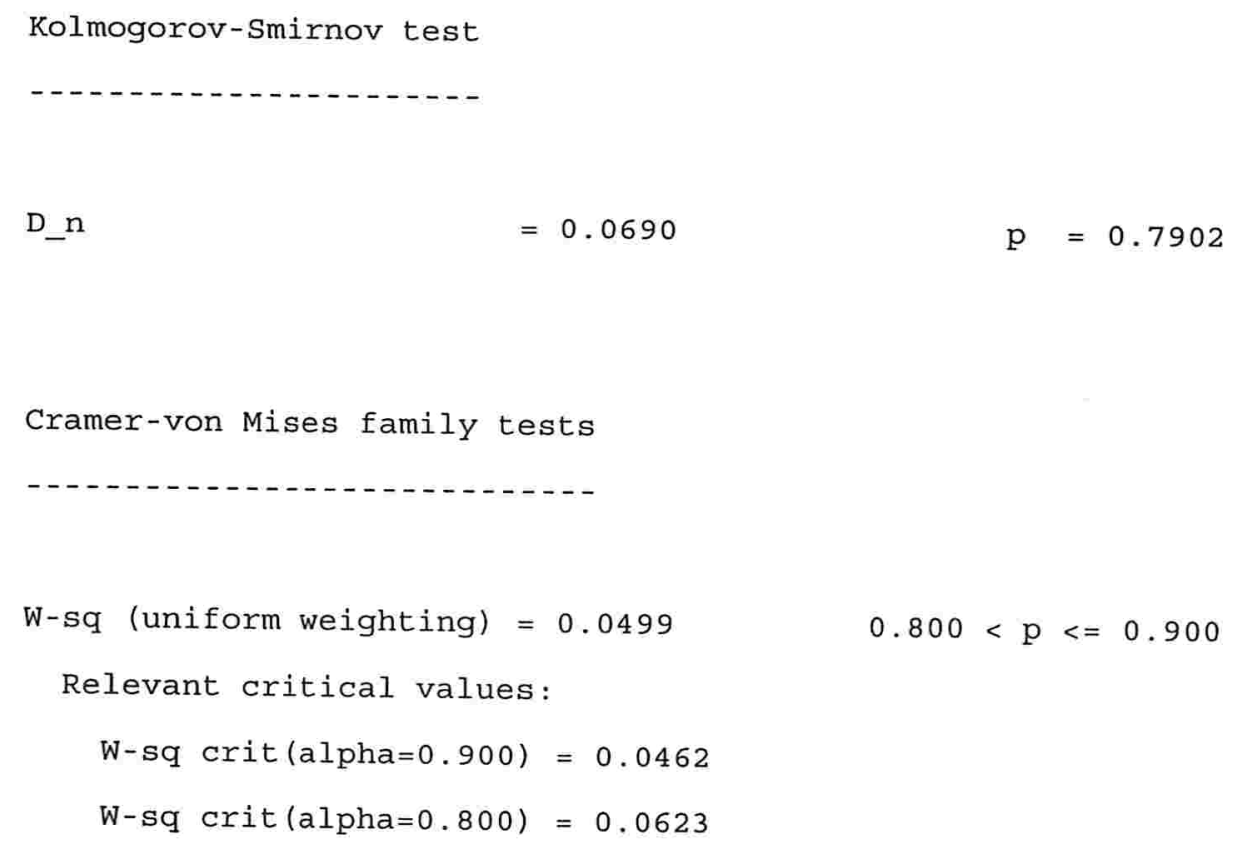



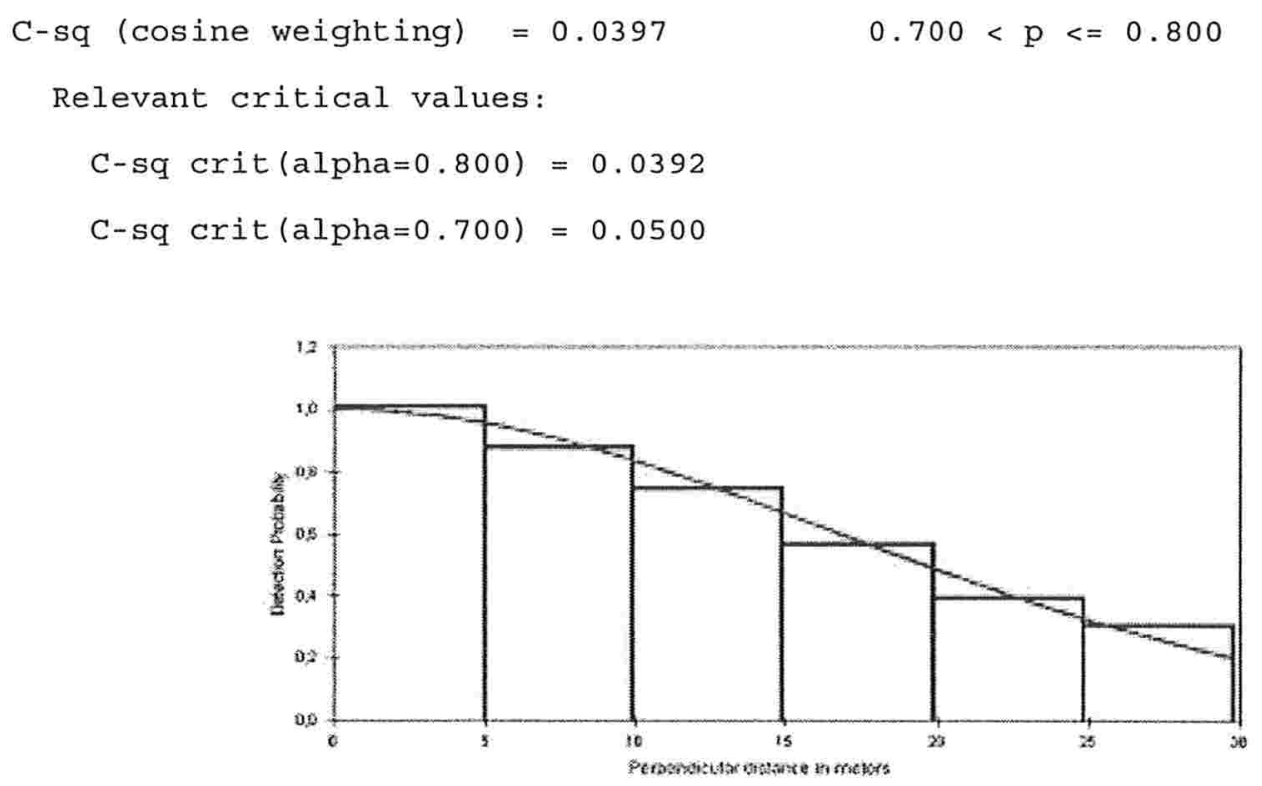

Figura C.1: Detection Fct/Global/Plot: Detection Probability 1

Perpendicular distance in meters Detection Fct/Global/Chi-sq GoF Test 1

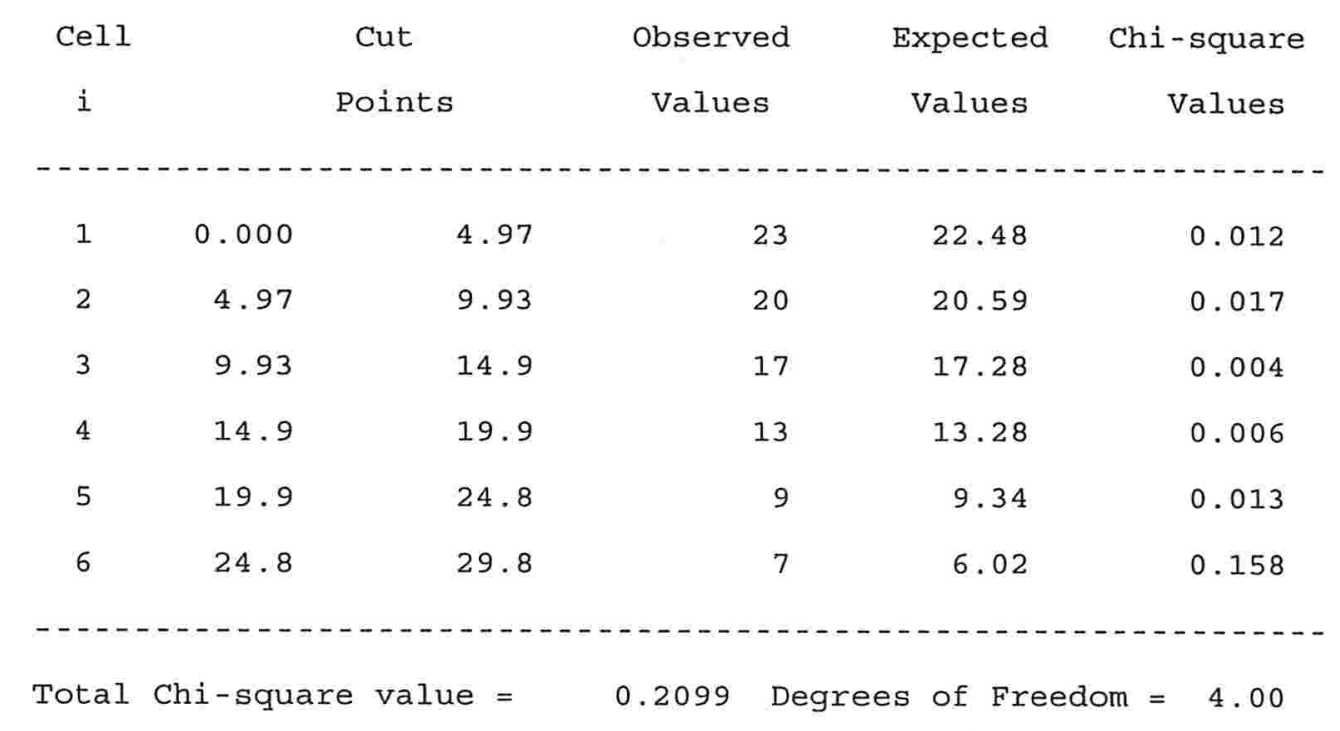


The program has limited capability for pooling. The user should judge the necessity for pooling and if necessary, do pooling by hand.

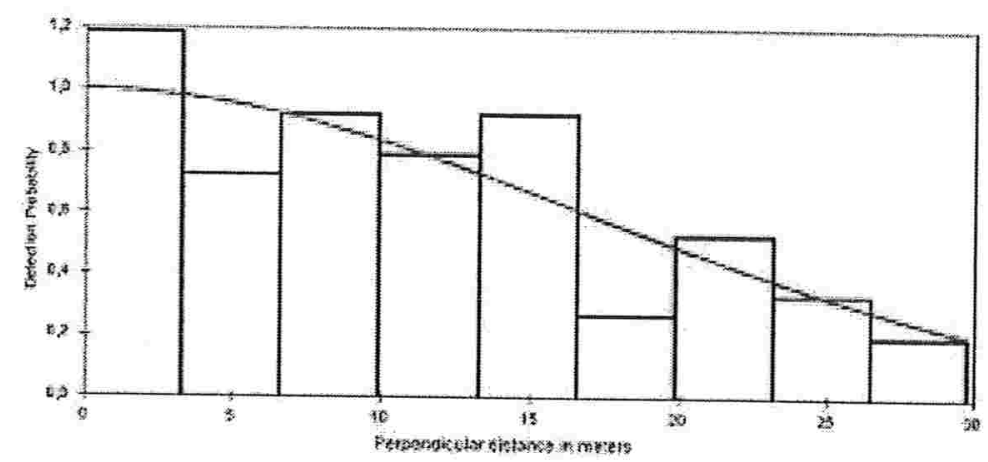

Figura C.2: Detection Fct/Global/Plot: Detection Probability 2

$$
\begin{aligned}
& \text { Perpendicular distance in meters } \\
& \text { Detection Fct/Global/Chi-sq GOF Test } 2
\end{aligned}
$$

\begin{tabular}{crrrrr} 
Cell & \multicolumn{2}{c}{$\begin{array}{c}\text { Cut } \\
\text { Points }\end{array}$} & $\begin{array}{c}\text { Observed } \\
\text { Values }\end{array}$ & $\begin{array}{c}\text { Expected } \\
\text { Values }\end{array}$ & $\begin{array}{c}\text { Chi-square } \\
\text { Values }\end{array}$ \\
1 & & Polue & & \\
2 & 3.31 & 6.62 & 18 & 15.11 & 0.552 \\
3 & 6.62 & 9.93 & 14 & 14.53 & 0.858 \\
4 & 9.93 & 13.2 & 12 & 11.95 & 0.024 \\
5 & 13.2 & 16.6 & 14 & 10.21 & 1.405 \\
6 & 16.6 & 19.9 & 4 & 8.40 & 2.301 \\
7 & 19.9 & 23.2 & 8 & 6.64 & 0.280 \\
8 & 23.2 & 26.5 & 5 & 5.04 & 0.000
\end{tabular}




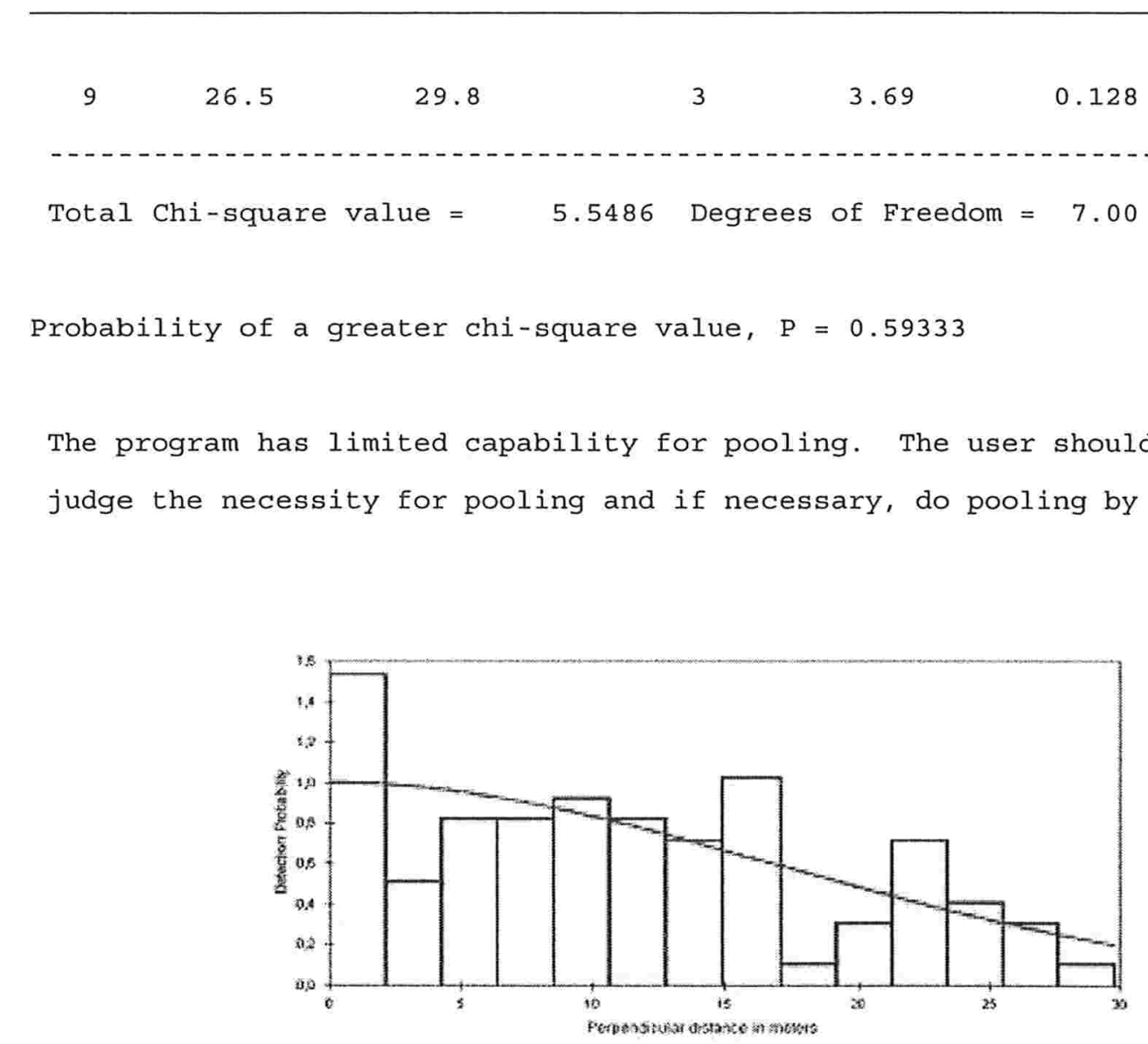

Figura C.3: Detection Fct/Global/Plot: Detection Probability 3

Perpendicular distance in meters

Detection Fct/Global/Chi-sq GOF Test 3

\begin{tabular}{|c|c|c|c|c|c|}
\hline Cell & & Cut & Observed & Expected & Chi-square \\
\hline i & & Points & Values & Values & Values \\
\hline 1 & 0.000 & 2.13 & 15 & 9.75 & 2.825 \\
\hline 2 & 2.13 & 4.26 & 5 & 9.59 & 2.200 \\
\hline 3 & 4.26 & 6.38 & 8 & 9.29 & 0.179 \\
\hline 4 & 6.38 & 8.51 & 8 & 8.85 & 0.081 \\
\hline 5 & 8.51 & 10.6 & 9 & 8.29 & 0.061 \\
\hline
\end{tabular}




\begin{tabular}{rrrrrr}
6 & 10.6 & 12.8 & 8 & 7.65 & 0.016 \\
7 & 12.8 & 14.9 & 7 & 6.94 & 0.001 \\
8 & 14.9 & 17.0 & 10 & 6.19 & 2.343 \\
9 & 17.0 & 19.2 & 1 & 5.44 & 3.622 \\
10 & 19.2 & 21.3 & 3 & 4.70 & 0.614 \\
11 & 21.3 & 23.4 & 7 & 4.00 & 2.259 \\
12 & 23.4 & 25.5 & 4 & 3.34 & 0.129 \\
13 & 25.5 & 27.7 & 3 & 2.75 & 0.023 \\
14 & 27.7 & 29.8 & 1 & 2.23 & 0.677 \\
$-\ldots-\ldots$ & & & & \\
\hline
\end{tabular}

Total Chi-square value $=15.0295$ Degrees of Freedom $=12.00$

Probability of a greater chi-square value, $\mathrm{P}=0.23983$

The program has limited capability for pooling. The user should judge the necessity for pooling and if necessary, do pooling by hand. Density Estimates/Global

\section{Quinta parte}

$\begin{array}{lcc}\text { Effort } & : & 300.0000 \\ \text { \# samples } & : & 1 \\ \text { Width } & 29.79632 \\ \text { \# observations : } & 89\end{array}$

Model

Half-normal key, $\mathrm{k}(\mathrm{y})=\operatorname{Exp}\left(-y^{*} * 2 /(2 * A(1) * * 2)\right)$

$\begin{array}{llccr} & \text { Point } & \text { Standard } & \text { Percent Coef. } & \text { 95\% Percent } \\ \text { Parameter } & \text { Estimate } & \text { Error } & \text { of Variation } & \text { Confidence Interval }\end{array}$




$\begin{array}{lccccc}\mathrm{f}(0) & 0.51621 \mathrm{E}-01 & 0.49220 \mathrm{E}-02 & 9.53 & 0.42729 \mathrm{E}-01 & 0.62364 \mathrm{E}-01 \\ \mathrm{p} & 0.65015 & 0.61991 \mathrm{E}-01 & 9.53 & 0.53815 & 0.78545 \\ \mathrm{ESW} & 19.372 & 1.8471 & 9.53 & 16.035 & 23.404 \\ \mathrm{n} / \mathrm{L} & 0.29667 & 0.31447 \mathrm{E}-01 & 10.60 & 0.24115 & 0.36496 \\ \mathrm{D} & 0.76571 \mathrm{E}-02 & 0.10917 \mathrm{E}-02 & 14.26 & 0.57760 \mathrm{E}-02 & 0.10151 \mathrm{E}-01\end{array}$

Measurement Units

Density: Numbers/Sq. meters

ESW : meters

Component Percentages of Var(D)

Detection probability : 44.7

Encounter rate : 55.3

Estimation Summary - Encounter rates

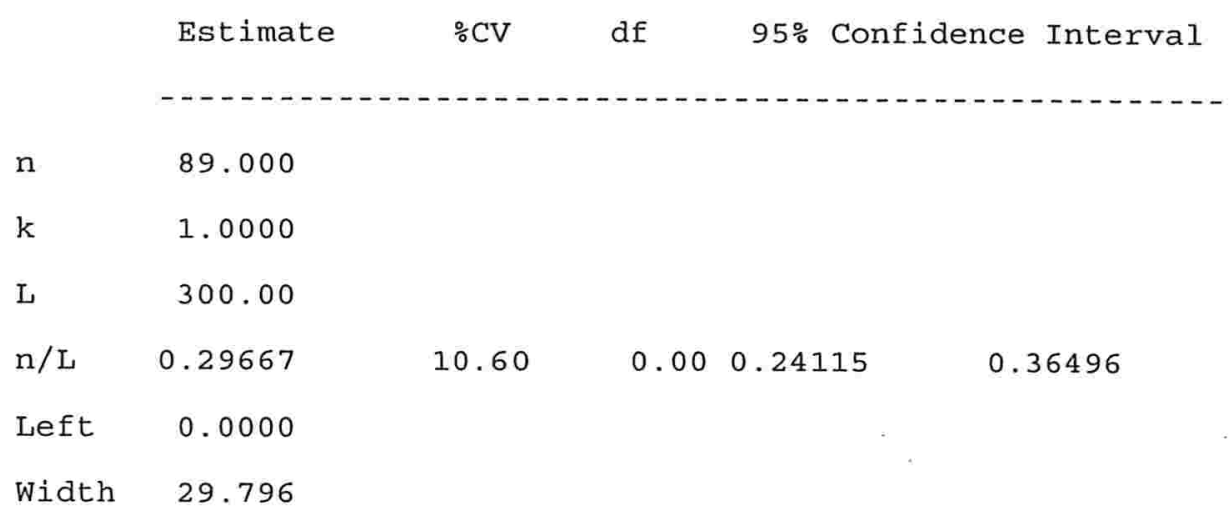

Estimation Summary - Detection probability

Estimate $\quad \% \mathrm{CV}$ df $95 \%$ Confidence Interval

Half-normal/Hermite 


\begin{tabular}{|c|c|c|c|c|c|}
\hline m & 1.0000 & & & & \\
\hline LnL & -294.35 & & & & \\
\hline AIC & 590.70 & & & & \\
\hline $\mathrm{AICC}$ & 590.75 & & & & \\
\hline $\mathrm{BIC}$ & 593.19 & & & & \\
\hline Chi-p & 0.23983 & & & & \\
\hline$f(0)$ & $0.51621 E-01$ & 9.53 & 88.00 & $0.42729 \mathrm{E}-01$ & $0.62364 \mathrm{E}-01$ \\
\hline$p$ & 0.65015 & 9.53 & 88.00 & 0.53815 & 0.78545 \\
\hline ESW & 19.372 & 9.53 & 88.00 & 16.035 & 23.404 \\
\hline
\end{tabular}

Estimation Summary - Density\&Abundance

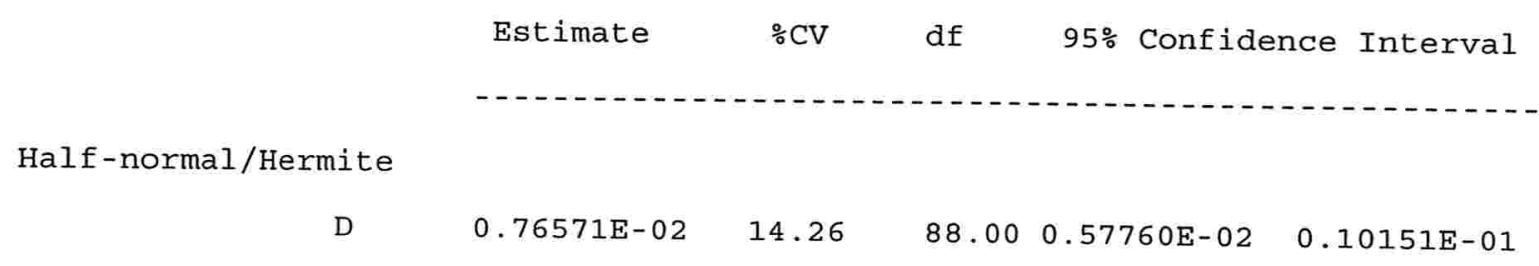




\section{Apêndice D}

\section{Saída do Programa Distance na Análise de um Conjunto de Dados para Pontos}

\section{Transectos}

Saída para Pontos Transectos

Primeira parte

Estimation Options Listing

Parameter Estimation Specification

Encounter rate for all data combined

Detection probability for all data combined

Density for all data combined

Distances :

Analysis based on exact distances 
Width: use largest measurement/last interval endpoint

Estimators :

Estimator

Key: Uniform

Adjustments - Function

: Cosines

- Term selection mode

: Sequential

- Term selection criterion : Akaike Information Criterion

(AIC)

- Distances scaled by : W (right truncation distance)

Estimator 2

Key: Uniform

Adjustments - Function

: Simple polynomials

- Term selection mode

: Sequential

- Term selection criterion

: Akaike Information Criterion (AIC)

- Distances scaled by

: W (right truncation distance)

Estimator 3

Key: Half-normal

Adjustments - Function

: Cosines

- Term selection mode

: Sequential

- Term selection criterion

: Akaike Information Criterion

(AIC)

- Distances scaled by

: W (right truncation distance)

Estimator 4

Key: Half-normal

Adjustments - Function

- Term selection mode

: Hermite poynomials

- Term selection criterion : Akaike Information Criterion (AIC)

- Distances scaled by : W (right truncation distance)

Estimator 5

Key: Hazard Rate

Adjustments - Function

: Cosines 


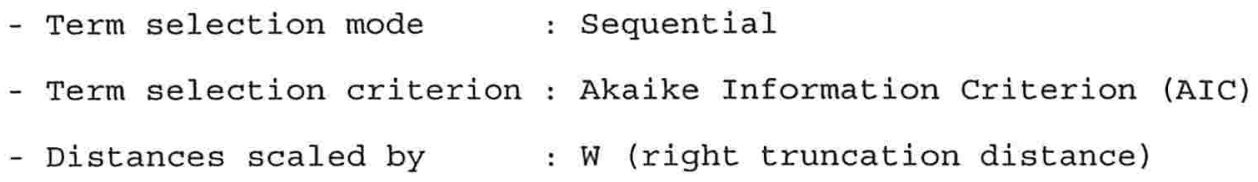

Cut points chosen by program

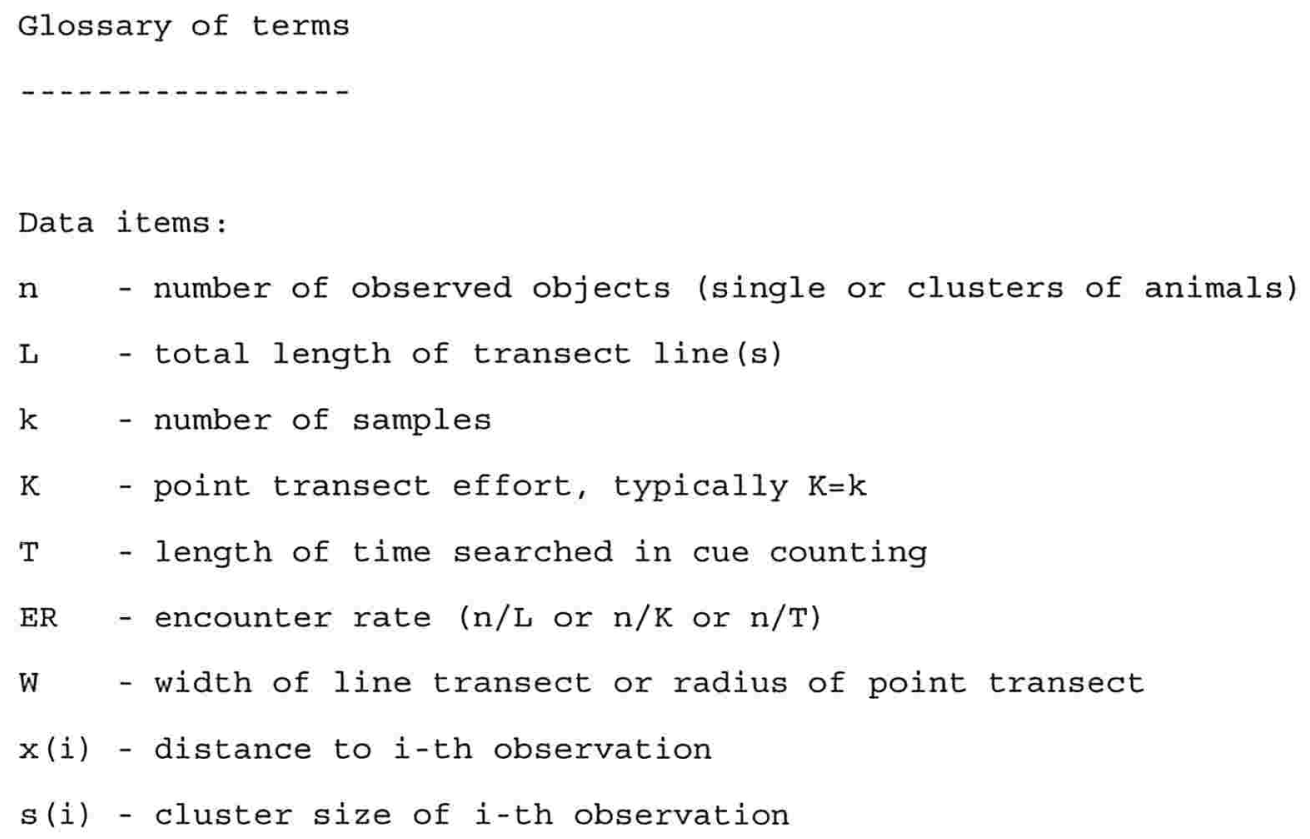




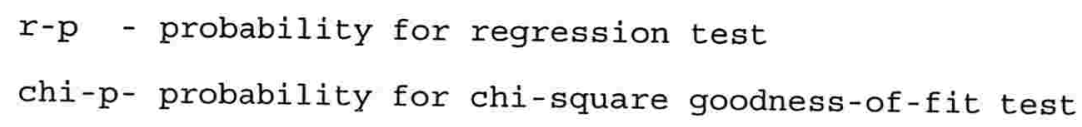

\section{Segunda parte}

$\begin{array}{lcc}\text { Effort } & : & 6.000000 \\ \text { \# samples } & : & 1 \\ \text { Width } & : & 28.66476 \\ \text { \# observations: } & 65\end{array}$

Model 1

Uniform key, $\mathrm{k}(\mathrm{y})=1 / \mathrm{W}$

Results: 


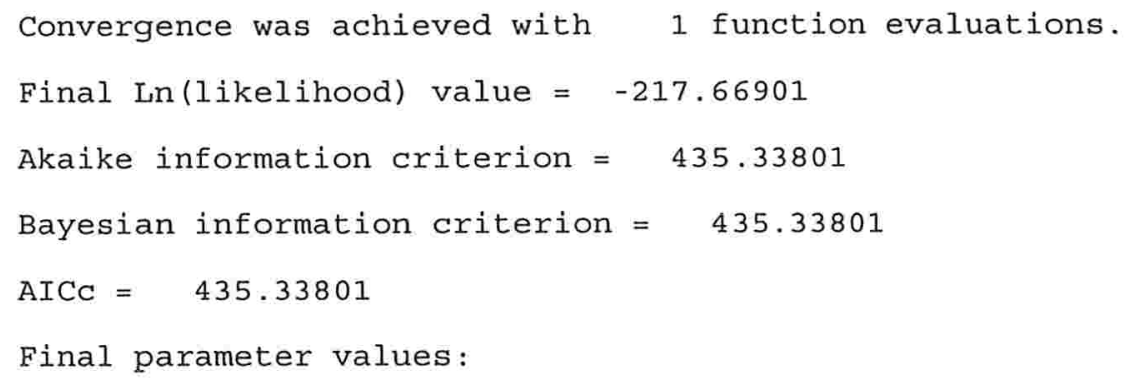




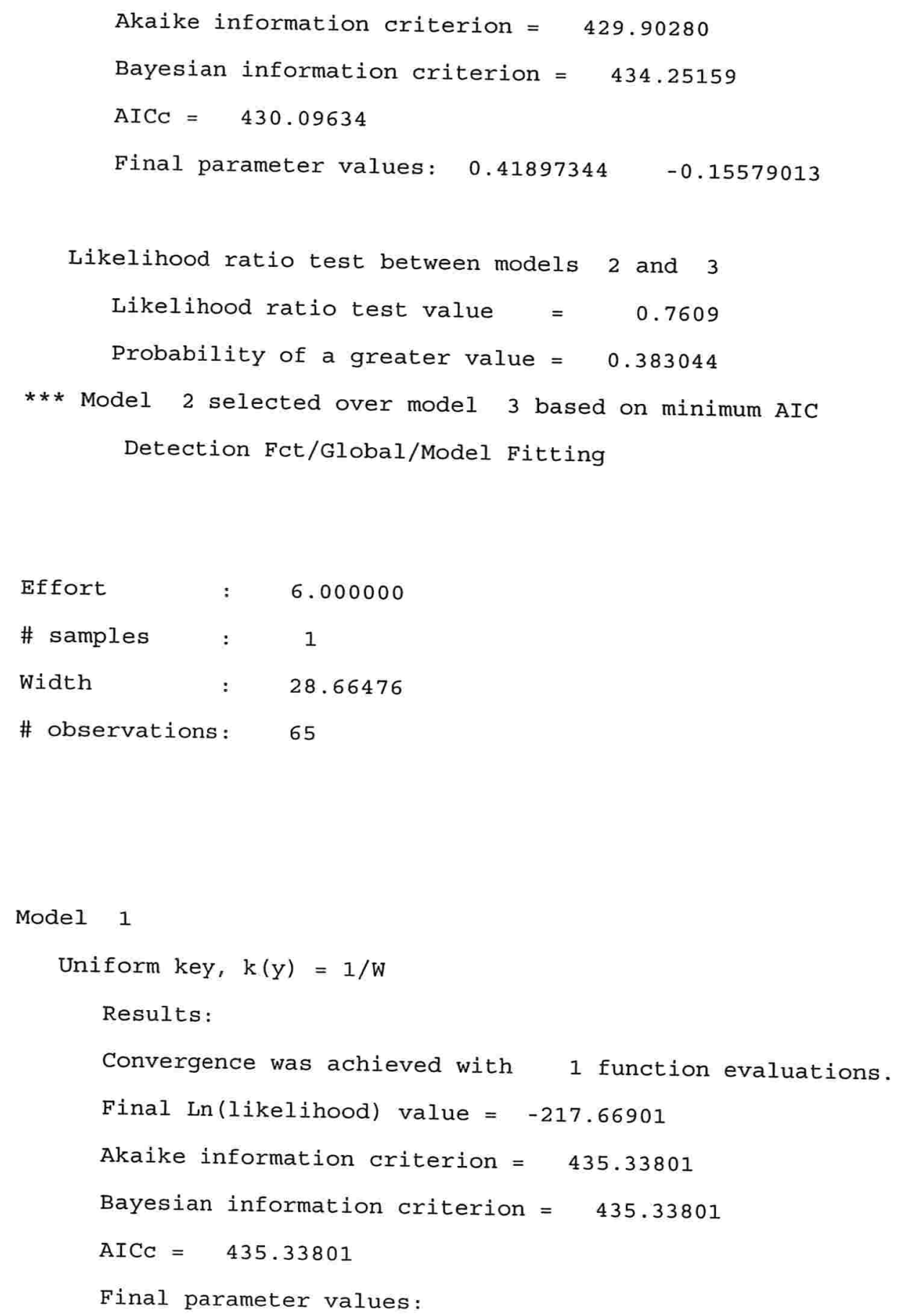




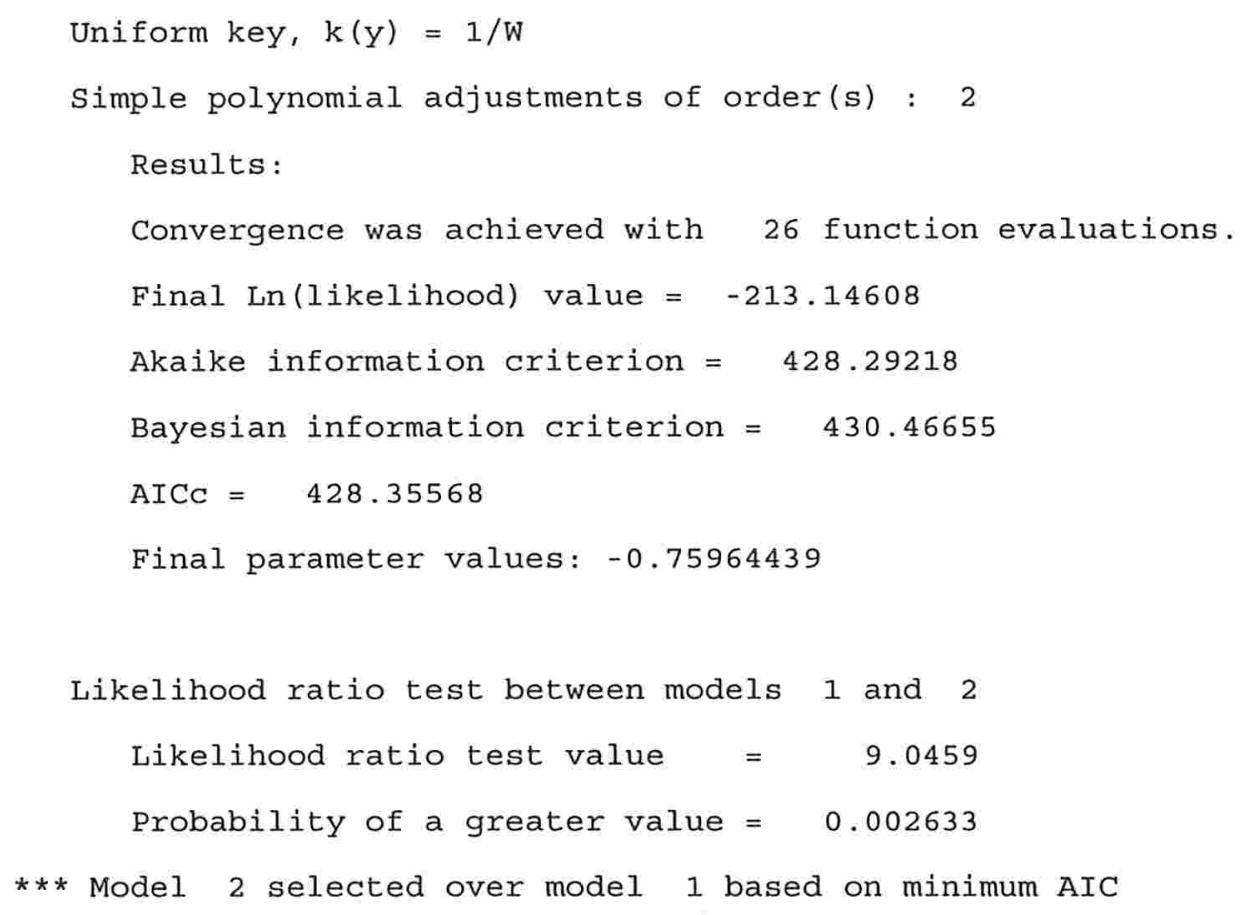


Detection Fct/Global/Model Fitting

$\begin{array}{lcc}\text { Effort } & : & 6.000000 \\ \text { \# samples } & : & 1 \\ \text { Width } & : & 28.66476 \\ \text { \# observations: } & 65\end{array}$

Model 1

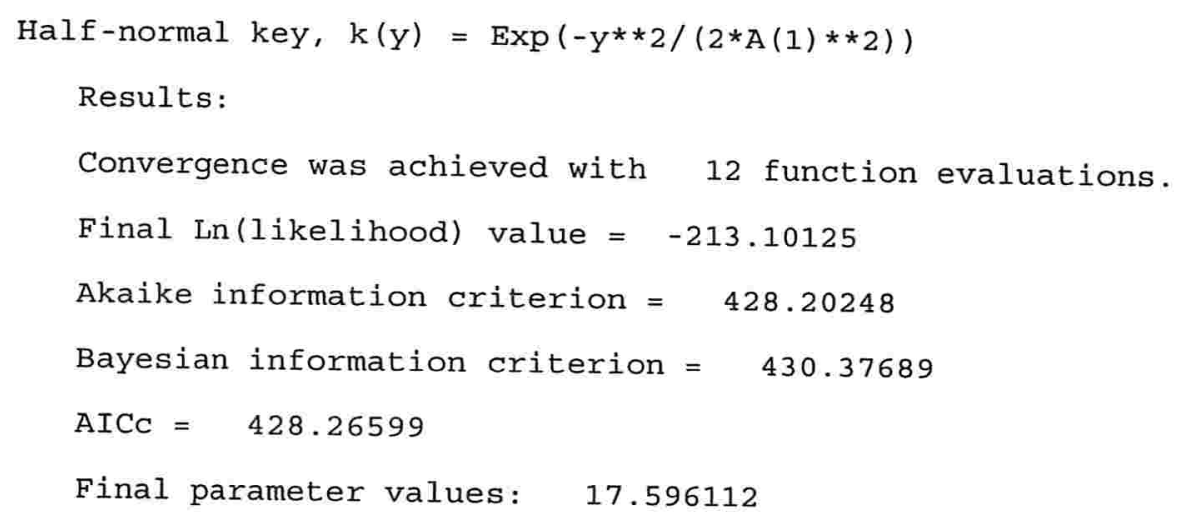

Model 2

Half-normal key, $k(y)=\operatorname{Exp}(-y * * 2 /(2 * A(1) * * 2))$

Cosine adjustments of $\operatorname{order}(s): 2$

Results:

Convergence was achieved with 10 function evaluations.

Final Ln(likelihood) value $=-213.02401$

Akaike information criterion $=430.04800$

Bayesian information criterion $=434.39679$

$\mathrm{AICC}=430.24155$

Final parameter values: $18.439938 \quad-0.84530931 \mathrm{E}-01$ 


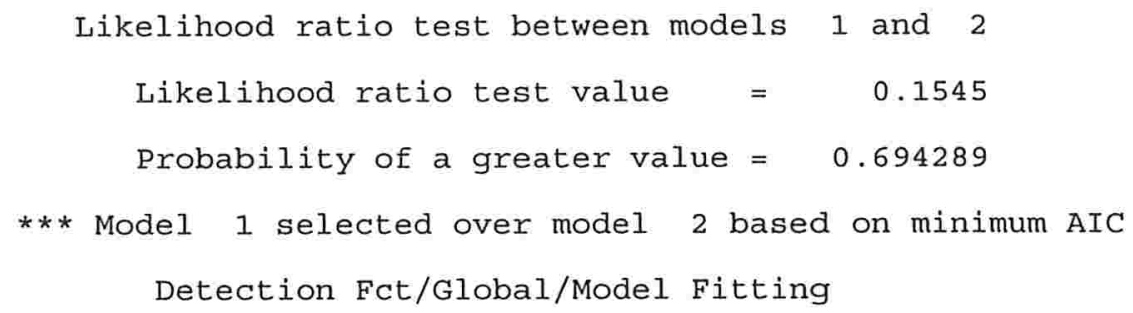

$\begin{array}{lcc}\text { Effort } & : & 6.000000 \\ \text { \# samples } & : & 1 \\ \text { Width } & : & 28.66476 \\ \text { \# observations : } & 65\end{array}$

Model 1

Half-normal key, $k(y)=\operatorname{Exp}(-y * * 2 /(2 * A(1) * * 2))$

Results :

Convergence was achieved with 12 function evaluations.

Final Ln(likelihood) value $=-213.10125$

Akaike information criterion $=428.20248$

Bayesian information criterion $=430.37689$

$\mathrm{AICC}=428.26599$

Final parameter values: 17.596112

Model 2

Half-normal key, $\mathrm{k}(\mathrm{y})=\operatorname{Exp}(-\mathrm{y} * * 2 /(2 * \mathrm{~A}(1) * * 2))$

Hermite polynomial adjustments of order(s) : 4

Results:

Convergence was achieved with 23 function evaluations. 


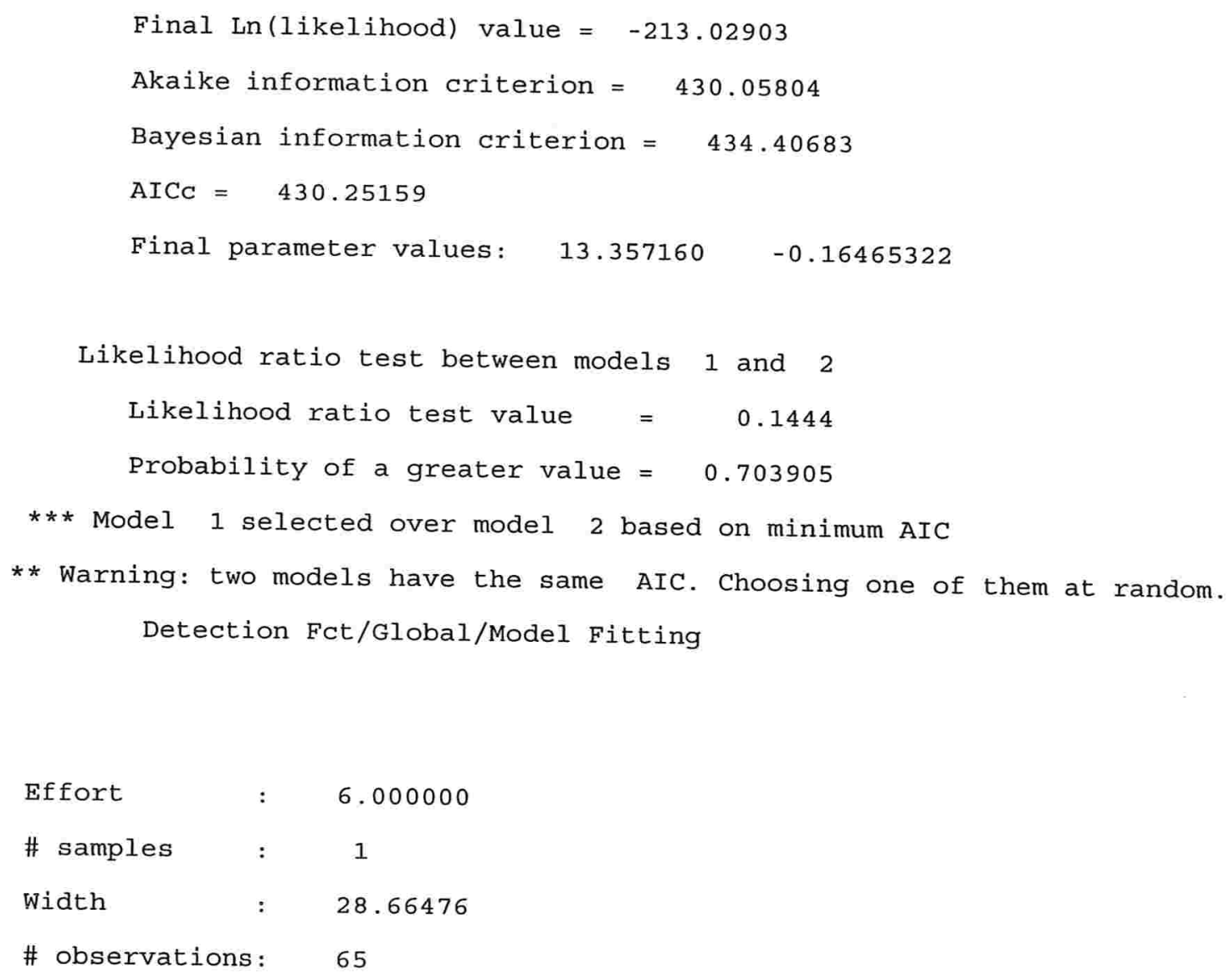




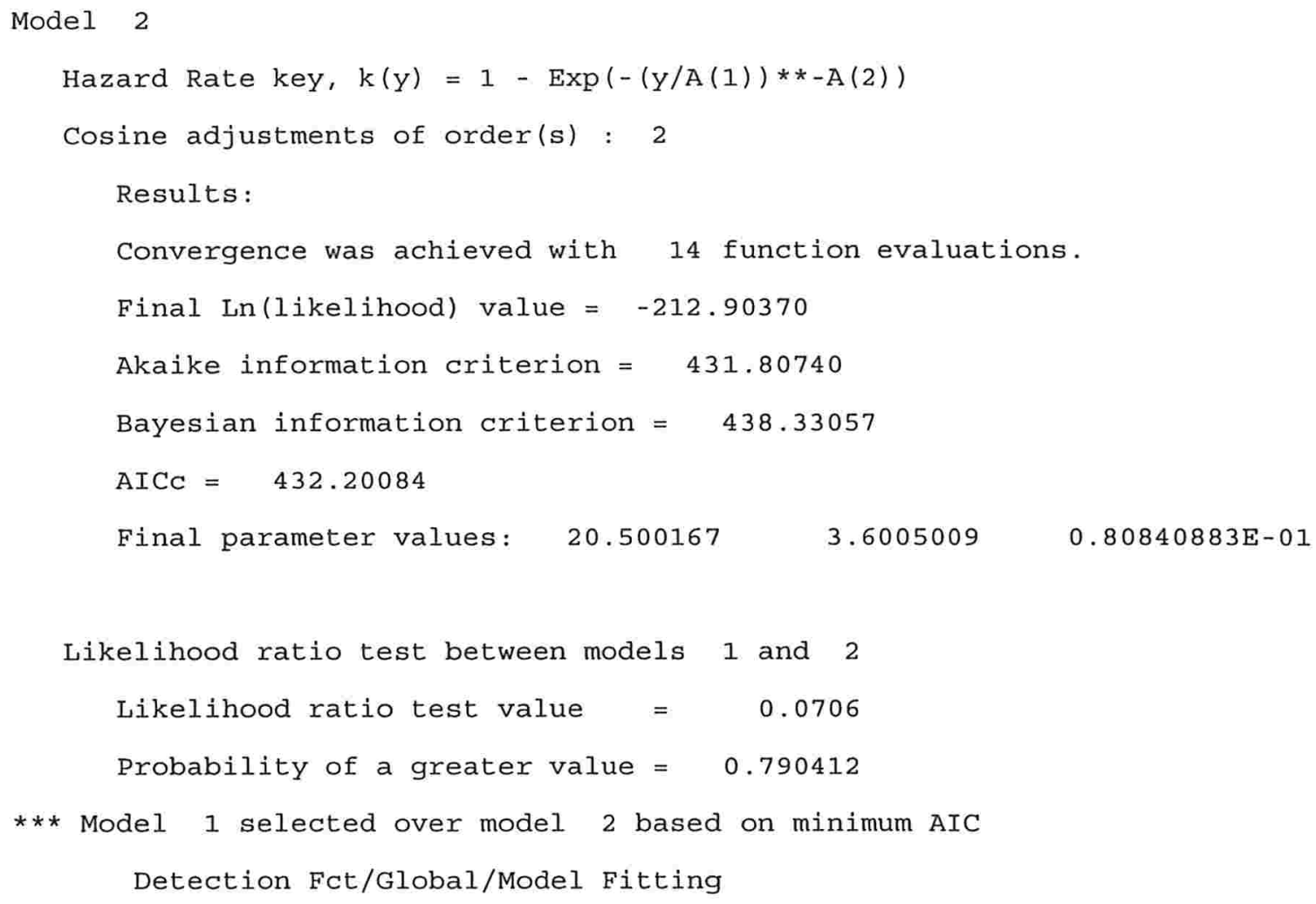

\section{Terceira parte}

$\begin{array}{lcc}\text { Effort } & : & 6.000000 \\ \text { \# samples } & : & 1 \\ \text { Width } & : & 28.66476 \\ \text { \# observations: } & 65\end{array}$

Model Selection -...-......-

Minimum $\mathrm{AIC}=428.2025$

Estimator chosen based on minimum AIC : Model

Half-normal key, $k(y)=\operatorname{Exp}(-y * * 2 /(2 * A(1) * * 2))$ Detection Fct/Global/Parameter Estimates 


$\begin{array}{lcc}\text { Effort } & : & 6.000000 \\ \text { \# samples } & : & 1 \\ \text { Width } & : & 28.66476 \\ \text { \# observations : } & 65\end{array}$

Model

Half-normal key, $\mathrm{k}(\mathrm{y})=\operatorname{Exp}(-y * * 2 /(2 * A(1) * * 2))$

\begin{tabular}{|c|c|c|c|c|}
\hline & Point & Standard & Percent Coef. & 95 Percent \\
\hline Parameter & Estimate & Error & of Variation & Confidence Interval \\
\hline------- & $-\cdots--\cdots---$ & $-\cdots-\cdots---$ & 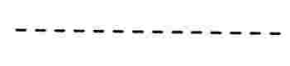 & - - - - - - - - - \\
\hline$A(1)$ & 17.60 & 3.034 & & \\
\hline$h(0)$ & $0.43959 \mathrm{E}-02$ & $0.78949 \mathrm{E}-03$ & 17.96 & $0.30794 \mathrm{E}-02$ \\
\hline ------- & $-\cdots---1$ & -------- & -----1 & $-\ldots \ldots$ \\
\hline
\end{tabular}

Detection Fct/Global/Plot: Qq-plot

Detection Fct/Global/K-S GOF Test

\section{Quarta parte}

Kolmogorov-Smirnov test
D_n
$=0.0559$
$\mathrm{p}=0.9872$

Cramer-von Mises family tests

$\mathrm{W}$-sq (uniform weighting) $=0.0358 \quad 0.900<\mathrm{p}<=1.000$

Relevant critical values: 
$\mathrm{W}-\mathrm{sq} \operatorname{crit}(\mathrm{alpha}=0.900)=0.0000$
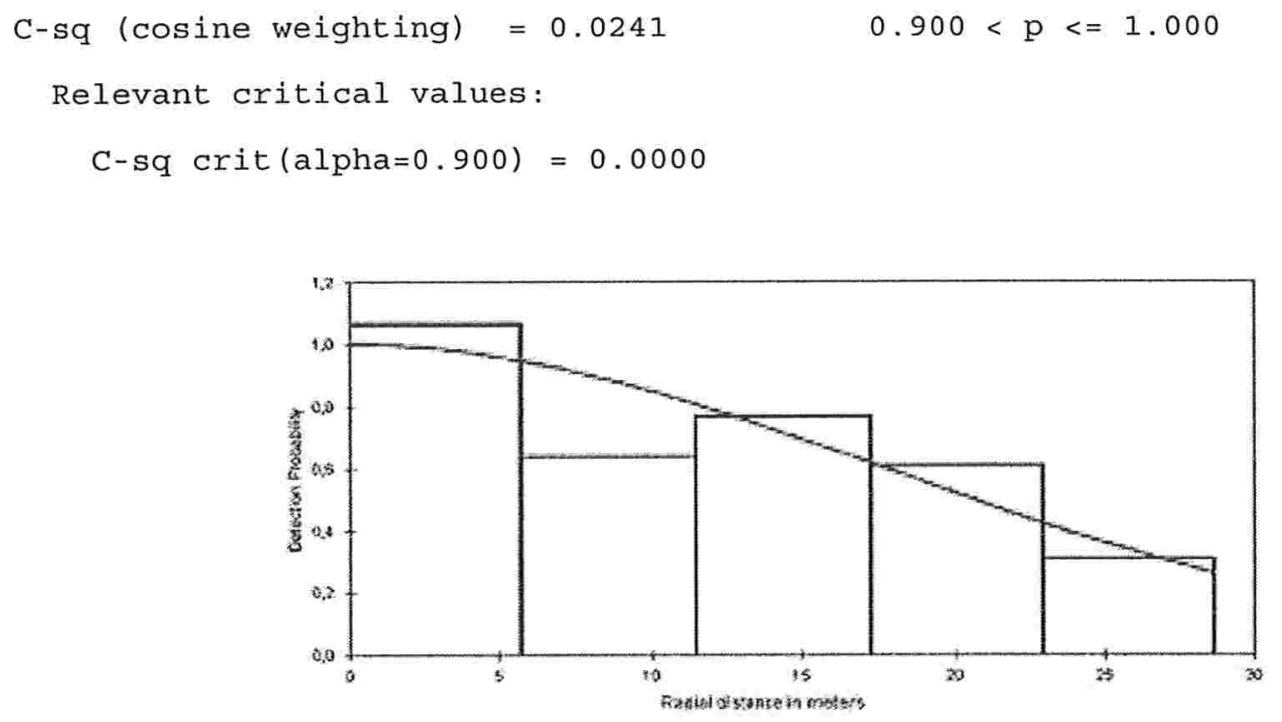

Figura D.1: Detection Fct/Global/Plot: Detection Probability 1

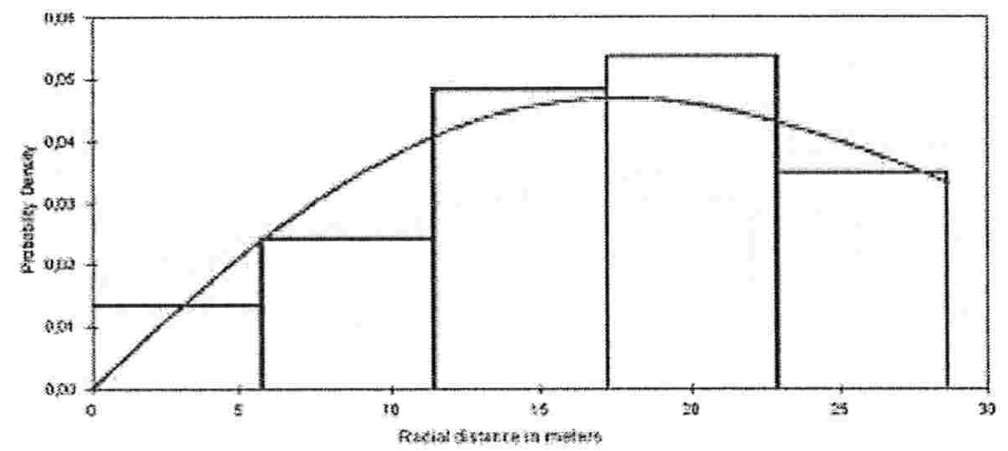

Figura D.2: Detection Fct/Global/Plot: Pdf 1

Radial distance in meters

Detection Fct/Global/Chi-sq GOF Test 1

Cell Cut Observed Expected Chi-square 


\begin{tabular}{|c|c|c|c|c|c|}
\hline$i$ & & & Values & Values & Values \\
\hline 1 & 0.000 & 5.73 & 5 & 4.57 & 0.040 \\
\hline 2 & 5.73 & 11.5 & 9 & 12.35 & 0.909 \\
\hline 3 & 11.5 & 17.2 & 18 & 16.68 & 0.105 \\
\hline 4 & 17.2 & 22.9 & 20 & 17.03 & 0.519 \\
\hline 5 & 22.9 & 28.7 & 13 & 14.37 & 0.131 \\
\hline
\end{tabular}

Total Chi-square value $=$

1.7031 Degrees of Freedom $=3.00$

Probability of a greater chi-square value, $P=0.63624$

The program has limited capability for pooling. The user should judge the necessity for pooling and if necessary, do pooling by hand.

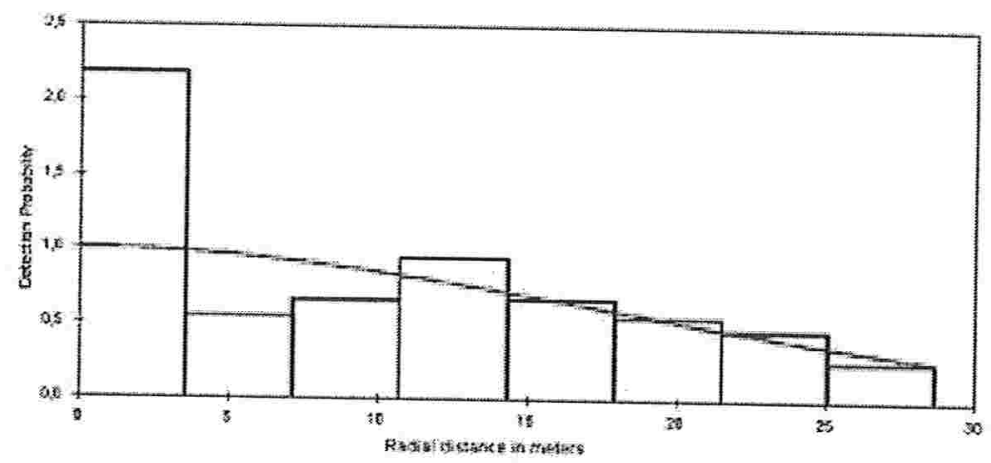

Figura D.3: Detection Fct/Global/Plot: Detection Probability 2

Radial distance in meters

Detection Fct/Global/Chi-sq GOF Test 2

$\begin{array}{ccccc}\text { Cell } & \text { Cut } & \text { Observed } & \text { Expected } & \text { Chi-square } \\ i & \text { Points } & \text { Values } & \text { Values } & \text { Values }\end{array}$




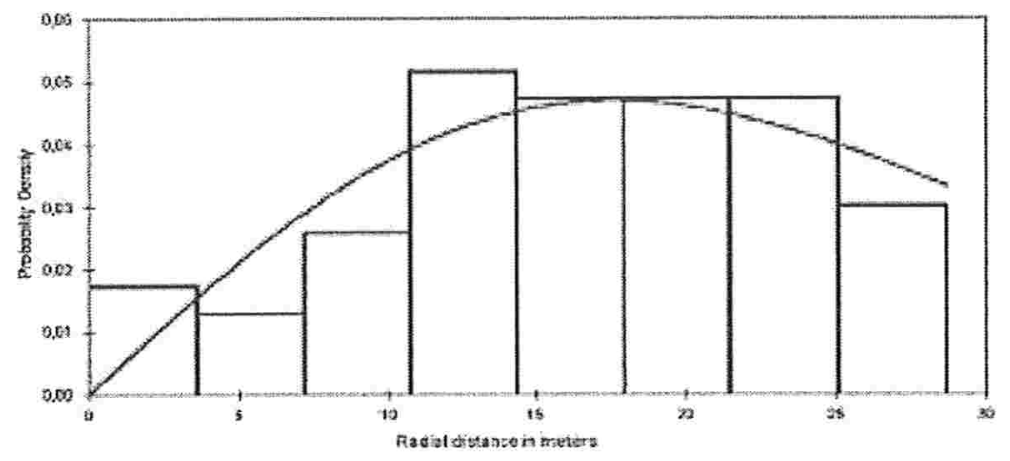

Figura D.4: Detection Fct/Global/Plot: Pdf 2

$\begin{array}{rrrrrr}1 & 0.000 & 3.58 & 4 & 1.82 & 2.629 \\ 2 & 3.58 & 7.17 & 3 & 5.23 & 0.948 \\ 3 & 7.17 & 10.7 & 6 & 8.02 & 0.508 \\ 4 & 10.7 & 14.3 & 12 & 9.92 & 0.437 \\ 5 & 14.3 & 17.9 & 11 & 10.81 & 0.003 \\ 6 & 17.9 & 21.5 & 11 & 10.74 & 0.006 \\ 7 & 21.5 & 25.1 & 11 & 9.91 & 0.120 \\ 8 & 25.1 & 28.7 & 7 & 8.56 & 0.285\end{array}$

Total Chi-square value $=\quad 4.9370$ Degrees of Freedom $=6.00$

Probability of a greater chi-square value, $P=0.55192$

The program has limited capability for pooling. The user should judge the necessity for pooling and if necessary, do pooling by hand.

Goodness of Fit Testing with some Pooling

$\begin{array}{ccccc}\text { Cell Cut } & \text { Observed } & \text { Expected } & \text { Chi-square } \\ i & \text { Points } & \text { Values } & \text { Values } & \text { Values }\end{array}$




$\begin{array}{rrrrrr}2 & 0.000 & 7.17 & 7 & 7.04 & 0.000 \\ 3 & 7.17 & 10.7 & 6 & 8.02 & 0.508 \\ 4 & 10.7 & 14.3 & 12 & 9.92 & 0.437 \\ 5 & 14.3 & 17.9 & 11 & 10.81 & 0.003 \\ 6 & 17.9 & 21.5 & 11 & 10.74 & 0.006 \\ 7 & 21.5 & 25.1 & 11 & 9.91 & 0.120 \\ 8 & 25.1 & 28.7 & 7 & 8.56 & 0.285\end{array}$

Total Chi-square value $=$

1.3603 Degrees of Freedom $=5.00$

Probability of a greater chi-square value, $P=0.92861$

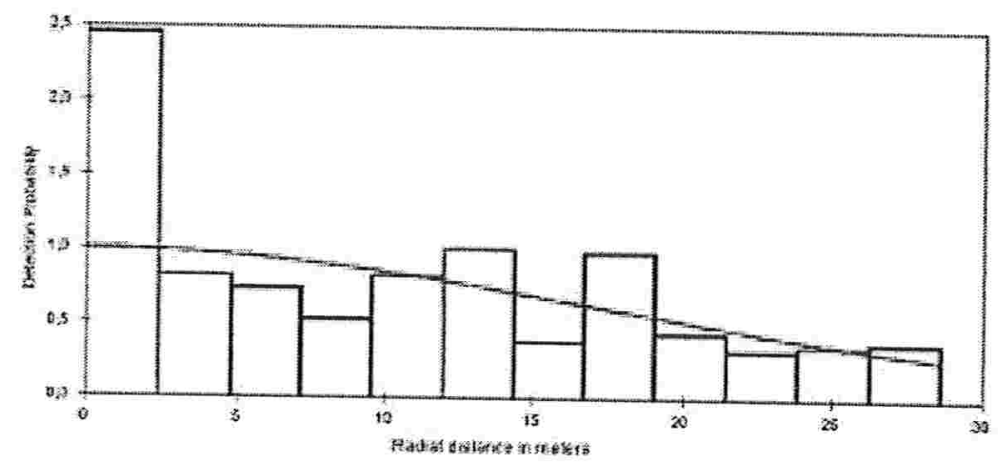

Figura D.5: Detection Fct/Global/Plot: Detection Probability 3

Radial distance in meters

Detection Fct/Global/Chi-sq GOF Test 3

\begin{tabular}{|c|c|c|c|c|c|}
\hline $\mathrm{Cell}$ & & Cut & Observed & Expected & Chi-square \\
\hline i & & Points & Values & Values & Values \\
\hline 1 & 0.000 & 2.39 & 2 & 0.81 & 1.741 \\
\hline 2 & 2.39 & 4.78 & 2 & 2.39 & 0.064 \\
\hline 3 & 4.78 & 7.17 & 3 & 3.84 & 0.184 \\
\hline
\end{tabular}




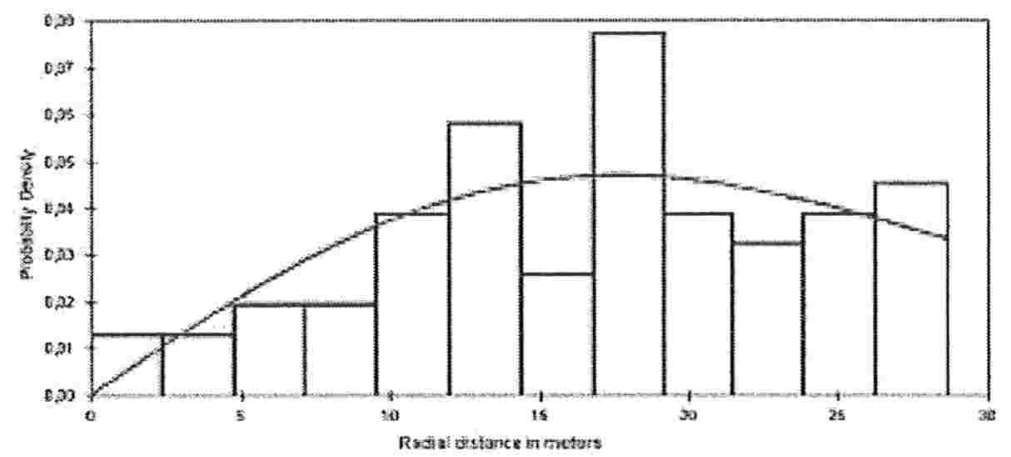

Figura D.6: Detection Fct/Global/Plot: Pdf 3

$\begin{array}{rrrrrr}4 & 7.17 & 9.55 & 3 & 5.09 & 0.856 \\ 5 & 9.55 & 11.9 & 6 & 6.08 & 0.001 \\ 6 & 11.9 & 14.3 & 9 & 6.77 & 0.732 \\ 7 & 14.3 & 16.7 & 4 & 7.17 & 1.400 \\ 8 & 16.7 & 19.1 & 12 & 7.27 & 3.075 \\ 9 & 19.1 & 21.5 & 6 & 7.11 & 0.174 \\ 10 & 21.5 & 23.9 & 5 & 6.74 & 0.448 \\ 11 & 23.9 & 26.3 & 6 & 6.19 & 0.006 \\ 12 & 26.3 & 28.7 & 7 & 5.54 & 0.384\end{array}$

Total Chi-square value $=9.0643$ Degrees of Freedom $=10.00$

Probability of a greater chi-square value, $P=0.52602$

The program has limited capability for pooling. The user should judge the necessity for pooling and if necessary, do pooling by hand.

Goodness of Fit Testing with some Pooling

$\begin{array}{ccccc}\text { Cell } & \text { Cut } & \text { Observed } & \text { Expected } & \text { Chi-square } \\ i & \text { Points } & \text { Values } & \text { Values } & \text { Values }\end{array}$




$\begin{array}{rrrrrl}2 & 0.000 & 4.78 & 4 & 3.20 & 0.199 \\ 3 & 4.78 & 7.17 & 3 & 3.84 & 0.184 \\ 4 & 7.17 & 9.55 & 3 & 5.09 & 0.856 \\ 6 & 9.55 & 11.9 & 6 & 6.08 & 0.001 \\ 7 & 11.9 & 14.3 & 9 & 6.77 & 0.732 \\ 8 & 14.3 & 16.7 & 4 & 7.17 & 1.400 \\ 9 & 19.1 & 19.1 & 12 & 7.27 & 3.075 \\ 10 & 21.5 & 21.5 & 6 & 7.11 & 0.174 \\ 11 & 23.9 & 23.9 & 5 & 6.74 & 0.448 \\ 12 & 26.3 & 26.3 & 6 & 6.19 & 0.006 \\ -12 & 28.7 & 7 & 5.54 & 0.384\end{array}$

Total Chi-square value $=$

7.4590 Degrees of Freedom $=9.00$

Probability of a greater chi-square value, $\mathrm{P}=0.58945$

Density Estimates/Global

\section{Quinta parte}

$\begin{array}{lcc}\text { Effort } & : & 6.000000 \\ \text { \# samples } & : & 1 \\ \text { Width } & : & 28.66476 \\ \text { \# observations : } & 65\end{array}$

Model

Half-normal key, $k(y)=\operatorname{Exp}(-y * * 2 /(2 * A(1) * * 2))$

\begin{tabular}{|c|c|c|c|c|}
\hline & Point & Standard & Percent Coef. & $95 \%$ Percent \\
\hline Parameter & Estimate & Error & of Variation & Confidence Interval \\
\hline
\end{tabular}




$\begin{array}{lccccc}\mathrm{h}(0) & 0.43959 \mathrm{E}-02 & 0.78949 \mathrm{E}-03 & 17.96 & 0.30794 \mathrm{E}-02 & 0.62753 \mathrm{E}-02 \\ \mathrm{p} & 0.55371 & 0.99445 \mathrm{E}-01 & 17.96 & 0.38788 & 0.79044 \\ \mathrm{EDR} & 21.330 & 1.9154 & 8.98 & 17.834 & 25.512 \\ \mathrm{n} / \mathrm{K} & 10.833 & 1.3437 & 12.40 & 8.5033 & 13.802 \\ \mathrm{D} & 0.75793 \mathrm{E}-02 & 0.16543 \mathrm{E}-02 & 21.83 & 0.49256 \mathrm{E}-02 & 0.11663 \mathrm{E}-01\end{array}$

Measurement Units

Density: Numbers/Sq. meters

EDR: meters

Component Percentages of $\operatorname{Var}(D)$

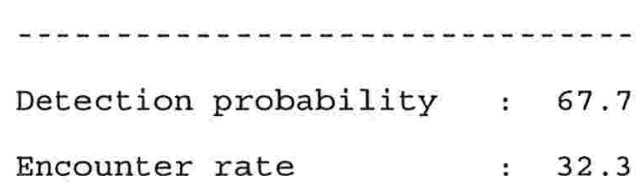

Estimation Summary - Encounter rates

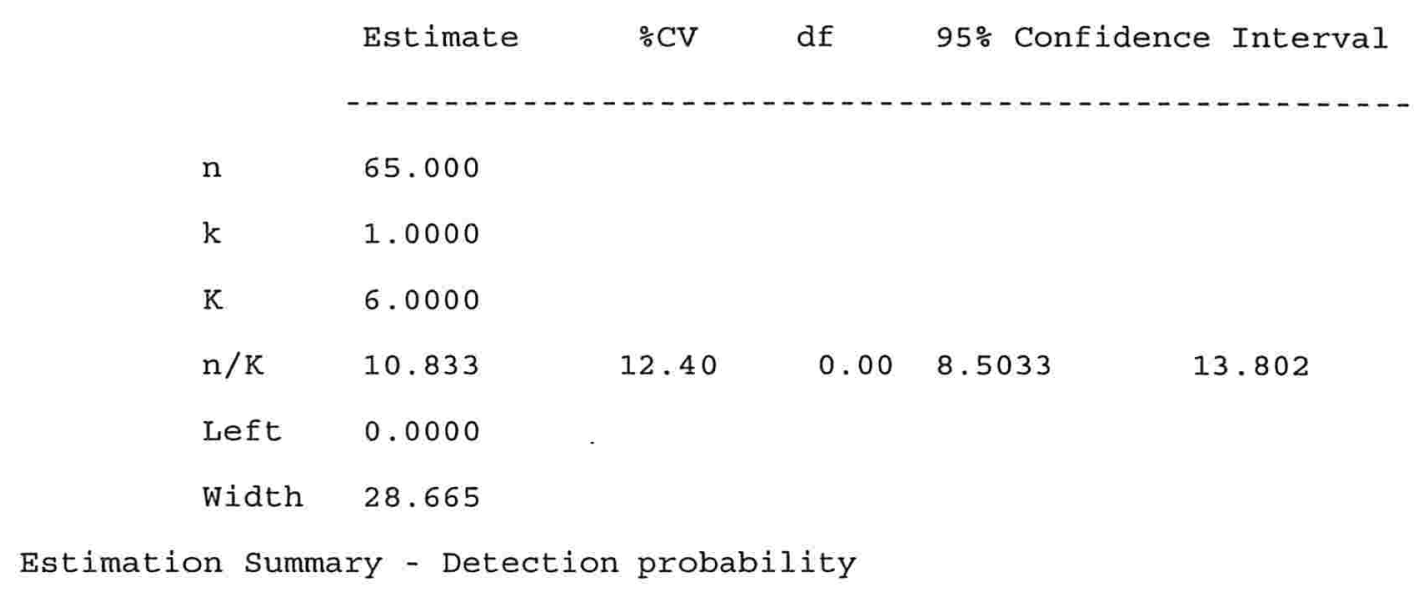

Estimate $\quad$ CV df $95 \%$ Confidence Interval

Half-normal/Hermite 


$\begin{array}{llllll}\mathrm{m} & 1.0000 & & & \\ \text { LnL } & -213.10 & & & \\ \text { AIC } & 428.20 & & & & \\ \text { AICC } & 428.27 & & & & \\ \text { BIC } & 430.38 & & & & \\ \text { Chi-p } & 0.58945 & 17.96 & 64.00 & 0.30794 \mathrm{E}-02 & 0.62753 \mathrm{E}-02 \\ \mathrm{~h}(0) & 0.43959 \mathrm{E}-02 & 17.96 & 64.00 & 0.38788 & 0.79044 \\ \mathrm{p} & 0.55371 & 8.98 & 64.00 & 17.834 & 25.512 \\ \text { EDR } & 21.330 & & \end{array}$

Estimation Summary - Density\&Abundance

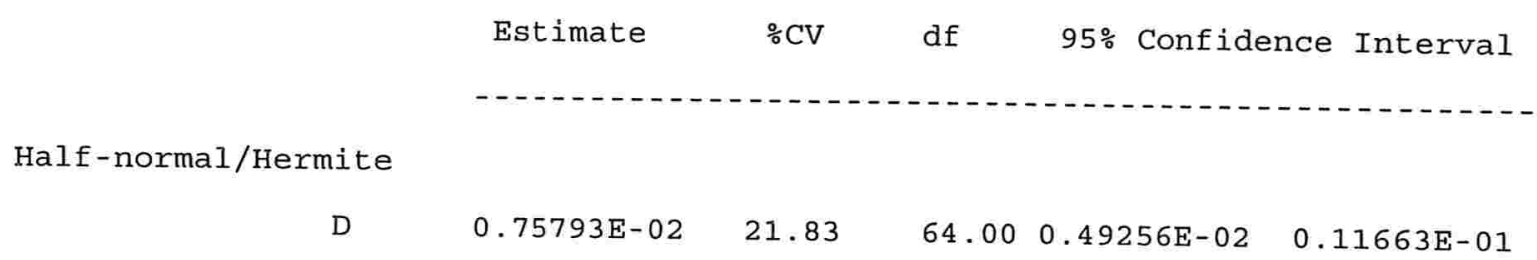




\section{Referências Bibliográficas}

[1] Anderson, D. R. e Pospahala, R. S. (1970). Correction of bias in belt transectes of immotile objects. Journal of Wildlife Management, 43, 141-146.

[2] Anderson, D. R. e Ohmart, R. D. (1981). Comparisons of avian census results using variable distance transect and variable circular pot techniques. In Estimating Numbers of Terrestrial Bids. Studies in Avian Biology N. 6 (eds C. J. Ralph and J. M. Scott). Cooper Ortnithological Society , 186-192.

[3] Barry, S. C. e Welsh, A. H. (2001). Distance sampling methodology. Journal Royal Statistics Society Series B, 63, 31-53.

[4] Bollinger, E. K., Gavin, T. A. e McIntyre, D. C. (1988). Comparison of transects and circular plots for estimating bobolink densities. Journal of Wildlife Management, 52, 777-786.

[5] Borchers, D. L., Zucchini, W. e Fewster, R. M. (1998a). Mark-recapture models for line transect surveys. Biometrics, 54, 1207-1220.

[6] Borchers, D. L., Buckland, S. T., Goedhart, P. W., Clarke. E. D. e Hedley, S. L. (1998b). Horvitz-Thompson estimators for double-platform line transect surveys. Biometrics, 54, 1221-1237.

[7] Borchers, D. L., Buchland, S. T. e Zucchini, W. (2002). Estimating Animal Abundance: closed populations. New York: Springer Verlag. 
[8] Buckland, S. T. (1985). Perpendicular distance models for line transect sampling. Biometrics, 41, 177-195.

[9] Buckland, S. T. (1987). On the variable circular plot method of estimating animal density. Biometrics, 43, 363-384.

[10] Buckland, S. T. (1992). Fitting density functions with polynomials. Applied Statistics, 41, 63-76.

[11] Buckland, S. T., Anderson, D. R., Burnham, K. P. e Laake, J. L. (1993). Distance Sampling; Estimating Abundance of Biological Populations. London: Chapman and Hall (http://dolphin.mcs.st-and.ac.uk/distancebook/download.html).

[12] Buckland, S. T., Anderson, D. R., Burnham, K. P., Laake, J. L. e Borchers, D.L. (2001). Introduction to Distance Sampling - Estimating Abundance of Biological Populations. Oxford: Oxford University Press.

[13] Buckland, S.T., Burnham, K.P. e Agustin, N.H. (1997). Model selection: an integral part of inference. Biometrics, 53, 603-618.

[14] Burnham, K. P. e Anderson, D. R. (1976). Mathematical models for non-parametric inerenes from line transect data. Biometrics, 32, 325-336.

[15] Burnham, K. P., Anderson, D. R. e Laake, J. L. (1980). Estimation of density from line transect sampling of biological porpulations. Wildlife Monografhs, N. 72.

[16] Chen, S. X. (1996). Empirical likelihood confidence intervals for nonparametric density estimation. Biometrics, 83, 329-341.

[17] Chen, S. X. (1998). Measurement errors in line transect surveys. Biometrics, 54, 899-908.

[18] Chen, S. X. (2000). Animal abundance estimation in independent observer line transect surveys. Environmental and Ecological Statistics, 7, 285-299. 
[19] Dudewicz, E.J., (1988). Modern Mathematical Statistics. New York: John Wiley \& Sons Inc.

[20] Eberhardt, L. L. (1968). Some developments in "distance sampling". Biometrics, 23, 207216.

[21] Edwards, D. K., Dorsey, G. L. e Crawfod, J. A. (1981). A comparison of three avian census methods. In Estimating Numbers of Terrestrial Birds. Studies in Avian Biology N. 6 (eds C. J. Ralph and J. M. Scott). Cooper Ortnithological Society, 170-176.

[22] Gates, C. E., Marshall, W. H. e Oldson, D. P. (1968). Line transect method of estimating grouse population densities. Biometrics, 24, 135-145.

[23] Gibbons, J. D. (1985). Nonparametric Methods for Quantitative Analysis. (2nd ed). Columbus: American Sciences Press.

[24] Hayes, R. J. e Buckland, S. T. (1983). Radial-distance models for the line-transect method. Biometrics, 39, 29-42.

[25] Mack, Y. P. e Quang, P. X. (1998). Kernel methods in line and point transect sampling. Biometrics, 54, 606-619.

[26] Melville, G. J. e Welsh, A. H. (2001). Line transect in small regions. Biometrics, 57, 11301137.

[27] Quang, P. X. (1990). Confidence intervals for densities in line transect sampling. Biometrics, $46,459-472$.

[28] Quang, P. X. (1993). Nonparametric estimators for variable circular plot surveys. Biometrics, 49, 837-852.

[29] Ramsey, F. L. e Scott, J. M. (1979). Estimating population densities from variable circular plot surveys. Sampling Biological Population (eds Cormark, R. M. Patil, Robson, D. S.). International Co-operative Publishing House, Fairland, USA, 155-181. 


\section{REFERÊNCIAS BIBLIOGRÁFICAS}

[30] Ramsey, F. L. e Harrison, K. (2004). A closer look at detectability. Environmental and Ecological Statistics, 11, 73-84.

[31] Seber, G. A. F. (1982). The Estimation of Animal Abundance and Related Parameters. London: Griffin.

[32] Skaug, H. J. e Schweder, T. (1999). Hazard models for line transect surveys with independent observers. Biometrics, 55, 29-36.

[33] Stephens, M.A. (1986). Goodness of Fit Statistics Techniques (eds Stephens, M.A., D’Agostino, R.B.). New York: M. Dekker.

[34] Stuart, A. e Ord, J. K. (1987). The Advanced Theory of Statistics, vol. 1, 4th ed. London: Griffin.

[35] Thomas, L., Laake, J. L., Strindberg, S., Marques, F. F. C., Buckland, S. T., Borchers, D. L., Anderson, D. R., Burnham, K. P., Hedley, S. L., Pollard, J. H. e Bishop, J. R. B. (2003). Distance 4.1 release 2. Research Unit for Wildlife Population Assessment, University of St Andrews, UK. (http://www.ruwpa.st-and.ac.uk/distance/).

[36] Turnock, B.J. e Quinn II, T. J. (1991). The effect of responsive movement on abundance estimation using line transect sampling. Biometrics, 47, 701-715.

[37] Zahl, S. (1989). Line transect sampling with unknown probability of detection along the transect. Biometrics, 45, 453-470. 